\title{
Robust Tower Fairings to Mitigate the Tower Shadow Effect for Extreme-Scale Downwind Turbines
}

\author{
A Thesis \\ Presented to \\ the faculty of the School of Engineering and Applied Science \\ University of Virginia
}

in partial fulfillment

of the requirements for the degree

Master of Science

by

\section{Carlos C. Noyes}

May 2016 


\section{APPROVAL SHEET}

The Thesis

is submitted in partial fulfillment of the requirements for the degree of

Master of Science

\section{Carlos Noyes}

Author

The thesis has been read and approved by the examining committee:

\begin{tabular}{c} 
Eric Loth \\
\hline Advisor \\
Carl Knospe \\
\hline Haibo Dong \\
\hline Chao Qin
\end{tabular}

Accepted for the School of Engineering and Applied Science:

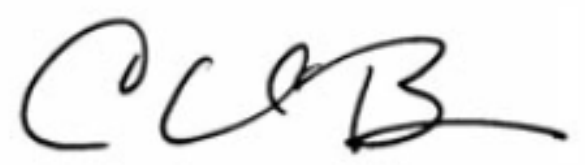

Craig H. Benson, Dean, School of Engineering and Applied Science

May 2016 


\section{Acknowledgements}

I would like to thank Dr. Eric Loth, for his leadership, guidance, and patience throughout my graduate studies. He has taught me a great many things, both technical and non-technical skills that will aid me throughout the entirety of my future career. I would like to thank the other members of Dr. Loth's research group specifically, Yong Yeong and Chris Qin, for their mentorship and for their continual assistance during my project. Finally, I would like to thank the sponsors at Dominion Power and the National Renewable Energy Lab, specifically Pat Moriarty and Scott Schreck, for contributing significantly to the technical aspects of this project. 


\section{Contents}

List of Figures $\quad$ vi

List of Tables $\quad \mathrm{X}$

$\begin{array}{ll}\text { Abstract } & \mathrm{Xi}\end{array}$

1 - Introduction 1

2 - A FAST Investigation of a 2 Blade, Load-Aligned, Downwind Rotor for a $13.2 \quad 4$ MW Wind Turbine

2.1 Introduction $\quad 6$

$\begin{array}{ll}2.2 \text { Methods } & 7\end{array}$

2.3 Results 9

$\begin{array}{ll}2.4 \text { Conclusions } & 13\end{array}$

3 - Measurements and Predictions of Tower Shadow and Tower Fairing Effects on 25 the UAE Rotor Blades

3.1 Introduction $\quad 28$

$\begin{array}{ll}3.2 \text { Methods } & 30\end{array}$

3.3 Results $\quad 32$

$\begin{array}{ll}3.4 \text { Conclusions } & 40\end{array}$

4 - An Experimental Investigation of Low Drag, Robust, Aerodynamic Fairings 60

$\begin{array}{ll}4.1 \text { Introduction } & 62\end{array}$

$\begin{array}{ll}4.2 \text { Methods } & 63\end{array}$

$\begin{array}{ll}4.3 \text { Results } & 65\end{array}$

$\begin{array}{ll}4.4 \text { Conclusions } & 69\end{array}$

5 - Robust Tower Fairing Design for Downwind Wind Turbines 90 
5.1 Introduction $\quad 93$

$\begin{array}{ll}5.2 \text { Methods } & 94\end{array}$

$\begin{array}{ll}5.3 \text { Results } & 97\end{array}$

$\begin{array}{ll}5.4 \text { Conclusions } & 100\end{array}$

6 - Conclusions 117 


\section{List of Figures}

2.1 Extreme-scale turbines for a) the non-torque forces on a conventional rotor blade, b) a conventional upwind turbine configuration, c) a downwind rotor blade aligned with the non-torque force distribution \& d) a downwind load-aligned turbine.

2.2 Baseline turbine response: a) turbulent wind profile with a characteristic wind speed of $11.3 \mathrm{~m} / \mathrm{s}, \mathrm{b}$ ) time series of generator power produced for both a conventional 3 blade rotor and a downwind 2 blade rotor \& c) root flap bending moment versus azimuth angle for both rotors.

2.3 a) Required blade length to meet steady power constraints used to define the D2L rotor, b) the total rotor mass for both rotors \& c) power produced by the generator for both rotors.

2.4 Baseline turbine response: a) turbulent wind profile with a characteristic wind speed of $11.3 \mathrm{~m} / \mathrm{s}, \mathrm{b}$ ) time series of generator power produced for both a conventional 3 blade rotor and a downwind 2 blade rotor \& c) root flap bending moment versus azimuth angle for both rotors.

2.5 Average turbine response from the U3 and D2L rotors, from 12 different turbulent wind profiles centered at $11.3 \mathrm{~m} / \mathrm{s}$ : a) power produced by the generator, b) average root flap bending moment \& c) Damage Equivalent Loading.

2.6 Average root flap bending moment against turbulent wind with characteristic wind speeds ranging from $2.825 \mathrm{~m} / \mathrm{s}$ to $22.6 \mathrm{~m} / \mathrm{s}$, for the U3 rotor and 6 different $\mathrm{D} 2 \mathrm{~L}$ rotors with coning angles ranging from $5^{\circ}$ to $20^{\circ}$. The wind speed that the rotor is operating in its load-aligned condition (mean $\mathrm{Mb}$ is zero) is noted in purple.

2.7 Damage equivalent loading against turbulent wind with characteristic wind speeds ranging from $2.825 \mathrm{~m} / \mathrm{s}$ to $22.6 \mathrm{~m} / \mathrm{s}$, for the U3 rotor and 6 different D2L rotors with coning angles ranging from $5^{\circ}$ to $20^{\circ}$. The wind speed that the rotor is operating in its load-aligned condition is noted in purple. 
2.8 Output metrics averaged over a range of wind speeds: a) Weibull distribution modeling the wind speed probability distribution function, $b$ ) net rotor mass as a function of coning angle, c) average DEL weighted by wind speed probability \& d) average power output weighted by wind speed probability.

3.1 UAE experimental configuration in the NASA Ames tunnel, a) flow visualization of tip vortices, \& b) UAE tower fairing (with arrow indicating vertical extent) upstream of a UAE blade instrumented with 5hole pressure probes.

3.2 Top view turbine schematic, a) upwind rotor $\&$ b) downwind rotor with fairing free to rotate about tower (components not to scale).

3.3 Schematic of relative flow parameters. $\beta$ is pitch plus local twist, $\alpha$ is taken relative to free stream, $\alpha_{\text {rel }}$ is relative to the chord line, $C_{n}$ is normal to chord line.

3.4 Relative flow angle as function of azimuthal angle at $\mathrm{r} / \mathrm{R}=0.67$ and $\mathrm{V}_{\infty}=5 \mathrm{~m} / \mathrm{s}$.

3.5 Relative flow velocity as function of azimuthal angle at $r / R=0.67$ and $\mathrm{V}_{\infty}=5 \mathrm{~m} / \mathrm{s}$.

3.6 Normal force coefficient as function of azimuthal angle at $\mathrm{r} / \mathrm{R}=0.63$ and $\mathrm{V}_{\infty}=5 \mathrm{~m} / \mathrm{s}$.

3.7 Normal force coefficient as function of azimuthal angle at $r / R=0.80$ and $\mathrm{V}_{\infty}=5 \mathrm{~m} / \mathrm{s}$.

3.8 Root flap bending moment as function of azimuthal angle at $\mathrm{V}_{\infty}=5 \mathrm{~m} / \mathrm{s}$.

3.9 Root flap bending moment as function of azimuthal angle at $\mathrm{V}_{\infty}=10 \mathrm{~m} / \mathrm{s}$.

3.10 Root flap bending moment as function of azimuthal angle at $\mathrm{V}_{\infty}=20 \mathrm{~m} / \mathrm{s}$.

3.11 Average and range of relative flow angle at $\mathrm{r} / \mathrm{R}=0.67$.

3.12 Average and range of relative flow velocity at $r / R=0.67$.

3.13 Average and range of normal force coefficient at $\mathrm{r} / \mathrm{R}=0.63$.

3.14 Average and range of root flap bending moment.

4.1 Chord view schematics of fairings: a) the profiles of all four models, \&

b) inlet velocity and fairing misalignment angle displayed.

4.2 Schematic of water channel, skim plate and PIV setup. 
4.3 Boundary layer separation at different Reynolds number: a) laminar boundary layer separation at $\operatorname{Re}<<105$, b) turbulent boundary layer separation at $\operatorname{Re}>>105, \&$ c) separation at $\operatorname{Re}=6.8 \times 104$ with the use of trip wires.

4.4 Trip tape located at $3 \%$ chord length from the leading edge. Approximately located at $50^{\circ}$ based on leading edge curvature.

4.5 Instantaneous velocity field at fairing misalignment angle of $0^{\circ}$.

4.6 Instantaneous velocity field at fairing misalignment angle of $10^{\circ}$.

4.7 Instantaneous velocity field at fairing misalignment angle of $20^{\circ}$.

4.8 Average velocity field at fairing misalignment angle of $0^{\circ}$.

4.9 Average velocity field at fairing misalignment angle of $10^{\circ}$.

4.10 Average velocity field at fairing misalignment angle of $20^{\circ}$.

4.11 Turbulence intensity field at fairing misalignment angle of $0^{\circ}$.

4.12 Turbulence intensity field at fairing misalignment angle of $10^{\circ}$. 85

4.13 Turbulence intensity field at fairing misalignment angle of $20^{\circ}$. 86

4.14 Normalized streamwise velocity component profiles at fairing 87 misalignment angle of $0^{\circ}$.

4.15 Normalized streamwise velocity component profiles at fairing misalignment angle of $10^{\circ}$.

4.16 Normalized streamwise velocity component profiles at fairing misalignment angle of $20^{\circ}$.

5.1 a) Schematic of tower fairing relative to the local incident flow and b) schematic of tower fairing used on a pre-aligned D2PA turbine.

5.2 Fairings showing rounded trailing edge versions based on the Eppler 863 airfoil.

5.3 Steady-state blade clearance for U3 rotor relative to the tower exterior (shown by black line) for no loading (blue line) and for maximum loading (purple line), which occurs at rated conditions.

5.4 Blade clearance for D2 \& D2PA rotors based on a fairing length limited by a minimal clearance of $\Delta \mathrm{x}_{\mathrm{min}}$. Showing region of interest for PIV results with dotted black line. 
5.5 Example of PIV data scaled to be used in analysis for the D2 and D2PA turbines.

5.6 Schematic of flow vectors on rotating blade element.

5.7 Dye visualization, PIV vector plots, and streamwise velocity profile plots, results for the cylinder \& the E863r45 fairing at a misalignment angle of $20^{\circ}$.

5.8 The progression from measured flow parameters to resulting blade lift for the cylinder model: a \& b) show flow directly measured PIV, c \& d) show calculated relative flow for the D2 turbine, \& e) shows the fractional lift on $\mathrm{D} 2$ rotor at $\mathrm{r} / \mathrm{R}=0.75$.

5.9 Fractional lift on the D2 rotor, for the cylinder and the fairings at a misalignment angle of $0^{\circ}$.

5.10 Fractional lift on the D2 rotor, for the cylinder and the fairings at a misalignment angle of $20^{\circ}$.

5.11 Fractional lift on the D2PA rotor, for the cylinder and the E863r45 fairings at all misalignment angles.

5.12 The peak shadow load for all test configurations measured for both rotors. 


\section{List of Tables}

2.1 Metrics of performance for the D2L rotors with three different coning

angles given as percent increase compared with the U3 baseline rotor at coning angle of $2.5^{\circ}$ 


\section{Abstract}

Motivated by manufacturing larger, more efficient, low cost, wind turbines, designers are considering downwind rotors. A downwind two-bladed rotor can produce equivalent power at a fraction of the cost compared with conventional upwind three-bladed rotors. The largest design obstacle for downwind rotors is the tower shadow effect, the aerodynamic effect that the tower wake has on the downwind rotor. The tower shadow effect can be mitigated by the use of an aerodynamic fairing to cover the tower. When designing a tower fairing, because in operation wind turbines will experience wind from varying directions, one should consider the fairing effectiveness at a variety of flow angles. Three tower fairings, with varying degrees of trailing edge roundness, were designed and experimentally characterized at misalignment angles, $0^{\circ}, 10^{\circ}$ and $20^{\circ}$. All three fairings significantly reduced the tower shadow effect at $0^{\circ}$ misalignment angle, but only one fairing, the E863r45, reduced the tower shadow effect at misalignment angles as large as $20^{\circ}$. Of the fairings tested the E863r45 fairing is the most robust and recommended for applications where tower shadow reduction is necessary for a range of flow angles. 


\section{Chapter 1}

\section{Introduction}

The ever increasing demand for larger wind turbines has pushed conventional upwind blade design to its limit. Increasing blade strength to withstand the speedily growing loads is proving both an expensive and soon an infeasible solution to the problem at hand. Decreasing the structural loads to more manageable levels can be done by aligning the loads along the rotor blade at a given wind condition. To achieve load alignment, downwind configuration is used and high coning angle is allowed. Thus, the stresses on each blade of a 13.2 MW wind turbine rotor can be sufficiently reduced and a blade can be removed from the conventional upwind three-bladed rotor. Chapter 2 shows this two-bladed downwind rotor would produce $4.37 \%$ more power, decrease blade DEL by $19.2 \%$, and decrease rotor mass by $27.5 \%$, compared with the unmodified upwind three-bladed rotor. The load-aligned concept could be one reasonable solution to tomorrow's stateof-art offshore turbines.

Downwind rotors can be effective in reducing rotor mass, and lowering blade stress for extreme-scale wind turbines. However, the tower shadow adds an aerodynamic complication that can be difficult to quantify and predict. Chapter 3 presents and analyzes a previously unpublished subset of data collected by NREL during an extensive wind tunnel campaign for Unsteady 
Aerodynamic Experiment Phase VI (UAE Phase VI). The experimental data includes relative flow fields, aerodynamic blade forces, and blade root flapwise bending moments all for both upwind and downwind turbines and, importantly, for downwind turbines with an aerodynamic tower fairing. It was shown that at high tip speed ratios (near design conditions), tower shadow is a dominating contributor to bending moments but can be mitigated by the use of a tower fairing aligned with the flow. At lower tip speed ratios where the blades can undergo aerodynamic stall and hysteresis, tower shadow was only a secondary contributor to bending moments and the tower fairing did not significantly impact bending moments (unless it was misaligned, in which case it exaggerated the variations). To interpret this data and assess predictive capability for a widely used wind turbine tool, the aeroelastic simulation code called FAST was used to predict the same experimental conditions. In general, FAST predicted the cycle-averaged aspects, but was unable to predict the unsteady fluctuations. These results suggest that wake modeling for downwind turbines may require modifications to improve the quantitative time-dependent description of tower shadow effects and of tower fairings.

Aerodynamic fairings can be used to minimize the tower shadow effect, but more generally can be used to cover cylinders to reduce many negative aerodynamic effects, acoustic noise, vibrations, drag and wake. Fairings perform well when the angle of the fluid flow is aligned with the fairing. With high misalignment angles fairings can exaggerate the flow criteria they were designed to mitigate. To understand the fluid physics of fairings at different misalignment angles, Chapter 4 reports on three aerodynamic fairings that were designed and tested, E863, E863r40 \& E863r45. The fairings had varying degrees of trailing edge rounding and were tested in a water tunnel at Reynolds number based on diameter of $6.82 \times 10^{4}$ using dye for flow visualization and particle image velocimetry for wake quantification. The E863 fairing was found to have the largest 
wake compared with the unfaired cylinder and the modified fairings, E863r40 \& E863r45, at large misalignment angles. The fairing with the largest degree of rounding, E863r45 was found to be the most robust fairing to the variety of misalignment angles.

Aerodynamic fairings are utilized for the optimization of many mechanical systems. They are a potential solution to the tower shadow effect, perhaps the single greatest obstruction for deployment of large downwind wind turbines. For optimal performance fairings should be aligned with the flow (zero degrees angle of attack), but this is not always feasible in turbine applications due to rapid changes in wind direction caused by gusts. To understand the potential impact of fairings for a variety of incident angles, Chapter 5 investigates the wake-rotor effect of the three previously tested fairings on conceptual 13.2 MW turbines. Of the three fairings tested, only the E863r45 fairing reduced the wake compared to a cylinder at misalignment angles as great as $20^{\circ}$, and thus is recommended for testing at higher Reynolds numbers and in unsteady flow conditions typical of a turbulent wind. 


\title{
Chapter 2
}

\section{A FAST Investigation of a 2 Blade, Load-Aligned, Downwind Rotor for a 13.2 MW Wind Turbine}

\begin{abstract}
The ever increasing demand for larger wind turbines has pushed conventional upwind blade design to its limit. Increasing blade strength to withstand the speedily growing loads is proving both an expensive and soon an infeasible solution to the problem at hand. Decreasing the structural loads to more manageable levels can be done by aligning the loads along the rotor blade at a given wind condition. To achieve load alignment, downwind configuration is used and high coning angle is allowed. Thus, the stresses on each blade of a 13.2 MW wind turbine rotor can be sufficiently reduced and a blade can be removed from the conventional upwind three-bladed rotor. This twobladed downwind rotor would produce $4.37 \%$ more power, decrease blade DEL by $19.2 \%$, and decrease rotor mass by $27.5 \%$, compared with the unmodified upwind three-bladed rotor. The load-aligned concept could be one reasonable solution to tomorrow's state-of-art offshore turbines.
\end{abstract}




\section{Nomenclature}

$\begin{array}{ll}\text { DEL } & \text { damage equivalent loading } \\ \text { D2 } & \text { downwind two-bladed rotor } \\ \text { D2L } & \text { downwind lengthened two-bladed rotor } \\ \mathrm{M}_{\mathrm{b}} & \text { root flapwise bending moment } \\ \mathrm{P} & \text { generator power output } \\ \mathrm{PDF} & \text { probability density function } \\ \mathrm{U} 3 & \text { mean wind speed } \\ \mathrm{V}_{\infty} & \text { wind speed normalized by rated wind speed } 11.3 \mathrm{~m} / \mathrm{s} \\ \mathrm{V}^{*} & \text { coning angle } \\ \theta_{\mathrm{c}} & \text { azimuth angle } \\ \psi & \end{array}$




\subsection{Introduction}

Wind turbines, over the last several decades, have grown significantly in size and power generation. In 1980, an average turbine produced $55 \mathrm{~kW}$ of power and had a rotor diameter of $15 \mathrm{~m} .{ }^{2.1,2.2}$ In 2014, MHI Vestas, installed a functional prototype of an 8MW wind turbine with a rotor diameter of $164 \mathrm{~m}$. This increase in size is to achieve utility-scale energy production and to reach stronger, more consistent winds higher in the atmosphere, which in turn lowers the cost of energy. ${ }^{2.3}$

Increasing rotor size is non-trivial. Turbine blades must be able to withstand the immense stress from the applied loads. Additionally, blades must be sufficiently stiff that they cannot deflect downstream and cause a tower strike. To satisfy these two design constraints, extreme-scale blades require large amounts of expensive material. Sandia National Labs, SNL, designed a series of $100 \mathrm{~m}$ long blades for a $13.2 \mathrm{MW}$ wind turbine that do meet the design constraint for extreme-scale turbines. They weight of the blades range from $103 \mathrm{Mg}$ to $53.5 \mathrm{Mg}$ depending on the material used. ${ }^{2.4}$ The SNL rotor blades are expensive due to the large amount expensive material used. Since wind turbine rotors are estimated as $23 \%$ of the systems capital expenditure any reduction of this cost would be large reduction in total cost of energy. ${ }^{2.5}$

Downwind wind turbines, which are turbines with the rotor downstream of the tower, are not a new concept. The first successful megawatt-size wind turbine, the Smith-Putnam turbine, was developed in $1941 .{ }^{2.6}$ Due primarily to the loud acoustic noise produced by downwind rotors, upwind rotors became the conventional design. ${ }^{2.7}$ However, downwind rotors offer distinct advantages over conventional upwind rotors in reference to extreme-scale blade design constraints. First, the stiffness constraint is relaxed because downstream bending will not lead to a tower strike. Secondly, the blade stress constraint can be lessened because the rotor blades can be load-aligned, 
Fig. 2.1. The non-torque loads that a blade experiences can be combined by the vector addition of gravitational, centrifugal, and thrust loads. If the blade geometry follows the stress vectors this would eliminate the shear stress component and drastically reduce the structural requirements for the blade. ${ }^{2.8}$

This investigation compares the performance of different rotors for a $13.2 \mathrm{MW}$, extremescale wind turbine. One conventional, upwind, 3-bladed rotor was tested and compared with 36 downwind 2-bladed rotors with varying degrees of coning, and length. The motivation for reducing the blade number from 3 to 2 is to reduce the mass of the rotor by approximately $1 / 3 \mathrm{rd} .{ }^{2.9}$ Specific coning angles could be more effective at increasing the average load-alignment at differing wind conditions. This investigation attempts to show that 2-bladed downwind rotors, compared with upwind 3-bladed rotors, can be successful at significantly reducing rotor mass while meeting the design constraints. Additionally, this investigation reveals the performance tradeoffs between different 2-bladed downwind rotors, at specific wind conditions and when the performance is averaged over the life of the turbine.

\subsection{Methods}

To investigate the advantages of a highly coned downwind two-bladed rotor compared with a conventional upwind three-bladed rotor for extreme-scale wind turbines, modifications were made to SNL's 13.2 MW wind turbine and FAST simulations were conducted. FAST is a code developed by the National Renewable Energy Laboratory (NREL) to simulate a vast range of wind turbine designs. ${ }^{2.10}$ The baseline turbine used in this investigation was SNL's 13.2MW turbine, originally scaled from NREL's 5MW baseline turbine. ${ }^{2.11}$ The turbine was designed to use a threebladed upwind rotor, with blades of length $100 \mathrm{~m}$, and operate at a rated wind speed, $\mathrm{V}_{\infty}$, of $11.3 \mathrm{~m} / \mathrm{s}$. This baseline rotor is named $\mathrm{U} 3$, for upwind three-bladed rotor. The blades used for all 
rotors in this investigation were SNL100-02. This blade was developed by SNL as a relatively light and practical composite blade with a mass of $53.5 \mathrm{Mg}$.

Motivated by significantly reducing rotor mass, the first modification to the rotor was to make it a downwind two-bladed rotor, D2. This is done in FAST by changing the sign of the variables, over hang (OverHang), shaft tilt (ShftTilt), center of mass for the nacelle (NacCMxn) and coning angle (PreCone), as well as changing the blade number (NumBl) from 3 to 2. It was found that further changes were beneficial: baseline blade pitch was set to $-1.8^{\circ}$, and gearbox ratio was set to 121 from 157.8 , this was to account for the higher rotor rotational speed required to be located on the maximum of the power coefficient vs. tip speed ratio curve. ${ }^{2.12}$ One additional adaption made to the D2 rotor was that teeter was turned on. This can decreases the range of bending moments that a blade experiences over one cycle, however a teetered rotor is fundamentally only possible with a 2-bladed rotor.

In order to achieve load alignment in the simulation, the second change to the rotor was to vary the value of coning angle, $\theta_{c}$. This is simply done in fast by changing the value of the variable, PreCone. Due to both the decrease of solidity from the reduction of a blade, and the decrease of swept area as $\theta_{\mathrm{c}}$ increases, there was an anticipated loss of power generation, $\mathrm{P}$, for the D2 rotor. To eliminate this loss of $\mathrm{P}$, the D2L rotor was designed. The blades of the D2L rotor were linearly stretched until $\mathrm{P}=13.15 \mathrm{MW}$ at steady rated $\mathrm{V}_{\infty}$, for a given $\theta_{\mathrm{c}}$. All local blade properties, linear density, linear stiffness, airfoil profile and its cord length, were held as default, however the total blade length was linearly stretched by $2.7 \mathrm{~m}-12.3 \mathrm{~m}$.

Simulations comparing the performance of different rotors were conducted. Each simulation ran for 16 minutes of simulated real time, with the first 6 minutes discarded, allowing the simulation to reach internal stability. The FAST outputs monitored were generator power 
(GenPwr), and the root flapwise bending moment of blade 1 and 2, (RootMyb1, RootMyb2). Statistical analysis was conducted on the outputs, and reported is the simulation mean of generator power and root flapwise bending moment, additionally reported is the damage equivalent loading, DEL. DEL is calculated from $\mathrm{M}_{\mathrm{b}}$ of both blade 1 and 2, using MLIFE. ${ }^{2.13}$ MLIFE is a script designed to calculate short term and long term damage from time series inputs.

Simulations were conducted with turbulent $\mathrm{V}_{\infty}$ ranging from $2.825 \mathrm{~m} / \mathrm{s}$ to $22.6 \mathrm{~m} / \mathrm{s}, 25 \%$ to $200 \%$ rated $\mathrm{V}_{\infty}$. The turbulent wind profiles were generated using TurbSim, a script designed to generate numerically random turbulent wind profiles. ${ }^{2.14}$ The turbulent model used was Kaimal, and the intensity was set to "B" (medium turbulent intensity). Twelve different turbulent wind profiles were generated for each $\mathrm{V}_{\infty}$ using different random seed values. The average of the 12 results was displayed for different $\theta_{c}$. Finally, MLIFE was used to calculate the velocity-weighted average of P and DEL for each of the different rotors. MLIFE employs a Weibull distribution with shape factor of 2, and a scaling factor of $11.284 \mathrm{~m} / \mathrm{s}$ to model the $\mathrm{V}_{\infty}$ probability distribution function, PDF.

\subsection{Results}

Fig. 2.2 shows the baseline response of the turbine for both the U3 and D2 rotors at steady rated wind, over a 16 minutes simulation. Shown in the left plot, $\mathrm{V}_{\infty}=11.3 \mathrm{~m} / \mathrm{s}$, and has no shear, veer or unsteady component. The middle plot shows the power produced by the generator. The controller requires a small amount of time to settle, indicated by the unstable region where time is less than $100 \mathrm{~s}$. To ensure the simulation is internally stable only data after 6 minutes is used for processing. The average power generated from the D2 rotor is lower than the U3 rotor by $3.94 \%$. This drop in $\mathrm{P}$ is due to the decrease in solidity between the 3 bladed and 2 bladed rotors. The right

plot shows the root flap bending moment of blade 1 plotted against azimuth angle. The U3 rotor 
has an average $\mathrm{M}_{\mathrm{b}}=43.2 \mathrm{MN} \cdot \mathrm{m}$ whereas the $\mathrm{D} 2$ rotor has a higher average $\mathrm{M}_{\mathrm{b}}=53.5 \mathrm{MN} \cdot \mathrm{m}$. The higher moment for the D2 rotor is because the rotor load must be distributed between one less blade. The D2 moment however is less than $150 \%$ that of the U3 case, indicating that there is a reduction in $\mathrm{M}_{\mathrm{b}}$ solely in moving the rotor downwind.

There was a drop in $\mathrm{P}$, witnessed in Fig. 2.2, and a the further drop in $\mathrm{P}$ anticipated as $\theta_{\mathrm{c}}$ increase. To compensate for this power loss the blades were lengthened to the point where the downwind rotor produces equivalent power to the conventional rotor at steady rated wind. Fig. 2.3a, shows the required blade length for a given $\theta_{c}$ to reach this power constraint. As $\theta_{c}$ increases the blade length must also increase to compensate for the smaller swept area of the rotor. Fig. 2.3b, displays the total rotor mass. The D2L rotor mass is decreased from the baseline rotor by $31.5 \%$ $25.1 \%$. This equates directly to rotor cost saving. Finally, fig. $2.3 \mathrm{c}$ shows the average power generated by both the U3 and the D2L rotor. They are both centered near the constrained 13.2MW.

The steady wind assumption is a useful simplification. However unsteady wind is much more physically realistic. Therefore the remaining results come from simulations with turbulent velocity profiles. Fig. 2.4, shows the baseline response of a turbulent FAST simulation. The left plot shows the turbulent wind profile generated by TurbSim, centered at rated conditions, $11.3 \mathrm{~m} / \mathrm{s}$. The center plot shows the power produced by the generator with the given wind input. In general the two rotor's power production profiles follow closely to each other, with the D2 rotor consistently producing slightly less than the U3 rotor. To avoid this power loss problem the D2L rotor is used for future simulations. The right plot shows instantaneous values of $\mathrm{M}_{\mathrm{b}} \mathrm{vs}$. azimuth angle. Only one in ten data points are shown to avoid an overcrowded figure. Similar to the steady case, on average $\mathrm{M}_{\mathrm{b}}$ for the $\mathrm{D} 2$ rotor is higher than for the $\mathrm{U} 3$ rotor. This is again because the load is distributed over one less blade. 
The following plots shown in Fig. 2.5 are created by averaging the results from 12 different randomly generated turbulent wind profiles centered on rated wind speed, $\mathrm{V}_{\infty}=11.3 \mathrm{~m} / \mathrm{s}$. The first plot shows the average power generated. The D2L rotor generates less power than the U3 rotor for all coning angles at this wind speed. This contrasts with the results from the steady wind where the power was constrained to be equal to that from the U3 rotor. This could be because the controller was developed for a conventional rotor therefore the parameters are not tuned perfectly and cause a slight delay with varying wind speeds. The center plot shows the relationship between the averages of $\mathrm{M}_{\mathrm{b}}$ and the $\theta_{\mathrm{c}}$. At low $\theta_{\mathrm{c}}$, the D2L rotor has an initial increase in $\mathrm{M}_{\mathrm{b}}$ compared to the $\mathrm{U} 3$ rotor. As noted previously, this increase is due primarily to the bending load being shared by one less blade. As the $\theta_{c}$ increases, the $M_{b}$ decreases to the point where both rotors have similar $\mathrm{M}_{\mathrm{b}}$ at $\theta_{\mathrm{c}} \sim 10^{\circ}$ and at $\theta_{\mathrm{c}}=20^{\circ}$ the $\mathrm{M}_{\mathrm{b}}$ from the D2L rotor is half as large as from the $\mathrm{U} 3$ rotor. The final plot displays DEL for the rotors. Similar to the trends seen for $\mathrm{M}_{\mathrm{b}}$ the DEL for the D2L rotor starts higher than that from the $\mathrm{U} 3$ rotor, but decreases as $\theta_{\mathrm{c}}$ increases. The DEL does not continue to decrease at the same rate that $\mathrm{M}_{\mathrm{b}}$ decreases. This is because DEL is composed both from the average value of $M_{b}$ as well as the spread of values. The spread of instantaneous $M_{b}$ values is not very sensitive to $\theta_{\mathrm{c}}$ therefore the DEL begin to plateau at higher $\theta_{\mathrm{c}}$ angles.

In reality a turbine will spend only a portion of time near rated conditions. Instead, it will experience a variety of wind speeds. To gather an understanding of effects of the rotors at different wind speeds, simulations were conducted with turbulent wind speeds ranging from $2.825 \mathrm{~m} / \mathrm{s}$ to $22.6 \mathrm{~m} / \mathrm{s}$, equating to $25 \%$ - $200 \%$ rated wind speed. Every simulated test condition was repeated with 12 different randomly generated turbulent wind profiles and the results were averaged together before they were plotted. Fig. 2.6 shows the relationship of $\mathrm{M}_{\mathrm{b}}$ to wind speed. Both rotors have similar trends. $\mathrm{M}_{\mathrm{b}}$ increases to reach a maximum near rated conditions, $\mathrm{V}_{\infty}{ }^{*}=1$, then begins 
to decrease as $\mathrm{V}_{\infty} *$ continues to increase. When $\mathrm{M}_{\mathrm{b}}=0$, the rotor is by definition operating in its load-aligned condition. As $\theta_{c}$ increases, the profile of the $M_{b}$ for the D2L rotor decreases and the load-aligned condition moves to lower wind speeds.

Fig. 2.7, shows the relation between DEL and wind speed. Similar to the trend seen in $\mathrm{M}_{\mathrm{b}}$, DEL starts low and increases to reach a maximum near $\mathrm{V}_{\infty} *=1$. Conversely with the trend of $\mathrm{M}_{\mathrm{b}}$, as $\mathrm{V}_{\infty} *$ continues to increase DEL does decrease indefinitely. The DEL from U3 rotor plateaus at value near $50 \mathrm{MN} \cdot \mathrm{m}$. The $\mathrm{D} 2 \mathrm{~L}$ rotors have differing behaviors depending on $\theta_{\mathrm{c}}$. The peak DEL experienced decrease as $\theta_{\mathrm{c}}$ increases. However, the DEL at larger $\mathrm{V}_{\infty} *$ increases as $\theta_{\mathrm{c}}$ increases. This is because the rotor experiences large negative $\mathbf{M}_{\mathrm{b}}$ at high $\theta_{\mathrm{c}}$ and fast wind speeds, seen in Fig. 2,6. Negative $\mathrm{M}_{\mathrm{b}}$ contributes as much as positive $\mathrm{M}_{\mathrm{b}}$ to DEL.

MLIFE was used to calculate velocity-weighted averages of the values. MLIFE employed a Weibull distribution, Fig. 2.8a, with shape factor $=2$ and scaling factor $=11.284 \mathrm{~m} / \mathrm{s}$ to model the wind speed distribution. This produces three different metrics of performance: rotor mass, velocity-averaged DEL, and velocity-average power. Rotor mass, Fig. $2.8 \mathrm{~b}$, does not vary with wind speed therefore is the same as shown in Fig. 2.3b. DEL and power are both very sensitive to wind speed therefore velocity-weighted averaging was a necessary step to provide a meaningful metric. Each data point in Fig. 2.8c \& d is calculated by MLFIE by synthesizing the data from all 15 different wind speeds, each with 12 different trials, totaling 180 different simulations. Fig. 2.8c shows the velocity-averaged DEL as a function of coning angle. The DEL for the D2L rotor decreases as $\theta_{c}$ increases and becomes less than that from the $U 3$ rotor at $\theta_{c}=9.5^{\circ}$. Fig. $2.8 \mathrm{~d}$ displays the relationship between velocity-averaged power output and $\theta_{c}$. The weighted power for both the U3 and D2L are similar. However the D2L rotor produces slightly more power than the U3 rotor by up to $4.91 \%$. Table 1 , summarizes the 3 metrics of performance for 3 different coning angles, 
$10^{\circ}, 15^{\circ}$ and $20^{\circ}$. All three coning angles have positive performance for all three metrics. Minimizing rotor cost would tend toward $\theta_{\mathrm{c}} \sim 10^{\circ}$, minimizing damage would lead to a $\theta_{\mathrm{c}} \sim 20^{\circ}$.

\subsection{Conclusions}

By better aligning the average force vector with the direction of the blade, a two-bladed downwind rotor with high coning angle can reduce rotor mass compared with conventional upwind three-bladed baseline rotor, while simultaneously lowering blade DEL and increasing annual energy production. Lowering the damage can be done by increasing the coning angle greater than $9.5^{\circ}$, and a coning angle as large as $20^{\circ}$ will lead to $25.8 \%$ reduction in lifetime damage equivalent loading. Average power generation is increased by lengthening the remaining two rotor blades by 2.7\%-12.3\%, depending on the coning angle. The mass saving comes from the reduction of rotor blade number from 3 to 2 . Some of the mass savings is lost due to the increased blade length which is dependent on coning angle. The net mass savings ranges from $31.5 \%$ to $25.8 \%$. The load-aligned concept is shown to be an effective and robust method for manufacturing less expensive and more effective rotors compared with conventional designs.

Future work could investigate the impact that blade curvature could play in further reduction of blade loading. Adjusting the coning angle can align the net blade load along the direction of the blade. However, a rotor blade that employs downwind curvature could be aligned with the non-torque loads along the entire span of the blade. Another option is to design a morphing rotor. This rotor could be dynamically actuated to adjust the coning angle to be optimized for changing wind conditions. A morphing rotor could also collapse in on itself during extreme wind conditions e.g. a hurricane, to protect from rare events which are a large design concern for extreme-scale wind turbines. Downwind, low mass, load-aligned, possibly dynamic, rotors are likely the most practical options for the extreme-scale wind turbines of the future. 


\section{References}

[2.1] Quarton, D. C. " The Evolution of Wind Turbine Design Analysis: A Twenty Year Progress Review". Wind Energy 1 (1998): 5-24.

[2.2] Shikha, T. S. Bhatti, and D. P. Kothari. "Aspects of technological development of wind turbines." Journal of Energy Engineering 129.3 (2003): 81-95.

[2.3] Esteban, Miguel, and David Leary. "Current developments and future prospects of offshore wind and ocean energy." Applied Energy 90.1 (2012): 128-136.

[2.4] Griffith, D. Todd. "The SNL100-02 Blade: Advanced Core Material Design Studies for the Sandia 100-meter Blade." Sandia National Laboratories Technical Report, SAND201310162 (2013).

[2.5] Fingersh, L., M. Hand, and A. Laxson. "Wind Turbine Design Cost and Scaling Model Wind Turbine Design Cost and Scaling Model [Internet]. 2006 page 1-43."

[2.6] Vargo, Donald J. "Wind energy developments in the 20th century." (1974).

[2.7] Butterfield, C. P., W. Musial, and J. Jonkman. "Overview of offshore wind technology." Presentation at the Chinese Renewable Energy Industry Association WindPower Conference, Shanghai, China. 2007.

[2.8] Ichter, Brian, et al. "Structural design and analysis of a segmented ultralight morphing rotor (SUMR) for extreme-scale wind turbines." Proceedings of the 42nd AIAA Fluid Dynamics Conference, New Orleans, LA. 2012.

[2.9] Ichter, Brian, et al. "A morphing downwind-aligned rotor concept based on a 13-MW wind turbine." Wind Energy (2015).

[2.10] Jonkman, Jason M., and Marshall L. Buhl Jr. "FAST user's guide." National Renewable Energy Laboratory, Golden, CO, Technical Report No. NREL/EL-500-38230 (2005). 
[2.11] Butterfield, Sandy, Walter Musial, and George Scott. "Definition of a 5-MW reference wind turbine for offshore system development." (2009).

[2.12] Resor, Brian Ray, et al. "Effects of Increasing Tip Velocity on Wind Turbine Rotor Design." Sandia National Laboratories: SAND2013-XXXX (2013).

[2.13] Hayman, G. J., and M. Buhl Jr. "Mlife users guide for version 1.00." National Renewable Energy Laboratory, Golden, CO (2012).

[2.14] Jonkman, Bonnie J. "TurbSim user's guide: Version 1.50." (2009). 


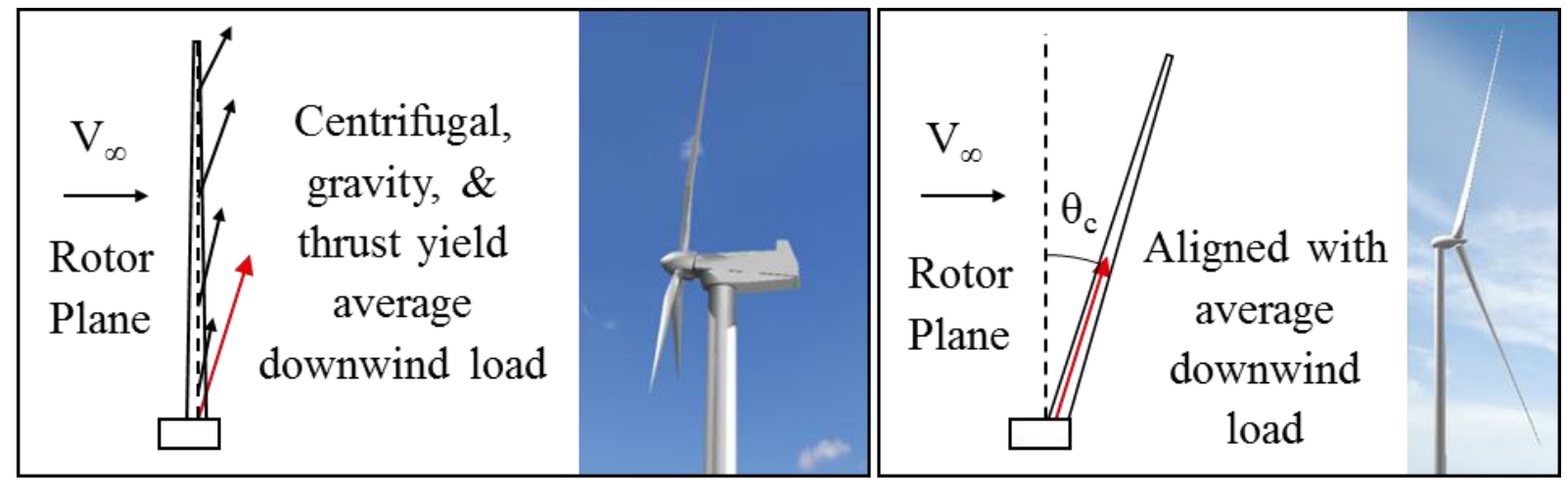

Figure 2.1: Extreme-scale turbines for a) the non-torque forces on a conventional rotor blade, $b$ ) a conventional upwind turbine configuration, c) a downwind rotor blade aligned with the nontorque force distribution \& d) a downwind load-aligned turbine. 

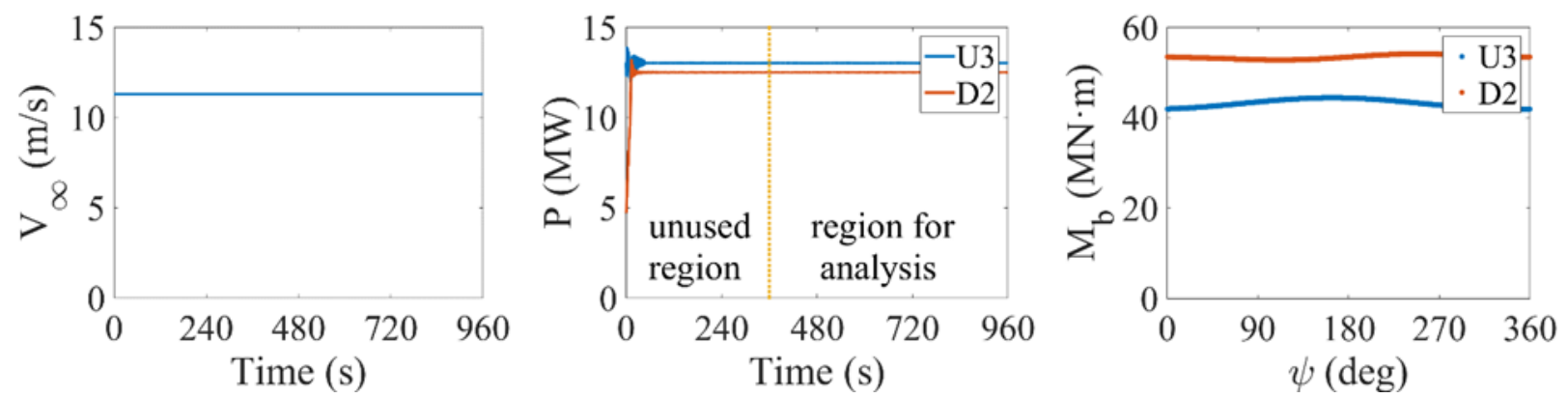

Figure 2.2: Baseline turbine response: a) turbulent wind profile with a characteristic wind speed of $11.3 \mathrm{~m} / \mathrm{s}, \mathrm{b}$ ) time series of generator power produced for both a conventional 3 blade rotor and a downwind 2 blade rotor \& c) root flap bending moment versus azimuth angle for both rotors. 

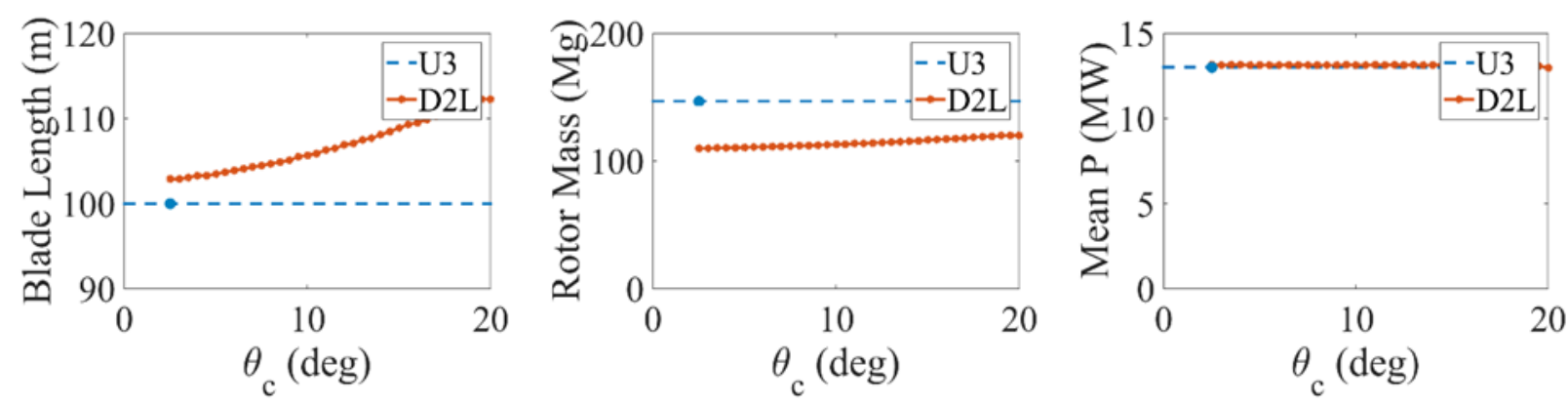

Figure 2.3: a) Required blade length to meet steady power constraints used to define the D2L rotor, b) the total rotor mass for both rotors \& c) power produced by the generator for both rotors. 

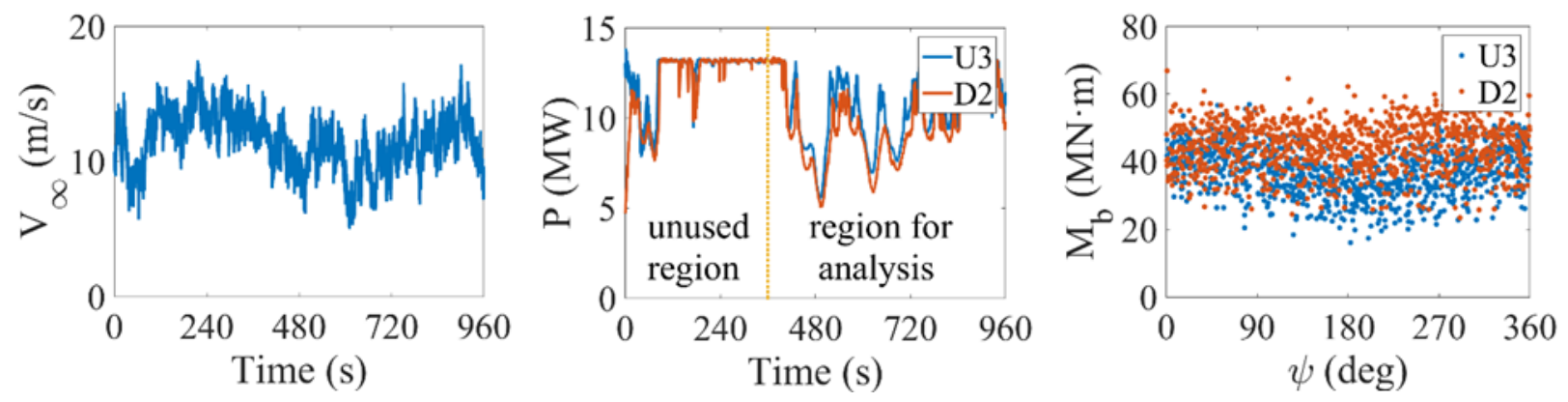

Figure 2.4: Baseline turbine response: a) turbulent wind profile with a characteristic wind speed of $11.3 \mathrm{~m} / \mathrm{s}$, b) time series of generator power produced for both a conventional 3 blade rotor and a downwind 2 blade rotor \& c) root flap bending moment versus azimuth angle for both rotors. 

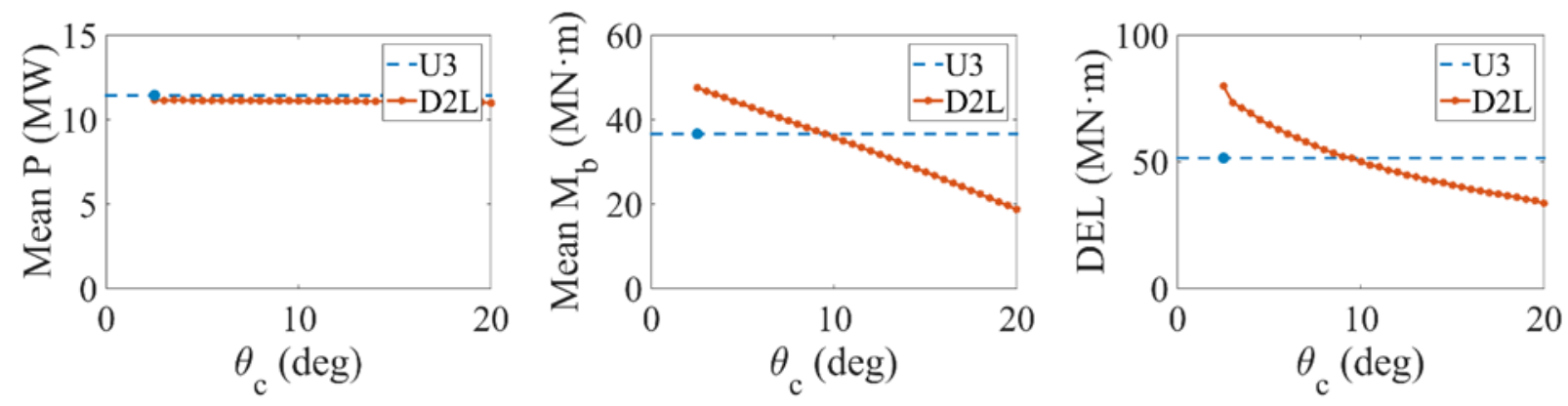

Figure 2.5: Average turbine response from the U3 and D2L rotors, from 12 different turbulent wind profiles centered at $11.3 \mathrm{~m} / \mathrm{s}:$ a) power produced by the generator, b) average root flap bending moment \& c) Damage Equivalent Loading. 

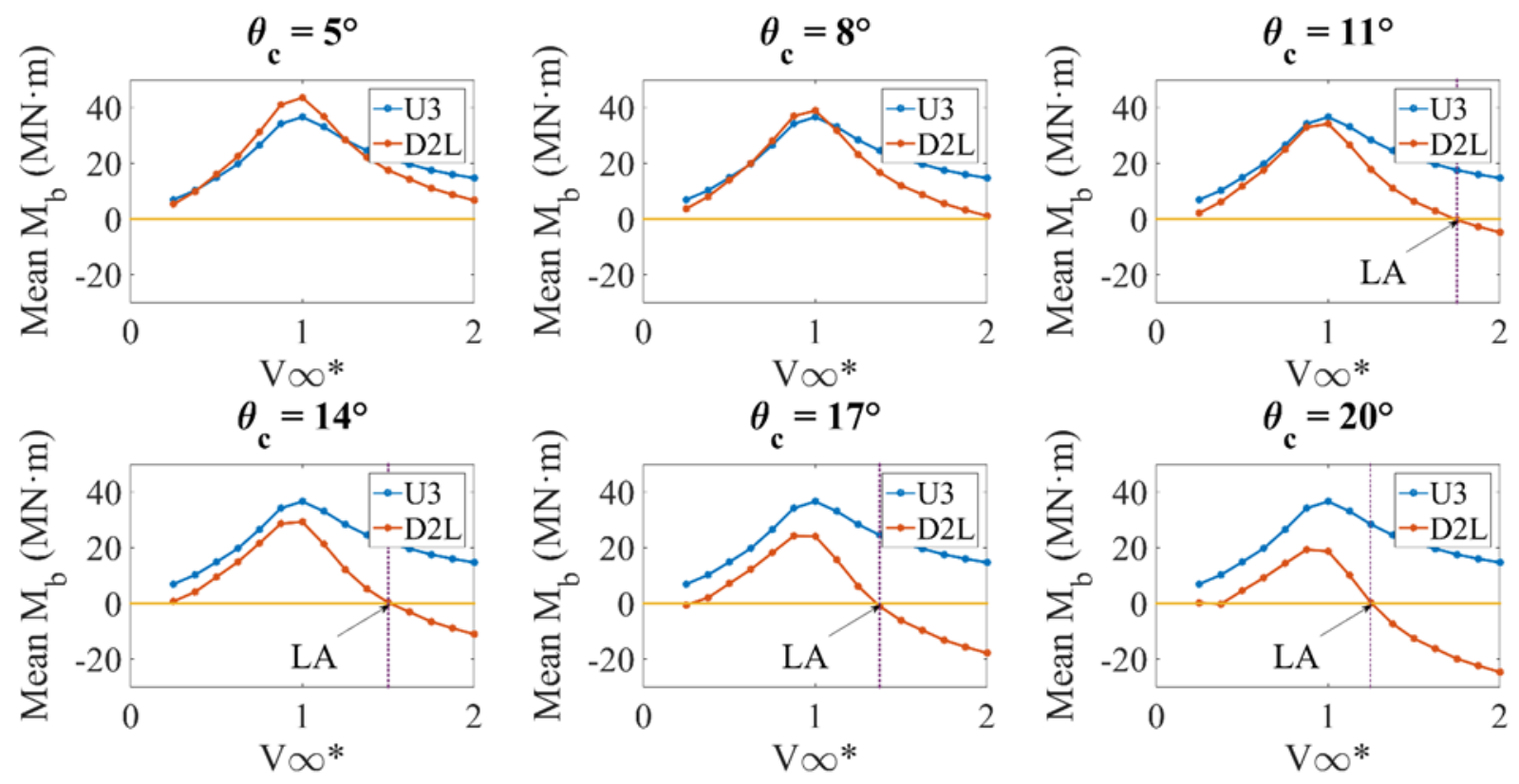

Figure 2.6: Average root flap bending moment against turbulent wind with characteristic wind speeds ranging from $2.825 \mathrm{~m} / \mathrm{s}$ to $22.6 \mathrm{~m} / \mathrm{s}$, for the $U 3$ rotor and 6 different D2L rotors with coning angles ranging from $5^{\circ}$ to $20^{\circ}$. The wind speed that the rotor is operating in its load-aligned condition (mean $M_{b}$ is zero) is noted in purple. 

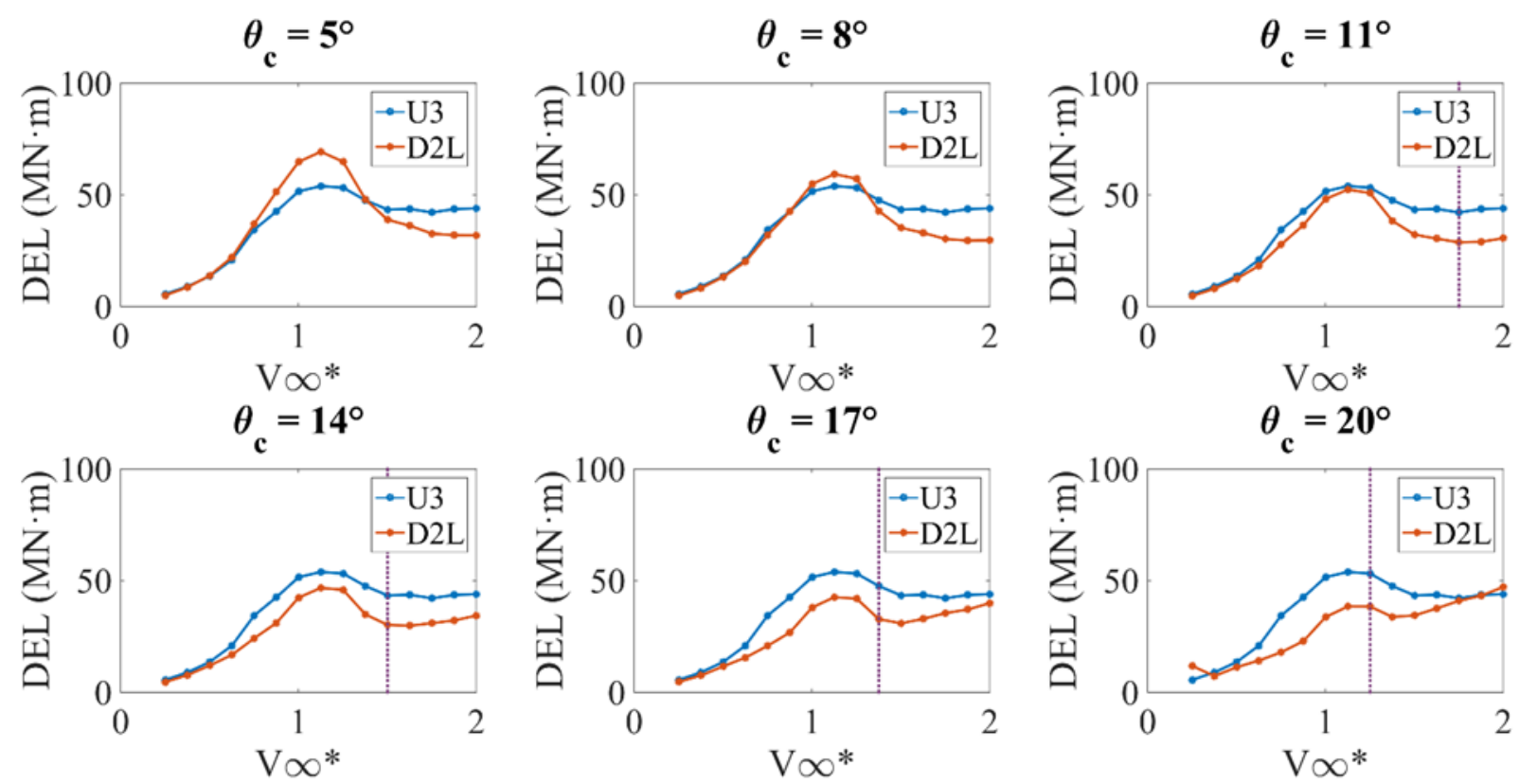

Figure 2.7: Damage equivalent loading against turbulent wind with characteristic wind speeds ranging from $2.825 \mathrm{~m} / \mathrm{s}$ to $22.6 \mathrm{~m} / \mathrm{s}$, for the U3 rotor and 6 different D2L rotors with coning angles ranging from $5^{\circ}$ to $20^{\circ}$. The wind speed that the rotor is operating in its load-aligned condition is noted in purple. 

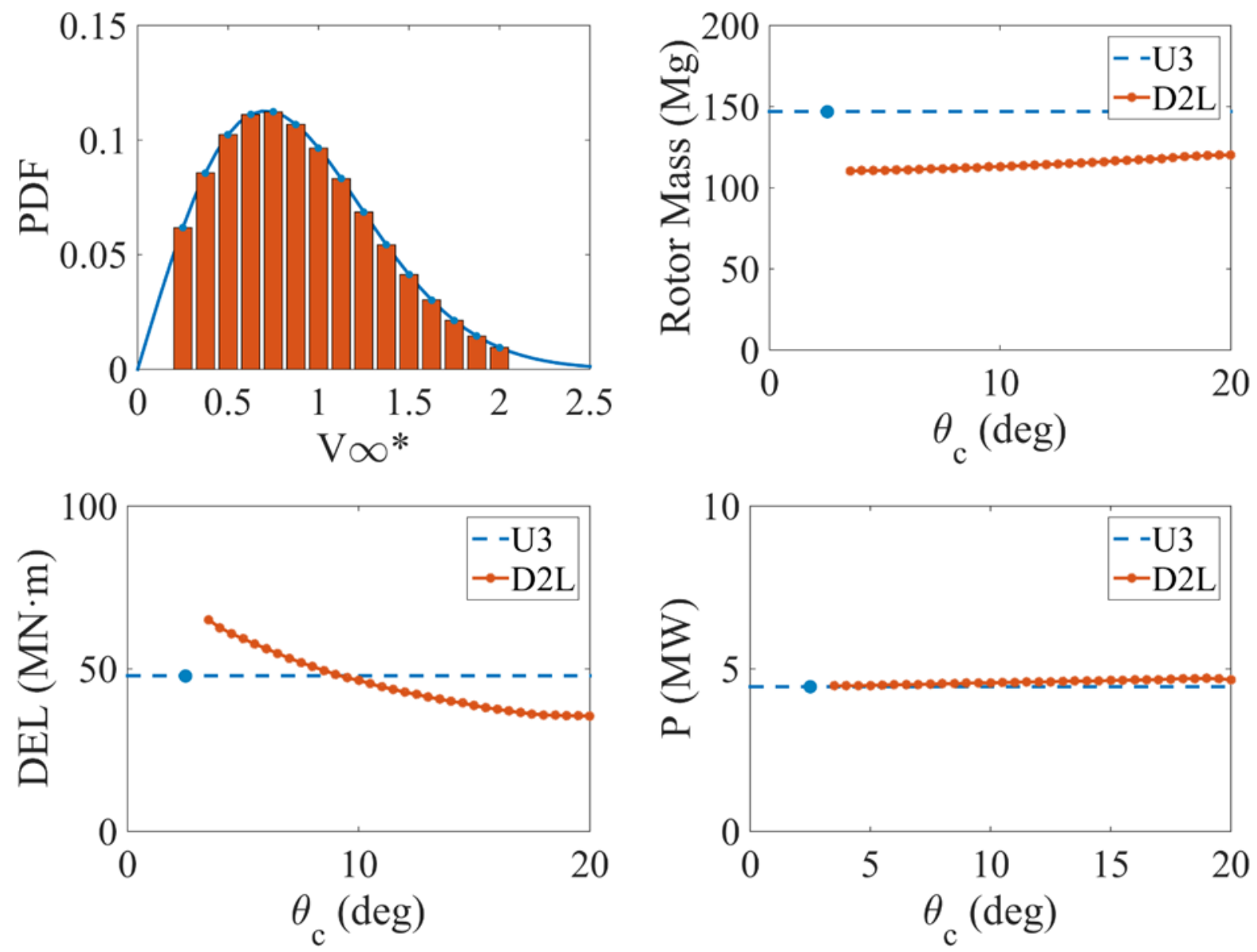

Figure 2.8: Output metrics averaged over a range of wind speeds: a) Weibull distribution modeling the wind speed probability distribution function, b) net rotor mass as a function of coning angle, c) average DEL weighted by wind speed probability \& d) average power output weighted by wind speed probability. 
Table 2.1: Metrics of performance for the D2L rotors with three different coning angles given as percent increase compared with the U3 baseline rotor at coning angle of $2.5^{\circ}$

\begin{tabular}{|c|c|c|c|}
\hline$\theta_{\mathrm{c}}$ & \%Rotor Mass & \%DEL & $\% \mathbf{P}$ \\
\hline $10^{\circ}$ & $-29.5 \%$ & $-2.85 \%$ & $2.63 \%$ \\
\hline $15^{\circ}$ & $-27.4 \%$ & $-19.2 \%$ & $4.37 \%$ \\
\hline $20^{\circ}$ & $-25.1 \%$ & $-25.8 \%$ & $4.91 \%$ \\
\hline
\end{tabular}




\title{
Chapter 3
}

\section{Measurements and Predictions of Tower Shadow and Tower}

\section{Fairing Effects on the UAE Rotor Blades}

\begin{abstract}
Downwind rotors can have some advantages in reducing rotor mass for extreme-scale wind turbines. However, the tower shadow adds an aerodynamic complication that can be difficult to quantify and predict. This study presents and analyzes a previously unpublished subset of data collected by NREL during an extensive wind tunnel campaign for Unsteady Aerodynamic Experiment Phase VI (UAE Phase VI). The experimental data includes relative flow fields, aerodynamic blade forces, and blade root flapwise bending moments all for both upwind and downwind turbines and, importantly, for downwind turbines with an aerodynamic tower fairing. It was shown that at high tip speed ratios (near design conditions), tower shadow is a dominating contributor to bending moments but can be mitigated by the use of a tower fairing aligned with the flow. At lower tip speed ratios where the blades can undergo aerodynamic stall and hysteresis, tower shadow was only a secondary contributor to bending moments and the tower fairing did not significantly impact bending moments (unless it was misaligned, in which case it exaggerated the variations). To interpret this data and assess predictive capability for a widely used wind turbine tool, the aeroelastic simulation code called FAST was used to predict the same experimental
\end{abstract}


conditions. In general, FAST predicted the cycle-averaged aspects, but was unable to predict the unsteady fluctuations. These results suggest that wake modeling for downwind turbines may require modifications to improve the quantitative time-dependent description of tower shadow effects and of tower fairings. 


\section{Nomenclature}

$\begin{array}{ll}\mathrm{d} & \text { tower diameter } \\ \mathrm{C}_{\mathrm{d}} & \text { drag coefficient } \\ \mathrm{C}_{\mathrm{n}} & \text { normal force coefficient } \\ \mathrm{M}_{\mathrm{b}} & \text { root flap bending moment } \\ \mathrm{r} & \text { radial location along blade } \\ \mathrm{R} & \text { blade tip radius } \\ \mathrm{Re} & \text { Reynolds number based on tower diameter } \\ \mathrm{V} & \text { instantaneous flow velocity magnitude } \\ \mathrm{V}_{\mathrm{rel}} & \text { instantaneous relative flow velocity magnitude } \\ \mathrm{V}_{\infty} & \text { free stream velocity magnitude } \\ \chi_{\mathrm{F}} & \text { normalized distance along the chord line } \\ \alpha & \text { instantaneous flow angle } \\ \theta_{\mathrm{c}} & \text { instantaneous relative flow angle } \\ & \end{array}$




\subsection{Introduction}

An average wind turbine in 1980 had a $15 \mathrm{~m}$ rotor diameter and produced $55 \mathrm{~kW}$ of power. ${ }^{3.1,3.2}$ Today, MHI Vestas manufactures a turbine with a rotor diameter of $164 \mathrm{~m}$ that produces $8.0 \mathrm{MW}$. Furthermore, Sandia national labs ${ }^{3.3}$ released the design for 'the hundred meter blade', and DTU Wind Energy ${ }^{3.4}$ has published work on a 10 MW reference turbine. However the trend of increasing size is not as fast as in previous decades due to the increasing blade mass to accommodate stress levels that occur as the blades grow in length. ${ }^{3.5}$ Structural limits are being reached with the conventional three-bladed, horizontal axis, upwind rotor design resulting in a search for innovative designs. ${ }^{3.6}$ One option, especially being considered to reduce rotor mass is the use of a two-bladed downwind configuration. In 2008, the first commercial 2-MW downwind turbine was built, and is now being operated by Wind Power Ibaraki Ltd. ${ }^{3.7}$ Moving from an upwind rotor to a downwind rotor may give significant structural advantages, that can help support the evolution of extreme-scale wind turbines of 10-20 MW..$^{3.8,3.9}$

However, a well-known large concern with downwind turbines is the potential impact of tower shadow, i.e., the downstream wake from the tower impacting the blades as they pass through. The tower shadow is an aerodynamically unsteady region, with significant variations in flow angle and velocity, and with a net momentum deficit. As the down wind turbine blades pass through this region of velocity deficit and increased turbulence, the relative flow seen by the blade is directly modified. In particular, this can cause a rapid change of the blade's aerodynamic loading ${ }^{3.10}$ which can, in turn, increase the root blade moments and, therefore, blade stresses. This cyclic loading could impact fatigue life of the blade. ${ }^{3.11}$

To quantify and understand tower shadow further Orlando et al., ${ }^{3.12}$ conducted an experiment to measure the wake caused by turbine towers at different Reynolds numbers. 
Anemometers were used to measure average wind speed at various locations. A key limitation of this experiment is that associated with instrumentation since only average data was collected, which gives no insight into the instantaneous and unsteady structures of the wake. Secondly, the data was collected from a tower without a rotor, which ignores any induction effect the rotor has on the wake flow field and does not allow direct examination of the impact on blade root moment. Using average experimental tower shadow measurements, Wang and Coton ${ }^{3.13,3.14}$ developed time-averaged wake deficit models for integration into a horizontal axis wind turbine simulator. This was an important first step to understanding the impact of tower shadow. However, the lack of unsteady flow features in the wake limits the physical realism of the model. A more realistic tower shadow model would ideally incorporate some level of unsteadiness as well as the average deficits and then validate these predictions with unsteady experimental data.

Fortunately such data exists, though it has not been previously published. National Renewable Energy Laboratory (NREL) performed several experiments on the UAE Phase VI turbine, including upwind and downwind configurations, Fig. 3.1. ${ }^{3.15}$ Instantaneous tower shadow measurements were taken, leading to a fuller understanding of the wake from a tower with possible rotor induction included. The tower shadow effect can be seen in Fig. 3.1a, by the flow visualization disturbed past the tower. The upwind turbine data in this campaign has been analyzed and used to verify predictive capability of several wind turbine aeroelastic models. . $^{3.16,} 3.17$ However, no studies have investigated the instantaneous tower shadow measurements, and their effects on the blade aerodynamics and structural dynamic effects.

This study analyzes previously unpublished portions of this experiment including both the measurements of tower shadow, as well as the effect that the tower shadow has on blade aerodynamics and structural dynamics. This is the first study to analyze these fully-coupled 
unsteady shadow effects experimentally on a downwind turbine. In addition, this study compares the effect of a tower fairing on blade aerodynamics and structural dynamics. No previous studies have been published with such results to the authors' knowledge. Using this unique data set can also allow determination of conditions when the tower shadow is likely to be a significant contributor to blade bending moments, or when it is only a secondary contributor. It further allows determination of the conditions for which a tower fairing is useful in mitigating the negative effects of the tower shadow. Lastly the study compares the time-dependent results with FAST, a turbine simulator developed by NREL, ${ }^{3.18}$ to determine if conventionally-used tower shadow models are qualitatively and quantitatively reasonable in predicting blade wake interactions for the above conditions.

\subsection{Methods}

The Unsteady Aerodynamic Experiment Phase VI (UAE Phase VI) was performed by NREL, at NASA Ames Research Center, in the NFAC $80 \mathrm{ft}$ x $120 \mathrm{ft}$ test section. Several different turbine configurations were tested. This included various rotor locations examining both upwind and downwind configurations, both rigid and teetered rotors, both cylindrical and faired tower geometries. It also included a variety of cone angles, yaw angles, blade pitches, rotor rpms, and test section velocities. Measurements included relative flow pressure, flow angles, blade surface pressures, and blade loads at a rate of $520.83(\mathrm{~Hz})$. This study focuses on the results that directly pertain to the differences between upwind and downwind rotors and those with and without the use of a tower fairing. The objective is to specifically investigate how the tower shadow affects the flow field, blade aerodynamics, and blade loading.

Four different runs were analyzed shown in Fig. 3.2:

Fig. 3.2a) Upwind rotor with a Cylindrical tower (UC) with coning angle, $\theta_{c}=0^{\circ}$ 
Fig. 3.2b) Downwind rotor with a Cylindrical tower (DC), $\theta_{c}=3.4^{\circ}$; Downwind rotor with a tower fairing aligned with the free stream (DF0), $\theta_{\mathrm{c}}=3.4^{\circ}$; and a downwind rotor with a tower fairing with a misalignment angle, $\chi_{\mathrm{F}}$, of $20^{\circ}(\mathrm{DF} 20), \theta_{\mathrm{c}}=3.4^{\circ}$.

The tower cylinder had a diameter (d) of $0.4064 \mathrm{~m}$ while the fairing that wrapped around this tower had a chord length of $0.89 \mathrm{~m}$, thus yielding a thickness to chord ratio 0.456 . Tests were completed at free stream velocities, $\mathrm{V}_{\infty}$, of 5, 7, 10, 15, 20 and $25 \mathrm{~m} / \mathrm{s}$, all at zero yaw. Four output variables were analyzed and presented in this paper: relative flow angle, $\alpha_{\text {rel }}$, relative flow velocity $\mathrm{V}_{\text {rel}}$, normal force coefficient $\mathrm{C}_{\mathrm{n}}$, and root flap bending moment $\mathrm{M}_{\mathrm{b}}$. The flow angle and the flow speed that the blade experiences in the rotating reference frame is $\alpha_{\text {rel }}$ and $V_{\text {rel }}$, calculated by combining the blade rotation, wr, and the flow speed approaching the blades, V, as shown in Fig. 3.3. Note that $\mathrm{V}$ differs from the free stream velocity, $\mathrm{V}_{\infty}$, because it is affected by induction and for the downwind cases the tower shadow. The relative flow parameters $\left(\mathrm{V}_{\text {rel }}\right.$ and $\left.\alpha_{\text {rel }}\right)$ were measured at $\mathrm{r} / \mathrm{R}=0.34,0.51,0.67,0.84 \& 0.91$. Flow field local speed and direction were measured using 5-hole probes extending from the leading edge of the blade, these can be seen in Fig. 3.1b. From the measured pressure of this probe, relative flow angle and relative flow velocity were both calculated. ${ }^{3.15}$ Surface pressures were also measured along the blade surface using pressure taps, which was used to calculate pressure coefficient at various positions along the span and chord. Subsequently, $\mathrm{C}_{\mathrm{n}}$ was calculated by integrating pressure coefficients along the chord, at $\mathrm{r} / \mathrm{R}=0.30$, 0.47, 0.63, $0.80 \& 0.95$. Finally, strain gauges mounted at the blade root were used to directly measure $\mathrm{M}_{\mathrm{b}}$.

To examine these experimental results, FAST, a wind turbine aeroelastic simulator developed by NREL, was used to model the different test conditions and output the same four variables previously defined. For downwind rotors, FAST models the wake of a tower using a 
steady wake model based on drag coefficient, $C_{d}$. FAST predicts $C_{d}$ using a look up table based on Reynolds number, Re, assuming a cylindrical cross-sectional geometry. To model the reduced drag and wake from a tower utilizing a flow-aligned tower fairing, the DF0 case was modeled by assuming that the fairing reduced $\mathrm{C}_{\mathrm{d}}$ to a value of 0.25 based on an approximation of similarly thick fairing aerodynamics from ${ }^{3.19,3.20}$. This model obviously neglects the wake unsteadiness but can show the impact of reducing the mean velocity deficit. For the fairing misaligned at 20 degrees (DF20), a comparable drag coefficient could not be reasonably approximated and furthermore the effects of unsteadiness were likely to be more extreme, indicating that a mean wake model may be inappropriate. Therefore no FAST simulations were conducted for the DF20 cases.

\subsection{Results}

The results will be examined in order of influence, starting with the impact of flow angles and then on flow speeds seen by the blades. This is followed by examining effects on aerodynamic blade force and then on blade root bending moment.

The data is presented vs. rotor azimuth angle, $\psi$, where $\psi=180^{\circ}$ refers to the instrumented blade pointing directly down i.e., the location that the tower shadow has the greatest effect. Data shown in black always refers to the raw data collected in the experiment. Whereas data in red represents the FAST output modeling the experiment. The detailed data sets analyzed the conditions of $\mathrm{V}_{\infty}=5 \mathrm{~m} / \mathrm{s}$, since this yields a tip speed ratio closer to typical design conditions. The tips speed ratio for Sandia's National Lab's 13.2 MW turbine is 7.08 at rated operating conditions

3.15. In particular, this led to a tip speed ratio of 7.58, and tower Reynolds number (based on d and $\left.\mathrm{V}_{\infty}\right)$ of 135,000 . 
Fig. 3.4 shows the relative flow angle at $\mathrm{r} / \mathrm{R}=0.67$ for 36 complete revolutions. This radial location was chosen as the point that approximately separates the swept area in half, i.e. the area inboard of this location approximately equals the swept area outboard of the location. For the upwind case (UC), the relative flow angle is smooth and generally unaffected by the tower shadow. Conversely in all three downwind cases the relative flow angle is greatly influenced by the tower shadow. This is especially true in the region of $150^{\circ}<\psi<200^{\circ}$, where the relative flow angle varies significantly. In general, the range of azimuth angle where the shadow effects were seen is about the same in all three downwind cases, indicating similar wake thicknesses (consistent with the assumption used by FAST for modeling the fairing wake effect). In particular, there is a strong decrease in relative flow angle near $\psi \sim 170^{\circ}$, this is often, but not always, preceded by an unexpected $\alpha_{\text {rel }}$ increase at $\psi \sim 160^{\circ}$. This demonstrates that the wake deficit is not symmetrically reduced nor is it exactly centered at $\psi=180^{\circ}$. Another interesting feature is the difference in angle extremes when comparing the conventional tower (DC) and the faired tower (DF0) cases. The DC case has relative angle values as low as $-5^{\circ}$ and as high as $8^{\circ}$, whereas in the DF0 case the relative angle values are generally confined between $0^{\circ}$ and $5^{\circ}$. In general, the DF0 case has variations on the order of one-half that of the DC case. However when the misalignment angle, $\chi_{\mathrm{F}}$, is increased to $20^{\circ}$ in the DF20 case, the faired tower performance is similar to the un-faired case. This suggests that the fairing alignment angle is critical to mitigate tower shadow effects.

The FAST simulation of the measured data reasonably predicts the upwind cases (UC) as well as the wake-free portion $\left(\psi<150^{\circ}\right.$ and $\left.\psi>200^{\circ}\right)$ of the downwind configurations (DC, DF0 and DF20). However, the UC case includes some experimental variation (ranging between $4^{\circ}$ and $5^{\circ}$, especially at $\psi \sim 270^{\circ}$ ) which suggests that the experimental conditions have some asymmetry perhaps owing to tower and wind tunnel induction effects. Considering now the shadow effects 
for the downwind configurations, it can be seen that the predictions are only qualitatively correct. For the DC case, FAST predict a smaller deficit and does not predict the shift in wake center to $\psi \sim 170^{\circ}$ nor the occasional increase seen around $\psi \sim 160^{\circ}$. The first shift is attributed to the pressure probes extending in front of the blade, leading to an azimuthal angle offset of about $9^{\circ}$, the second effect (preceding increase) can be attributed to wake unsteadiness as observed by O' Connor et $a l .{ }^{3.20}$ In addition, the significant variation associated with difference between different revolution realizations, i.e. the lack of data repeatability for a given $\psi$, is not captured by the FAST predictions. This indicates that a steady wake deficit model does a poor job of capturing the instantaneous relative angles seen by the blade. For the faired DF0 case, the FAST predictions indicate a substantial reduction in shadow effects, which is inconsistent with the substantial variations seen in the measurements. This indicates that a factor of two reduction in drag coefficient within FAST does not quantitatively capture even the mean shadow effects with respect to relative flow angle seen by the blade.

Fig. 3.5 shows the relative flow velocity, taken at $\mathrm{r} / \mathrm{R}=0.67$, plotted against azimuth angle. Again, there is little variation with azimuthal angle in the upwind case, conversely there is a significant shadow effect in the downwind cases. This includes significant wake deficits, as expected by conventional models such as used in FAST, but also significant velocity increases for several of the realizations. These wide differences are again attributed to the fact that the wake from a cylinder can cause the flow to deflect, where such angle changes can either increase or decrease the relative velocity once in a rotating reference frame. The DC cases has the largest variations indicating the biggest shadow effect from the tower wake. Consistent with the results for the relative flow angle, the DF0 case has variations on the order of one-half that of the DC 
case. Interestingly, the DF20 case shows some wake mitigation effects of the fairing in terms of relative velocity, a result not seen for the flow angle in figure 3.4.

For the predictions, FAST again reasonably captures the results for the upwind configuration and the wake free portion for the downwind configuration, within the azimuthal variation of about $0.5 \mathrm{~m} / \mathrm{s}$ seen for all cases, and with fluctuations of about $+/-0.2 \mathrm{~m} / \mathrm{s}$ at a given $\psi$. FAST vastly under-predicts the shadow deficits and completely misses the unsteady relative velocity increases that can occur (which are attributed to the unsteady component of the wake field). There is also a $0.5 \mathrm{~m} / \mathrm{s}$ offset for the DF0 case which is not expected but may indicate that the induction effects can be impacted by the presence of the tower fairing.

Fig. 3.6 shows the normal force coefficient, taken at $\mathrm{r} / \mathrm{R}=0.63$, plotted against azimuth angle. Interestingly, the force coefficient for azimuthal angles away from the shadow effect shows more fluctuations (on the order of $+/-10 \%$ ) from the relative velocity field (for which the variations were on the order of $1 \%$ or less). This is most evident for the DC case. This suggests that unsteady variations in the rotor coupled with that of the flow can significantly influence the aerodynamic force fluctuations, especially if there is a shadow effect.

With respect to the shadow effects, the plots of $C_{n}$ have many of the same qualitative characteristics as the plots from the relative flow parameters, i.e. a pronounced dip and a slight asymmetry. However, the wake effects are more centered at about $\psi=180^{\circ}$ and the wake more consistently leads to a force reduction (very few force increases). Additionally the fairing has a similar effect on $C_{n}$ as on the relative flow field variables, the fairing decreases the peak $C_{n}$ deficit in the DF0 case by about two-fold. Again, this reduction is lost for the DF20 (misaligned fairing) case as it behaves similarly to the DC (cylindrical tower case). 
Interestingly, FAST significantly over-predicts the average $\mathrm{C}_{\mathrm{n}}$ (by about $15-20 \%$ ) for the UC case, perhaps due to flow unsteadiness that FAST cannot accurately predict. The predicted impact of the tower shadow effect on normal force as show for the DC case is surprisingly reasonable given that the relative velocity effects were poorly predicted and under-predicted. This indicates that flow angularity has a much more important impact on blade force, presumably through angle of attack influence, than do changes in relative flow speed. However, the variations for a given azimuthal angle are completely missed by FAST. The aligned faired configuration (DF0) is also reasonably predicted by FAST in terms of the average changes, while the unsteady effects are completely missed. Again, the DF20 case shows that the fairing improvements are generally lost for a $20^{\circ}$ misalignment. It is worth noting that FAST tends to over-predict the effects of the shadow if one considers results averaged for a fixed azimuthal angle.

Fig. 3.7 shows the normal force coefficient taken at $\mathrm{r} / \mathrm{R}=0.80$, a location where the power extracted per unit blade length is higher owing to higher relative velocities. At this radial location, the normal force coefficient behaves similarly compared with at $r / R=0.63$ both inside and outside of the wake region, although the unsteadiness impact is somewhat reduced. FAST again overpredicts the average value in this span-wise location, misses the effects of unsteadiness, and overpredicts the level of improvement associated with the fairing. This indicates consistency at varying locations on the blade span.

Fig. 3.8 shows root flap bending moment plotted against azimuth angle. Away from the wake, there is an offset between the upwind and downwind cases, of about $1 \mathrm{kN} \cdot \mathrm{m}$. This offset can be attributed differences in the relative rotor coning angle for the rotors. The upwind rotor has no coning but the downwind rotors have a coning of $3.4^{\circ}$. This coning leads to a negative $\mathrm{M}_{\mathrm{b}}$ due to centrifugal loading lowering the average bending moment from the upwind case. However, all 
the cases show oscillation in the moment at a rate of about $6 / \mathrm{rev}$, which is attributed to the structural frequency associated with flapwise bending of the blade. This unsteadiness in the experiment is enough to excite the root flap bending moment even for the upwind configuration. For the DC case, the magnitude of these oscillations is increased by about three-fold for $\psi<270^{\circ}$, indicating that the shadow effect has increased the blade dynamics and the potential for fatigue failure. The fairing reduce the magnitude of the fluctuations by about two-fold, whereas the DF20 case shows no improvement over the unfaired (DC) case.

As was the case with the normal force coefficient, FAST over predicts the average root flap bending moment in all cases. In the downwind cases, FAST captures the 6/rev oscillations but this oscillation frequency does not show up in the upwind (UC) configuration. This can be attributed to the lack of unsteadiness incorporated by the simulation. As with the force, FAST over-predicts the impact of the shadow effect on the bending moment for the DC case. As such, the relative magnitude of point-wise variations (e.g. in local flow angle) do not correspond to the same relative magnitude of surface-integrated variations (e.g. in blade moment), at least for the present UAE experimental conditions. It also indicates that the FAST code cannot predict this difference.

To identify the sensitivity that the free stream velocity, and therefore tip speed ratio has on the above trends, the remaining plots analyze the effects from higher $\mathrm{V}_{\infty}$ conditions. Fig. 3.9 and 10 show the root flap bending moment at $\mathrm{V}_{\infty}=10 \mathrm{~m} / \mathrm{s}$ and $20 \mathrm{~m} / \mathrm{s}$ respectively. Again, there is a consistent $1 \mathrm{kN} \cdot \mathrm{m}$ off set between the upwind and downwind cases for all speeds, a difference again attributed to the coning angle relative to the definition of bending moment. However, at these higher speeds, the bending moment is even less steady, and deviates further from the cyclic average. This is attributed to the lower tip speed ratios leading to increased likelihood of 
aerodynamic hysteresis and even stall (an intentional area of investigation for the UAE campaign). The UC case behaves extremely unsteadily (especially at $20 \mathrm{~m} / \mathrm{s}$ ) and the tower fairing does not allow for any mitigation at $\chi_{\mathrm{F}}=0^{\circ}$ and even exaggerates the situation at $\chi_{\mathrm{F}}=20^{\circ}$ (especially at 20 $\mathrm{m} / \mathrm{s}$ ). As for the FAST predictions, the deviation between experimental and modeled data appears to decrease at higher $\mathrm{V}_{\infty}$, as expected due to increased importance of aerodynamic unsteadiness in these cases. However, the FAST predictions also erroneously suggest that the aligned fairing (DF0) can reduce the bending moment oscillations.

To more clearly show the influence of tunnel velocity, Fig. 3.11 through Fig. 3.14 show a summary for all the different free stream velocities in terms of mean values away from the wake (indicated by a circle) and extreme values (indicated by a vertical line). As in the previous figures, the black represents the measured UAE data and the red represents the FAST simulation. The mean values away from the wake were based on an average for $\psi<90^{\circ}$ and $\psi>270^{\circ}$ for the relative flow angle, relative velocity and the normal force coefficient. However, the mean value of the root flap bending moment was based on $0^{\circ}<\psi<360^{\circ}$ since the wake impact region was not clearly defined. In all cases the error bars represent the spread of values, from maximum to minimum over all $\psi$ values.

Fig. 3.11 shows the statistical summary, minimum, average and maximum for the relative flow angle taken at $r / R=0.67$. Comparing the upwind and downwind cases, it becomes clear that tower shadow causes a substantially increased variation in relative flow angle at all speeds (the variations are negligible for all UC cases). One can also see that the tower fairing reduces the effect of this wake at every speed. Additionally it is clear from the DF20 case that the fairing at high $\chi_{\mathrm{F}}$ performs as bad as or worse than the unfaired case. In terms of predictions, FAST consistently under-predicts the relative flow angle mean value for both upwind and downwind cases. However, 
it more severely under-predicts the range in the wake for the downwind cases, especially at higher $\mathrm{V}_{\infty}$.

Fig. 3.12, shows the summary of the relative flow velocity measured at $r / R=0.67$. There is minimal spread in the UC case, maximum and minimum are close to the average, indicating that the tower shadow plays the dominant role in the variation of relative flow velocity. With the possible exception of $\mathrm{V}_{\infty}=10 \mathrm{~m} / \mathrm{s}$, the fairing reduces the range of the measured relative flow velocity. Again, the DF20 case performed comparably or worse than the DC case at every speed. FAST again severely under-predicts the spread of the values and does not predict any increase in values, but the wake-free averages are reasonably predicted by FAST.

Fig. 3.13 shows the summary for the normal force coefficient, measured at $\mathrm{r} / \mathrm{R}=0.63$. For the UC case at high $\mathrm{V}_{\infty}$, it is clear that the tower shadow is not the sole cause for variation in $C_{n}$. It is likely that the low tip speed ratios cause a high amount of unsteady separation which contributes to the variation in $\mathrm{C}_{\mathrm{n}}$ in the upwind case at high tunnel speeds. The downwind cases show a larger range than the upwind cases but this relative increase becomes secondary to unsteady aerodynamic effects at higher speeds. The aligned fairing (DF0) only slightly reduces the spread of the normal force coefficient, possibly because the tower shadow is only a secondary contributor of unsteadiness to the primary cause of stall and separation. FAST again under-predicts the extent of the range in both the upwind and downwind cases, and this prediction is particularly poor at high $\mathrm{V}_{\infty}$.

Fig. 3.14 shows the summary of the root flap bending moment. This is perhaps the most important plot as it shows the net integrated effect on the parameter most closely linked to fatigue and structural failure. To see the effect of tower shadow, one may compare bending moment for 
a given tunnel speed. At low $\mathrm{V}_{\infty}$, the upwind case (UC) has a smaller moment range than the corresponding downwind cases and the DF0 case performs better than then DC or DF20 case. However at higher $\mathrm{V}_{\infty}$, the UC, DC and DF0 cases tend to perform similarly but the DF20 case has a much wider spread. This leads to the conclusion that unsteadiness of the root flap bending moment at low tip speed ratios is not caused solely by the tower shadow, where unsteady aerodynamics also plays a significant role. However tower shadow is not always negligible because the DF20 case causes the worst variations at the higher speeds.

In terms of predictive capability for the upwind (UC) case, FAST does not predict the spread seen experimentally, especially at higher tunnel speeds. On the other hand, it predicts the average values well at the higher $\mathrm{V}_{\infty}$ values but over-predicts at the lower speeds. As such, FAST tends to fail when there is unsteadiness in the blade aerodynamics. FAST tends to predict the range with no shadow effects for a cylindrical tower but consistently under-predicts the range for the faired tower case.

\subsection{Conclusions}

At low free stream velocities (high tip speed ratios), it was observed that there was a pronounced tower shadow effect on the relative flow angle and velocity. This translated to distinct effects on the normal force coefficient. Because the relationship between normal force coefficient and azimuth angle closely resembled that of the relative flow angle, it can be inferred that the relative flow angle is the dominant value driving the normal force coefficient. The fairing aligned with the flow was shown to reduce the tower shadow effects on the relative flow field, leading to a reduced effect on the normal force coefficient. Consequently, this led to a reduction on the root flap bending moment. However, the fairing with a misalignment angle of $20^{\circ}$, did not reduce the 
shadow effect on the relative flow field, and therefore did not significantly reduce the effect on the normal force coefficient or the root flap bending moment.

At high free stream velocities, it was similarly observed that the tower had a pronounced effect on the relative flow field, compared with the upwind case. However, it was seen that this did not directly correspond to a predictable effect on the normal force coefficient. The normal force coefficient was instead very unsteady and unpredictable. It is likely that normal force coefficient at these low tip speed ratios is not as sensitive to changes in the relative flow field as it is to unsteady aerodynamic effects such as unsteady aerodynamics and flow hysteresis. Therefore, at these high free stream velocities the root flap bending moment was unsteady in all cases. The fairing with a misalignment angle of $0^{\circ}$ had little positive effect reducing the root flap bending moment oscillations. However, the misaligned fairing was shown to have a significant and adverse effect on the root flap bending moment.

The FAST model of the UAE simulated some aspects of the experiment accurately. FAST models the azimuthal averages in the change of relative flow angle and velocity due to shadow effects well. FAST did not predict the spread of values measured experimentally, this is primarily true in the case of relative flow velocity. This unsteady deviation from the azimuthal average is not incorporated into the tower shadow model. When FAST predicted the aerodynamic and structural effect on the blades, as seen in the normal force coefficient and root flap bending moment the trends were captured, but there were non-negligible biases primarily at the higher tip speed ratios. At the lower tip speed ratios where the experimental data was shown to be much more unsteady with high deviations from the azimuthal average, the predictions by FAST were less physically realistic, not capturing the spread of values experimentally determined, however the predictions followed the azimuthal average closer than the simulations from higher tip speed ratios. 
FAST is a useful tool, with some room for improvement. Some of the complexities of tower shadow have been revealed. At higher tip speed ratios tower shadow plays a larger role in blade aerodynamics and structural response. At these instances tower fairings can be very useful in mitigating negative effects on the rotor. At lower tip speed ratios it is likely that blade response is dominated by more factors than just tower shadow, and tower fairings may only aid in reducing a secondary factor. Additionally it was shown that tower fairings should be aligned with the wind direction or they could exaggerate the problem. In time, and after more experiments, tower shadow will be understood well enough that downwind rotors could be used as a viable and possibly superior alternative to upwind rotors. 


\section{References}

[3.1] Quarton, D. C. " The Evolution of Wind Turbine Design Analysis: A Twenty Year Progress Review". Wind Energy 1 (1998): 5-24.

[3.2] Shikha, T. S. Bhatti, and D. P. Kothari. "Aspects of technological development of wind turbines." Journal of Energy Engineering 129.3 (2003): 81-95.

[3.3] Griffith, D. Todd, and Thomas D. Ashwill. "The Sandia 100-meter all-glass baseline wind turbine blade: SNL100-00." Sandia National Laboratories, Albuquerque, Report No. SAND2011-3779 (2011).

[3.4] Bak, Christian, et al. "Light Rotor: The 10-MW reference wind turbine." EWEA 2012European Wind Energy Conference \& Exhibition. 2012.

[3.5] Kim, Taeseong, Torben J. Larsen, and Anders Yde. "Investigation of potential extreme load reduction for a two-bladed upwind turbine with partial pitch." Wind Energy 18.8 (2015): 1403-1419.

[3.6] Veers, Paul S., et al. "Trends in the design, manufacture and evaluation of wind turbine blades." Wind Energy 6.3 (2003): 245-259.

[3.7] Matsunobu, Takashi, et al. "Development of 2-MW Downwind Turbine Tailored to Japanese Conditions." Hitachi Review 58.5 (2009): 213.

[3.8] Ichter, Brian, et al. "A morphing downwind-aligned rotor concept based on a 13-MW wind turbine." Wind Energy (2015). 
[3.9] Loth, Eric, et al. "Segmented ultralight pre-aligned rotor for extreme-scale wind turbines." 50th AIAA Aerospace Sciences Meeting including the New Horizons Forum and Aerospace Exposition. 2012.

[3.10] Leishman, J. Gordon. "Challenges in modeling the unsteady aerodynamics of wind turbines." ASME 2002 Wind Energy Symposium. American Society of Mechanical Engineers, 2002.

[3.11] Yoshida, Shigeo, and Soichiro Kiyoki. "Load equivalent tower shadow modeling for downwind turbines." Nippon Kikai Gakkai Ronbunshu B Hen(Transactions of the Japan Society of Mechanical Engineers Part B)(Japan) 19.6 (2007): 1273-1279.

[3.12] Orlando, Stephen, Adam Bale, and David A. Johnson. "Experimental study of the effect of tower shadow on anemometer readings." Journal of Wind Engineering and Industrial Aerodynamics 99.1 (2011): 1-6.

[3.13] Wang, Tongguang, and Frank N. Coton. "A high resolution tower shadow model for downwind wind turbines." Journal of Wind Engineering and Industrial Aerodynamics 89.10 (2001): 873-892.

[3.14] Wang, Tongguang, and Frank N. Coton. "An unsteady aerodynamic model for HAWT performance including tower shadow effects." Wind Engineering 23.5 (1999): 255-268.

[3.15] Simms, D. A., et al. Unsteady aerodynamics experiment phase VI: wind tunnel test configurations and available data campaigns. Golden, Colorado, USA: National Renewable Energy Laboratory, 2001. 
[3.16] Coton, Frank N., Tongguang Wang, and Roderick A. McD Galbraith. "An examination of key aerodynamic modelling issues raised by the NREL blind comparison." Wind Energy 5.2-3 (2002): 199-212.

[3.17] Munduate, Xabier, Frank N. Coton, and Roderick A. McD Galbraith. "An investigation of the aerodynamic response of a wind turbine blade to tower shadow." Journal of solar energy engineering 126.4 (2004): 1034-1040.

[3.18] Jonkman, Jason M., and Marshall L. Buhl Jr. "FAST user's guide." National Renewable Energy Laboratory, Golden, CO, Technical Report No. NREL/EL-500-38230 (2005).

[3.19] Calkins, D. E. "Two-dimensional hydrodynamic characteristics of a bluff symmetrical fairing section." AIAA journal 22.9 (1984): 1216-1221.

[3.20] O'Connor, Kyle, Eric Loth, and Michael S. Selig. "Experiments on Fairing Designs for a Wind Turbine Tower." AIAA Journal (2016): 1-7. 

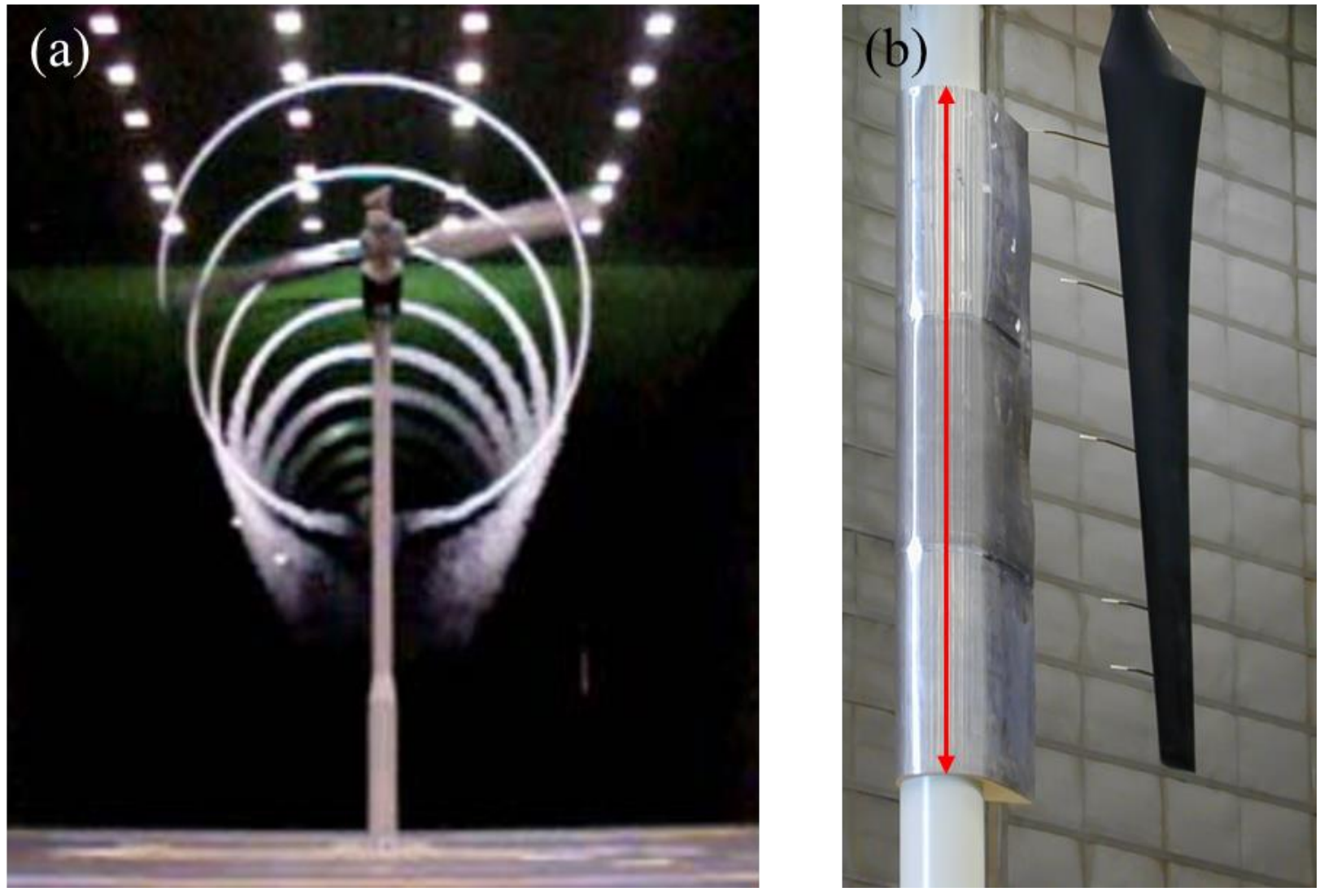

Figure 3.1: UAE experimental configuration in the NASA Ames tunnel, a) flow visualization of tip vortices, \& b) UAE tower fairing (with arrow indicating vertical extent) upstream of a UAE blade instrumented with 5-hole pressure probes. 

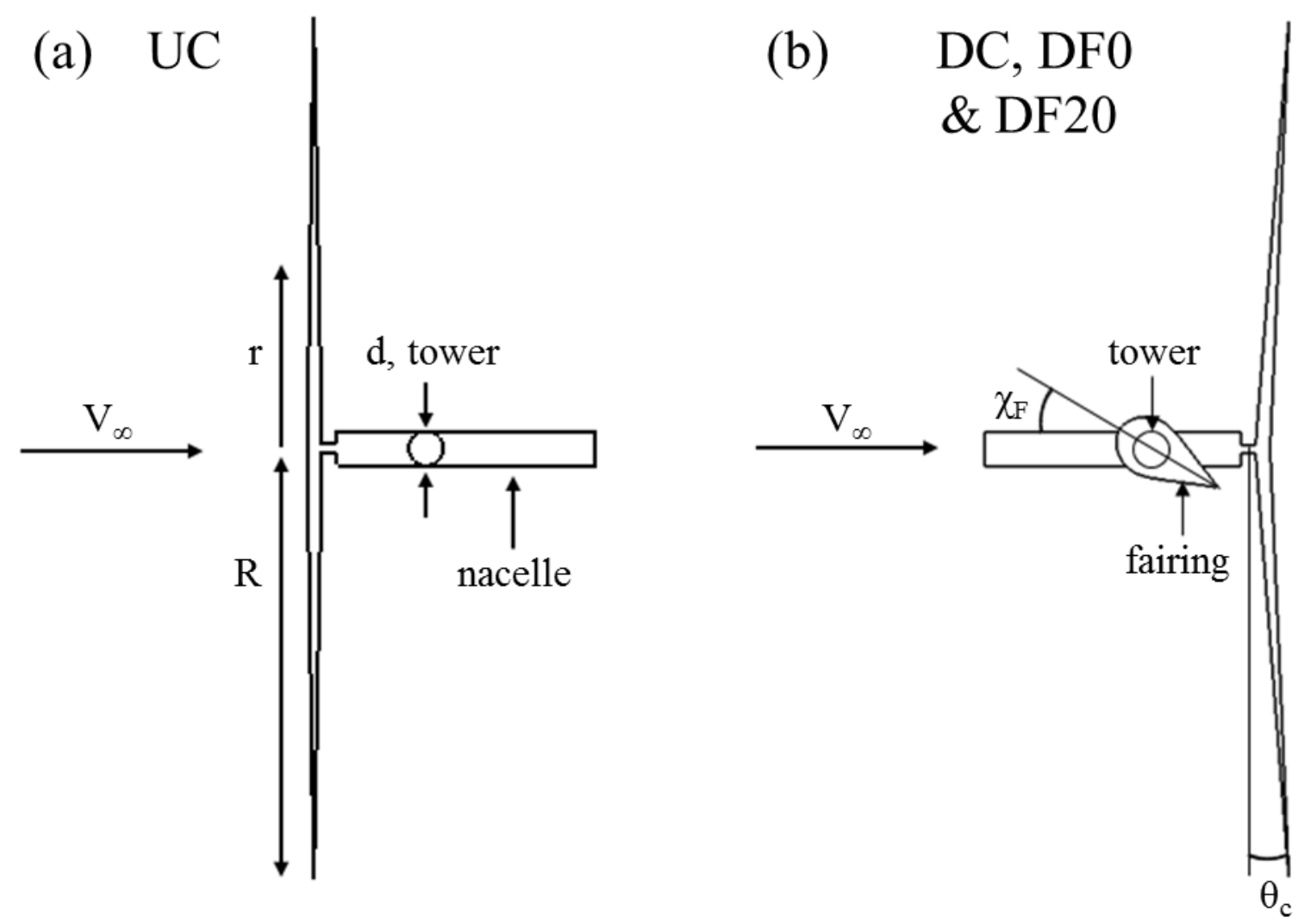

Figure 3.2: Top view turbine schematic, a) upwind rotor \& b) downwind rotor with fairing free to rotate about tower (components not to scale). 


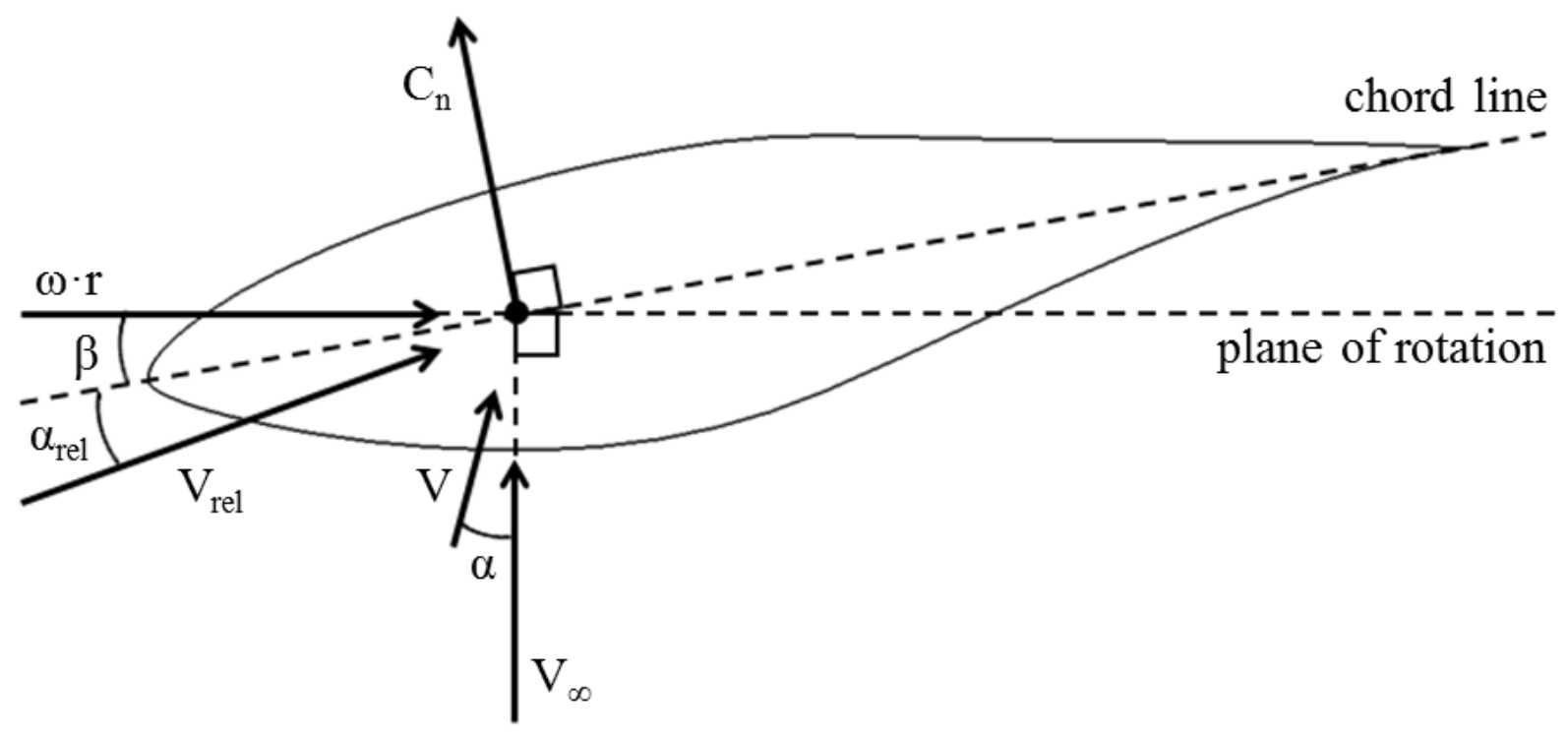

Figure 3.3: Schematic of relative flow parameters. $\beta$ is pitch plus local twist, $\alpha$ is taken relative to free stream, $\alpha_{\text {rel }}$ is relative to the chord line, $C_{n}$ is normal to chord line. 

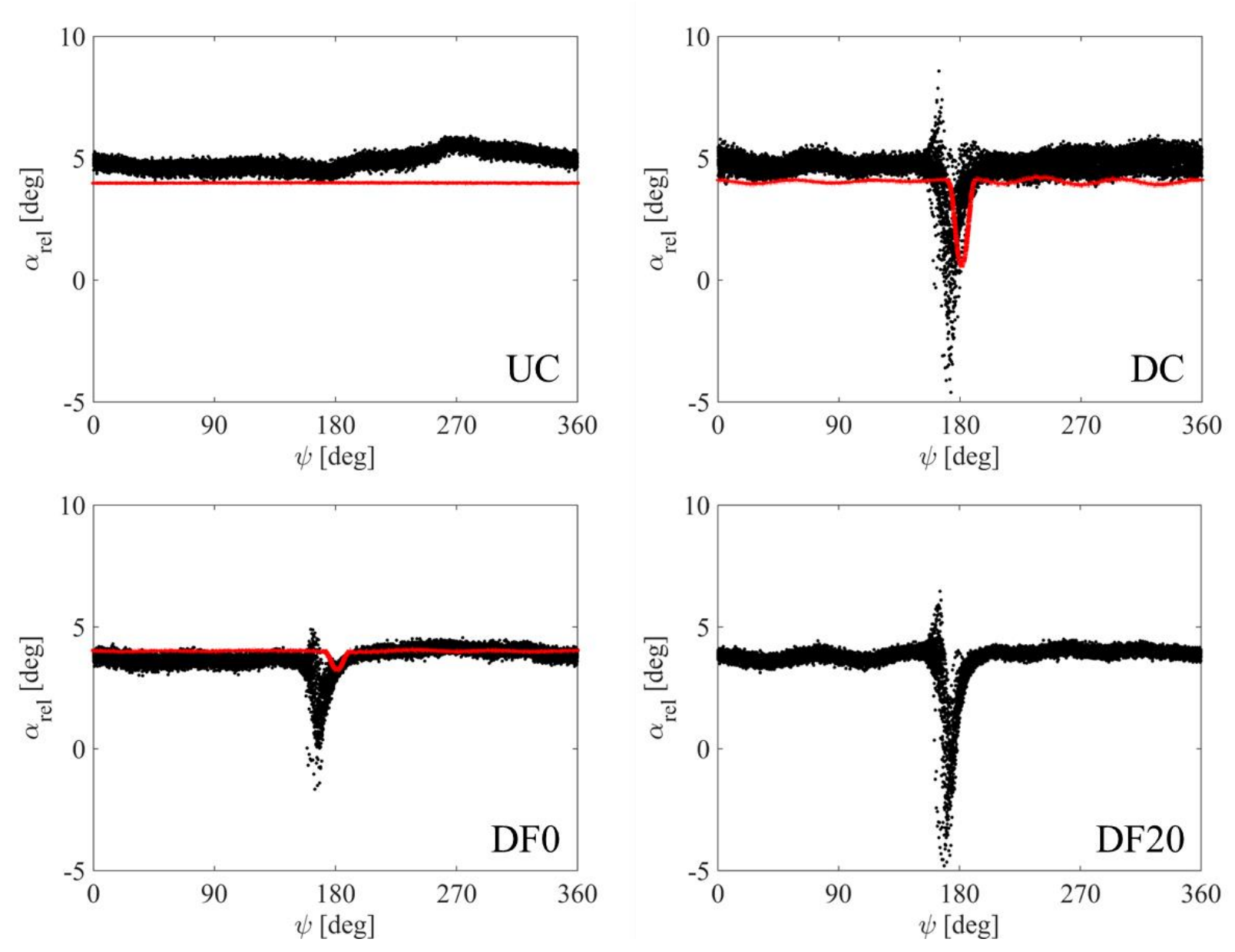

Figure 3.4: Relative flow angle as function of azimuthal angle at $r / R=0.67$ and $V_{\infty}=5 \mathrm{~m} / \mathrm{s}$. 

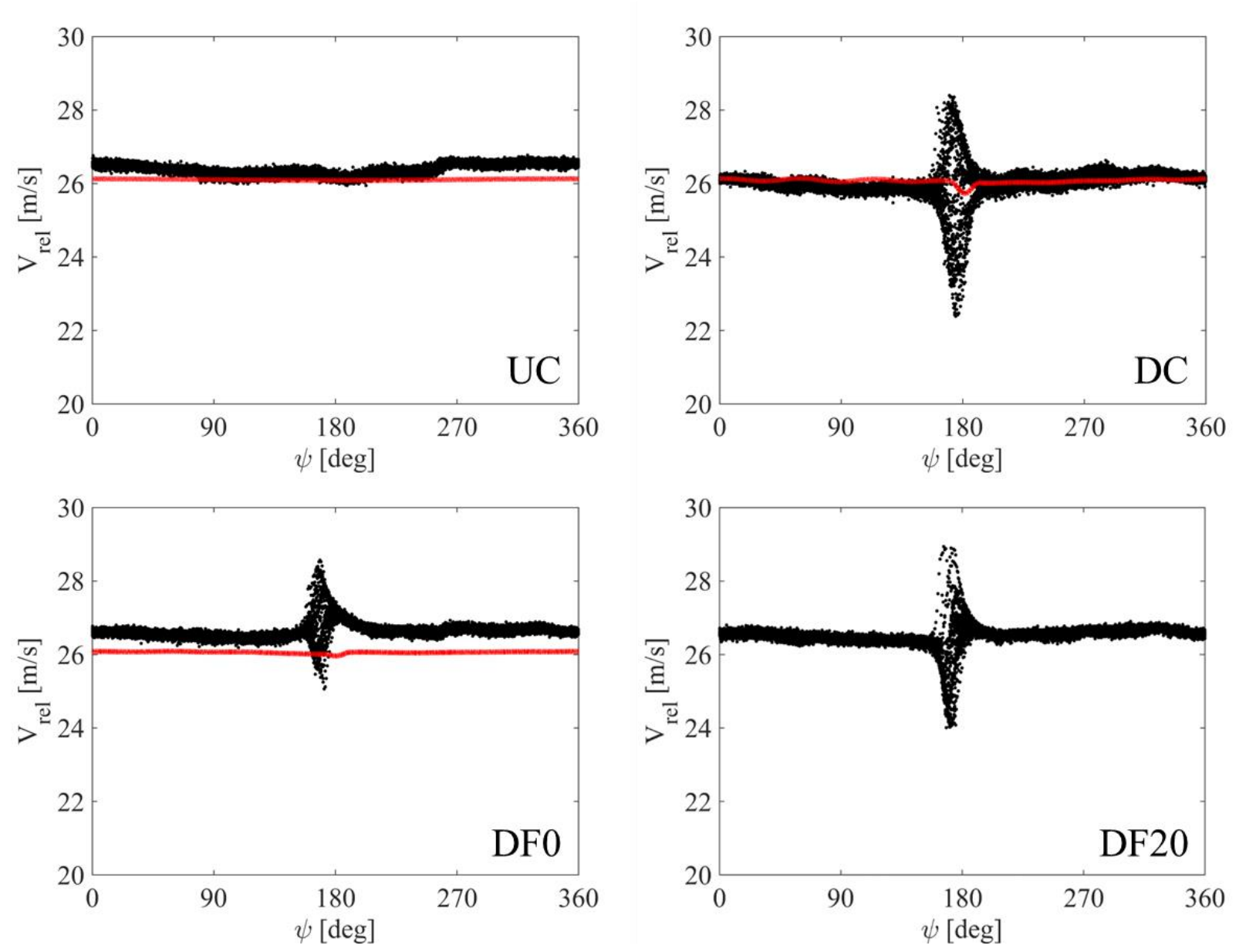

Figure 3.5: Relative flow velocity as function of azimuthal angle at $r / R=0.67$ and $V_{\infty}=5 \mathrm{~m} / \mathrm{s}$. 

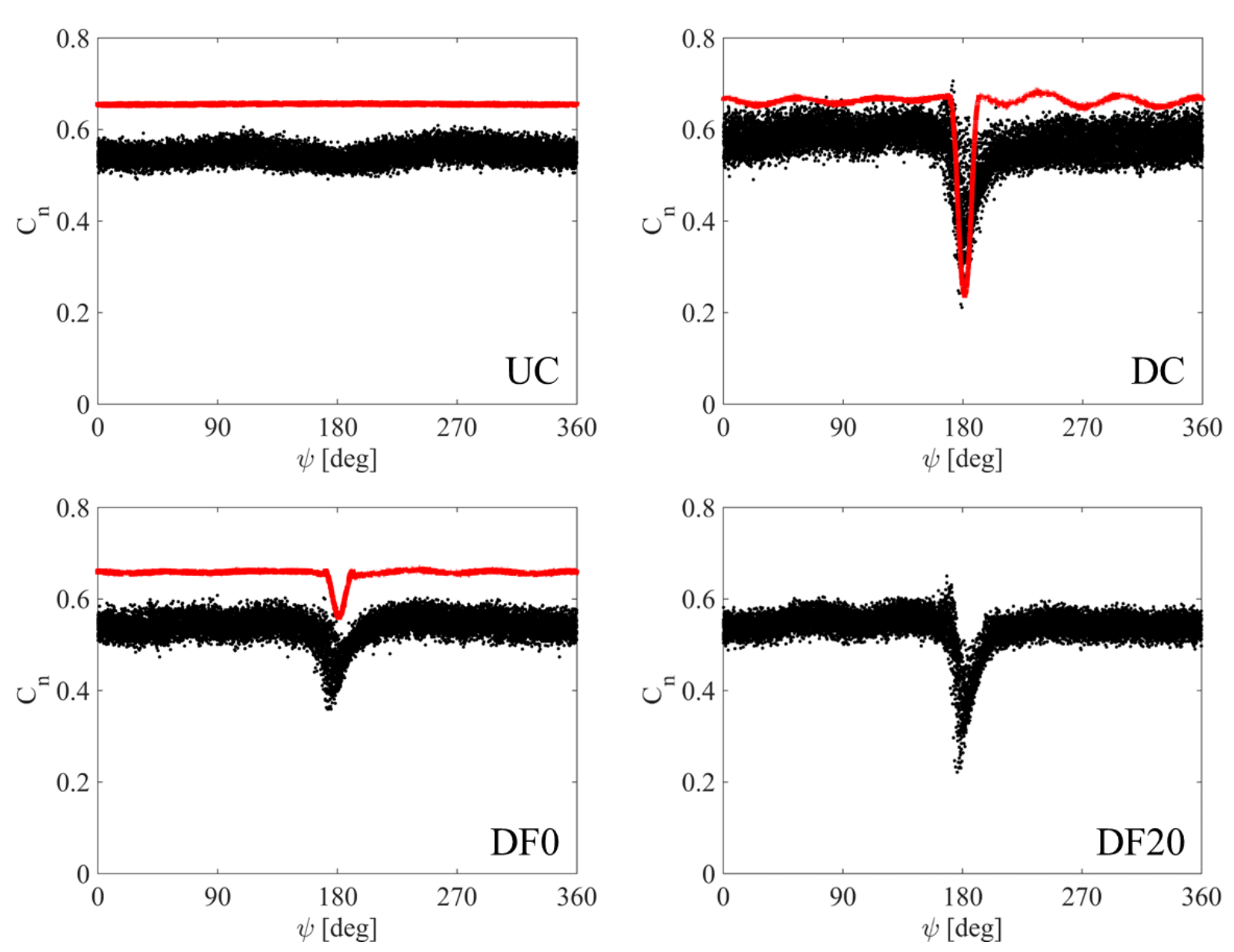

Figure 3.6: Normal force coefficient as function of azimuthal angle at $r / R=0.63$ and $V_{\infty}=5 \mathrm{~m} / \mathrm{s}$. 

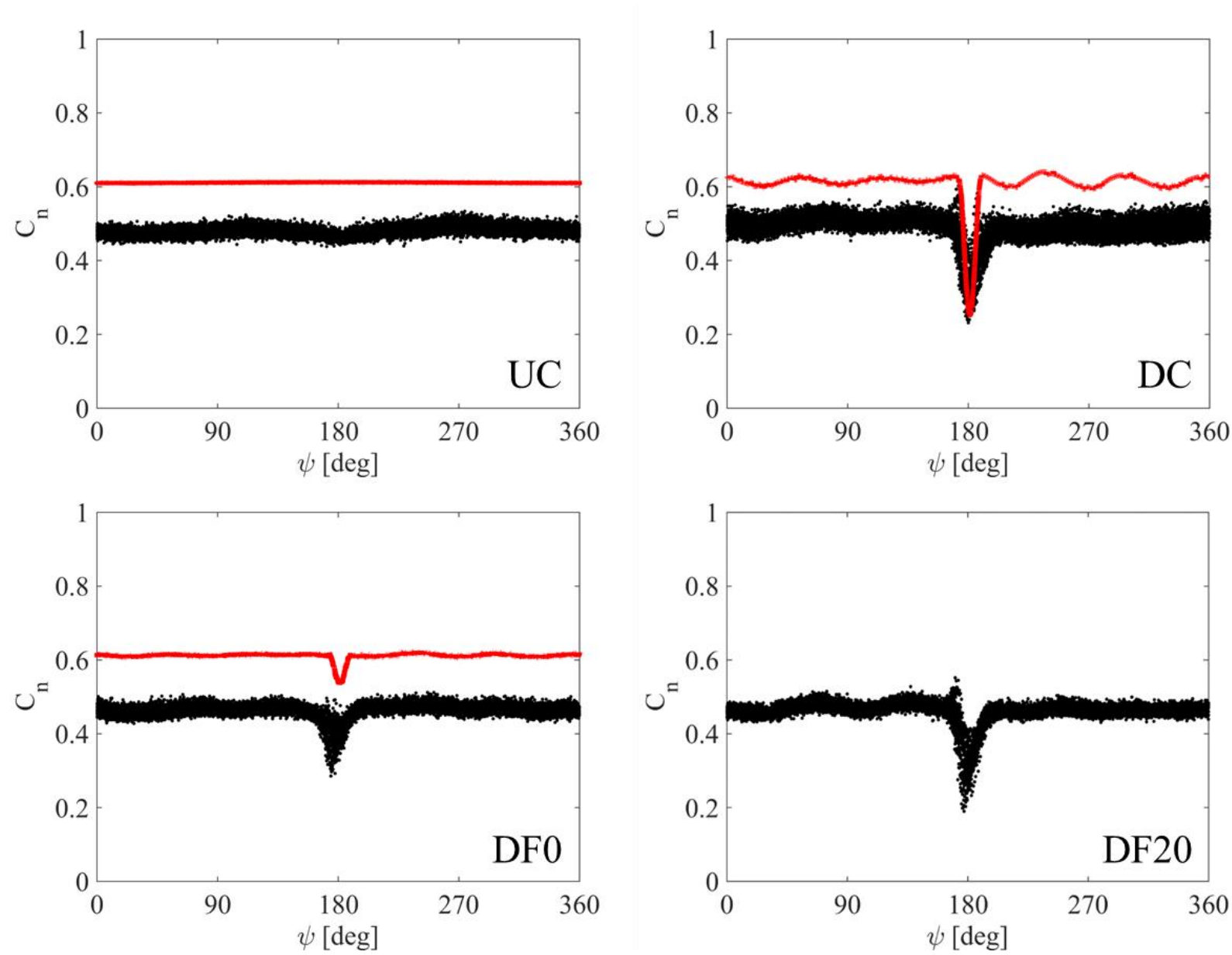

Figure 3.7: Normal force coefficient as function of azimuthal angle at $r / R=0.80$ and $V_{\infty}=5 \mathrm{~m} / \mathrm{s}$. 

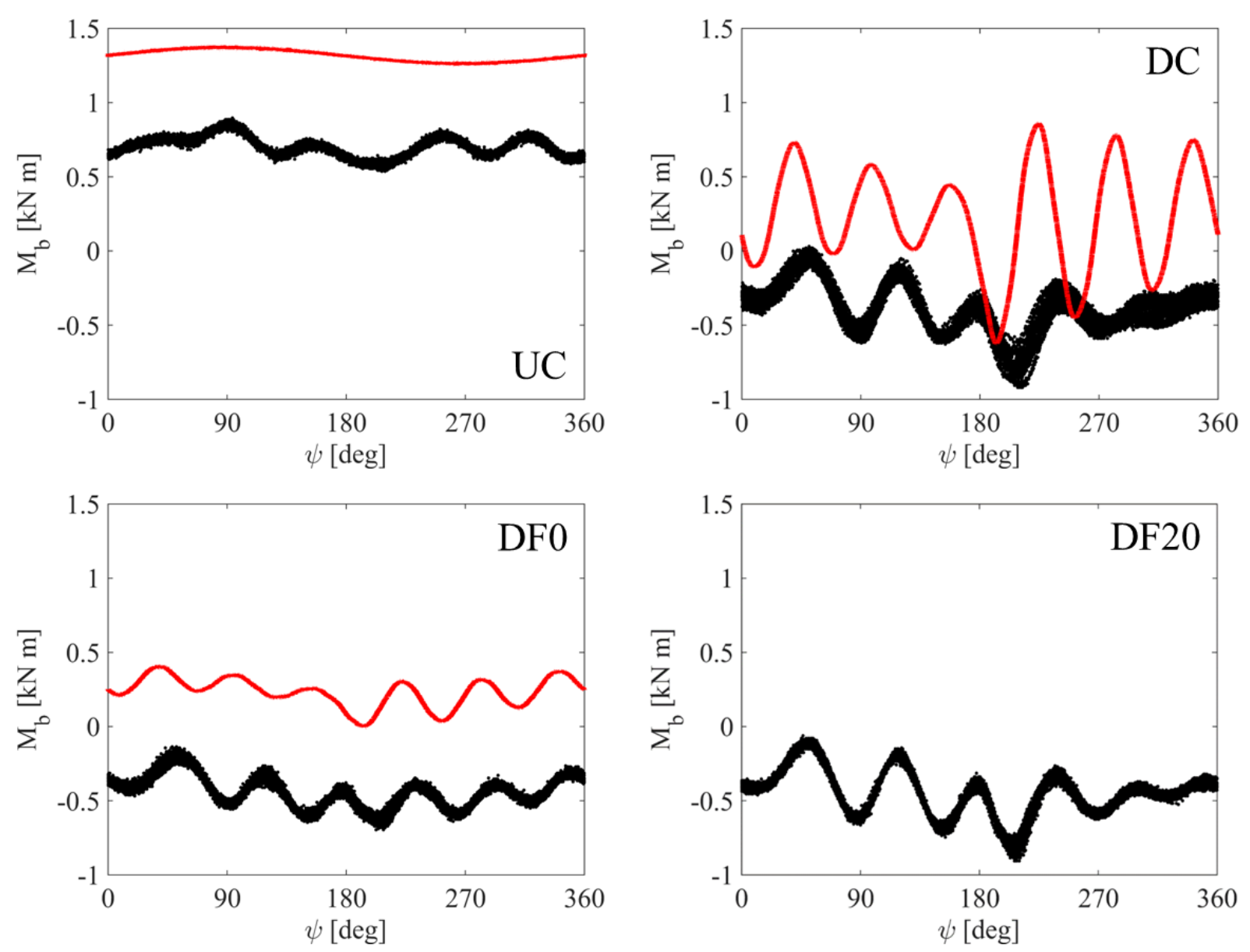

Figure 3.8: Root flap bending moment as function of azimuthal angle at $V_{\infty}=5 \mathrm{~m} / \mathrm{s}$. 

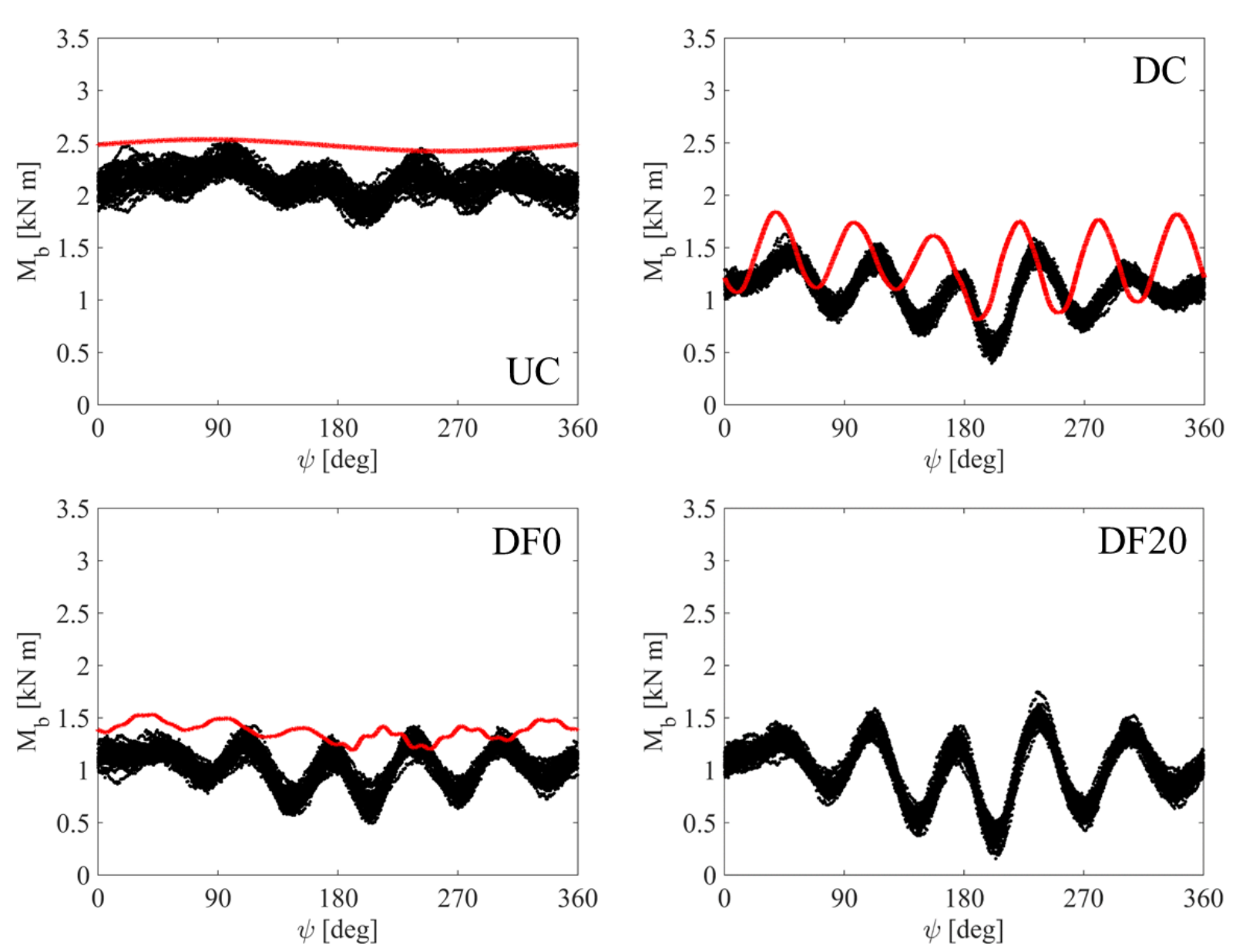

Figure 3.9: Root flap bending moment as function of azimuthal angle at $V_{\infty}=10 \mathrm{~m} / \mathrm{s}$. 

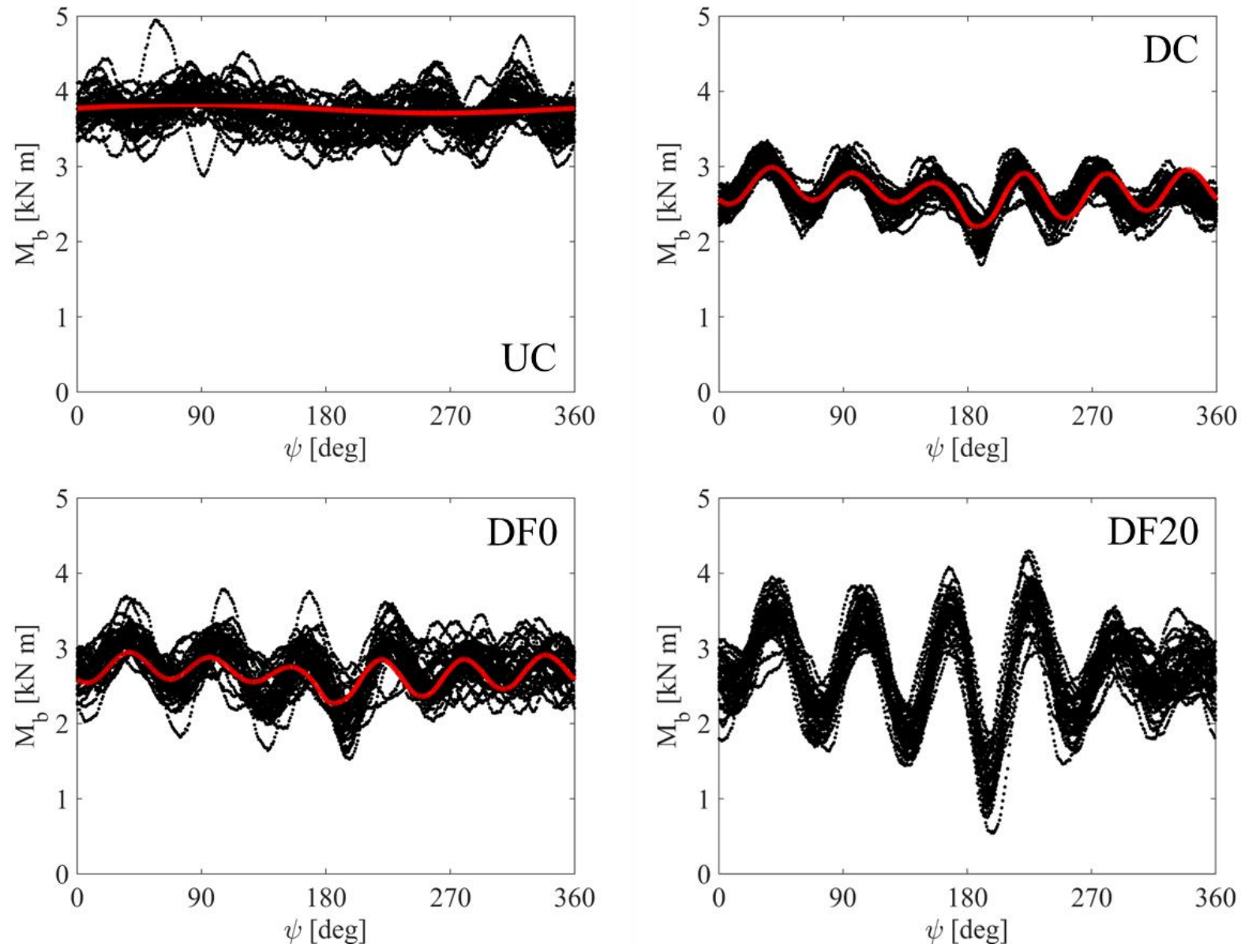

Figure 3.10: Root flap bending moment as function of azimuthal angle at $V_{\infty}=20 \mathrm{~m} / \mathrm{s}$. 

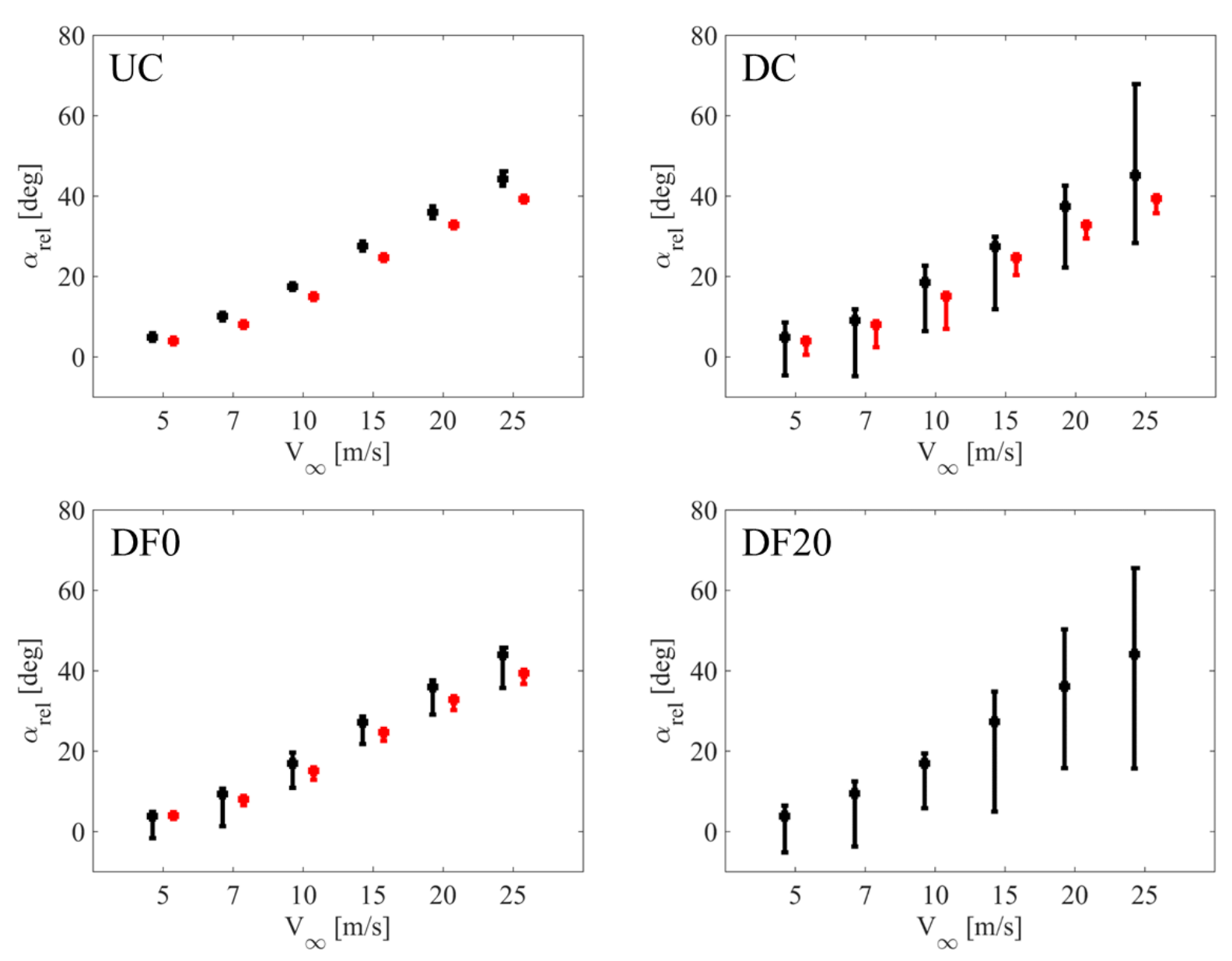

Figure 3.11: Average and range of relative flow angle at $r / R=0.67$. 

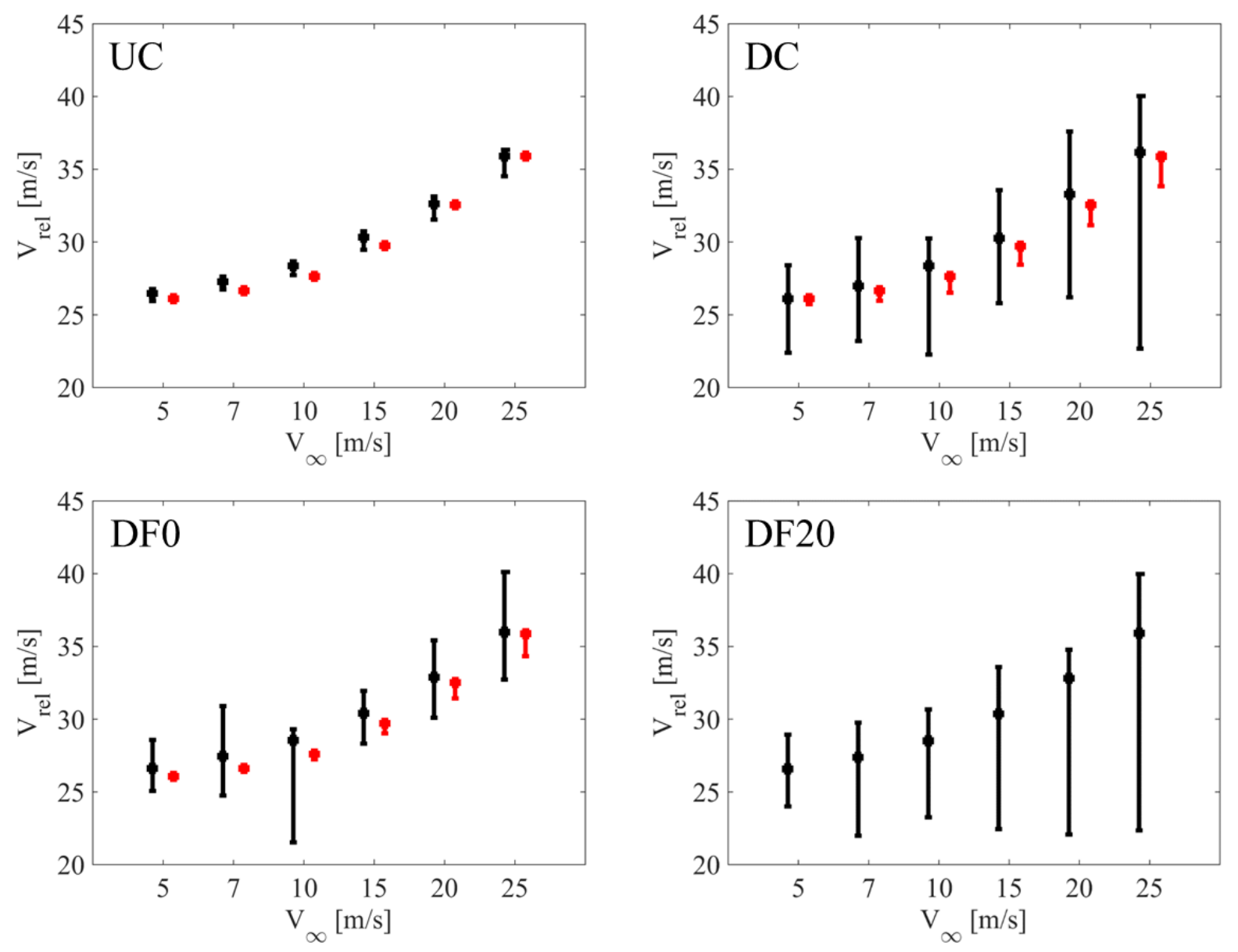

Figure 3.12: Average and range of relative flow velocity at $r / R=0.67$. 

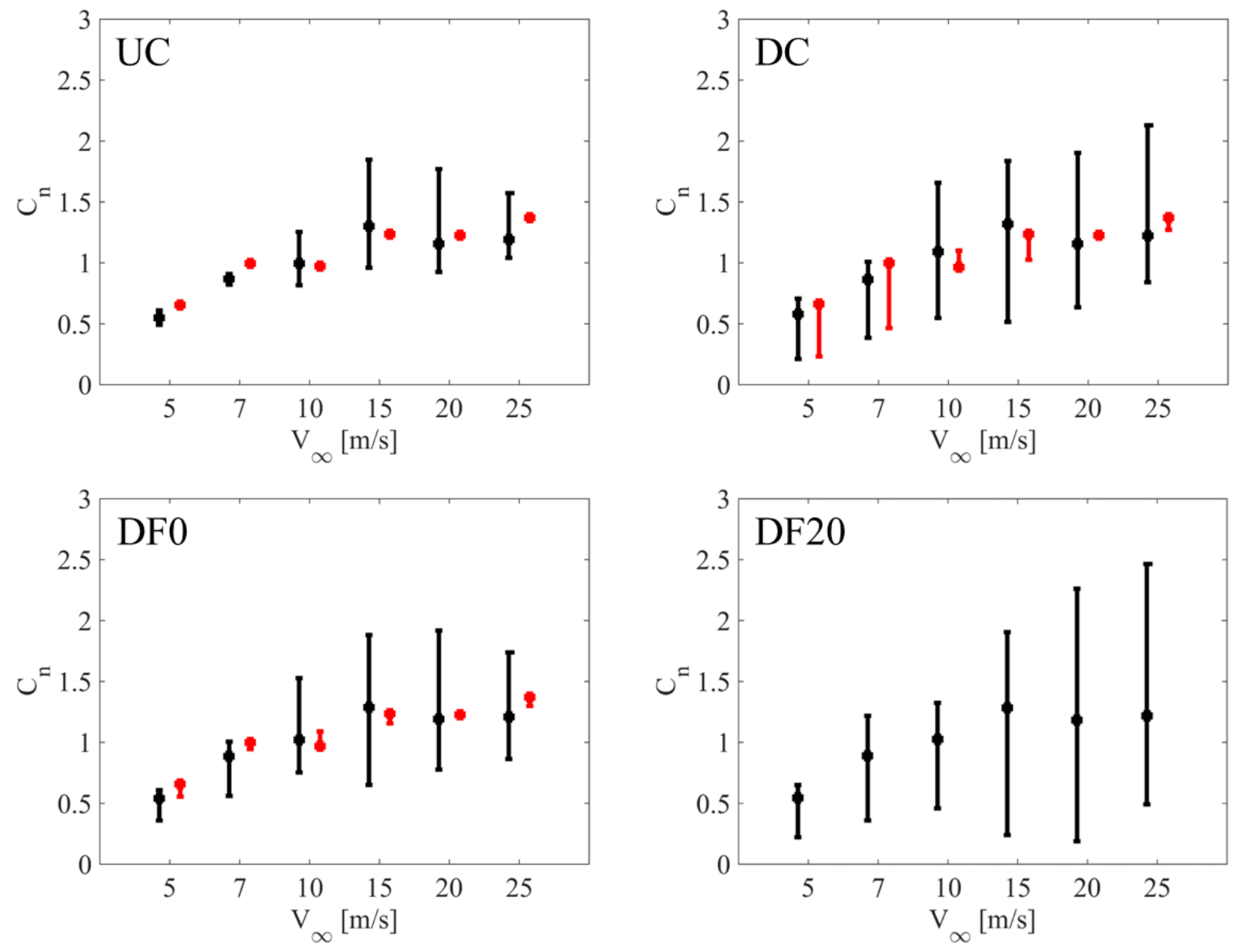

Figure 3.13: Average and range of normal force coefficient at $r / R=0.63$. 

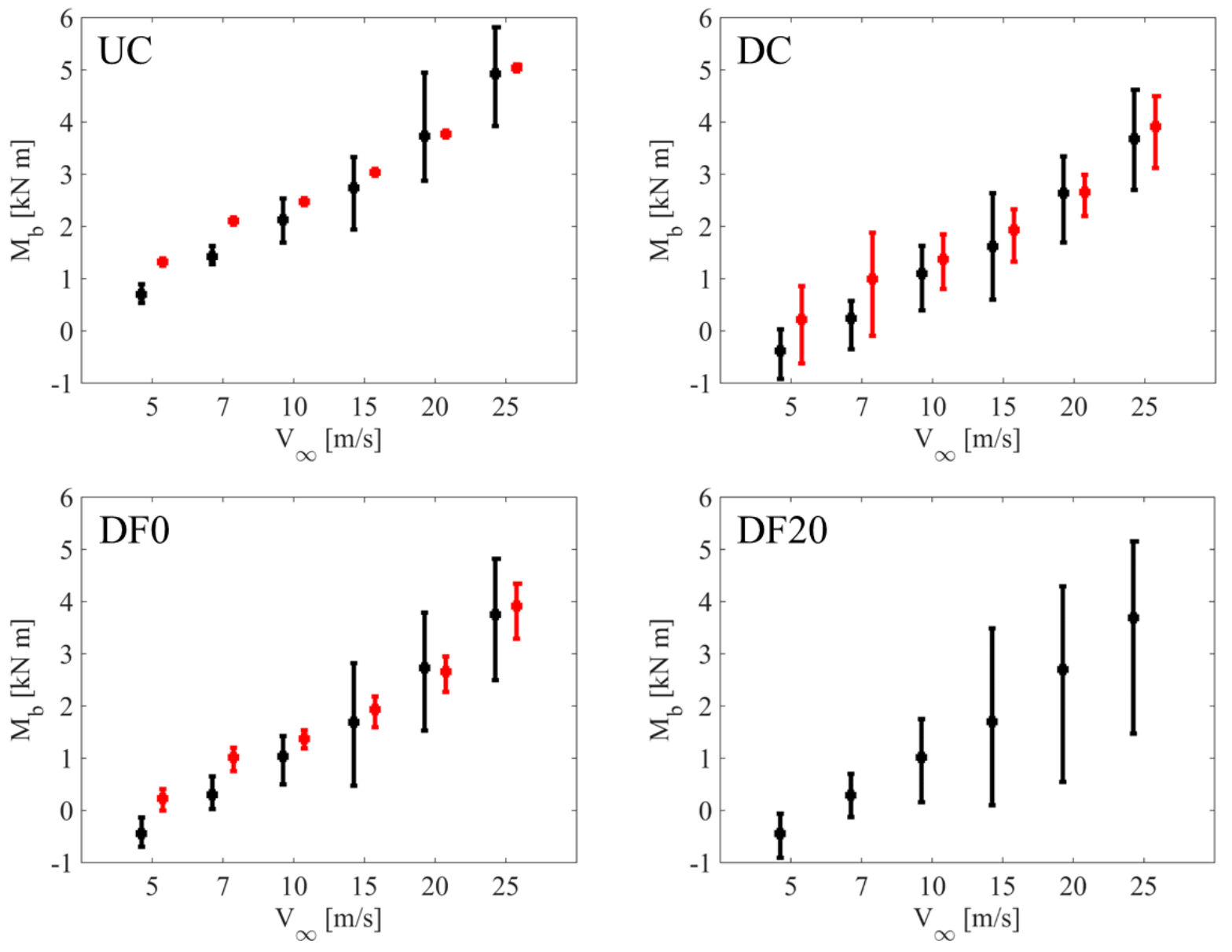

Figure 3.14: Average and range of root flap bending moment. 


\title{
Chapter 4
}

\section{An Experimental Investigation of Low Drag, Robust,}

\section{Aerodynamic Fairings}

\begin{abstract}
Aerodynamic fairings can be used to cover cylinders reducing negative aerodynamic effects, acoustic noise, vibrations, drag and wake. Fairings perform well when the angle of the fluid flow is aligned with the fairing. With high misalignment angles fairings can exaggerate the flow criteria they were designed to mitigate. To understand the fluid physics of fairings at different misalignment angles three aerodynamic fairings were designed and tested. The fairings had varying degrees of trailing edge rounding and were tested with particle image velocimetry at different misalignment angles. The fairing with no trailing edge rounding was found to have the largest wake compared with the unfaired cylinder and the modified fairings at large misalignment angles. The fairing with the largest degree of rounding was found to be the most robust fairing to the variety of misalignment angles.
\end{abstract}




\section{Nomenclature}

Re Reynolds number based on diameter

D cylinder diameter

$\chi_{\mathrm{F}} \quad$ misalignment angle

$\mathrm{V}_{\text {inlet }} \quad$ free stream tunnel velocity

V local velocity magnitude

$\overline{\mathrm{V}} \quad$ average local velocity magnitude

$\mathrm{u}_{\mathrm{x}} \quad$ local streamwise velocity component

PIV particle image velocimetry

$\operatorname{Re}_{\text {crit }} \quad$ Reynolds number threshold leading to turbulent boundary layer separation

$\mathrm{X}$ streamwise distance from the center of the cylinder

$\mathrm{y}$ streamwise normal distance from the center of the cylinder

TI two-dimensional turbulence intensity 


\subsection{Introduction}

The flow over a cylinder, above Reynolds numbers of about 150 , is characterized by a large unsteady wake. The wake will cause drag in many physical systems. ${ }^{4.1}$ Additionally, the wake from a cylinder causes vortex induced vibrations ${ }^{4.2}$ compromising the structural integrity of the system. The unsteady wake may cause unwanted acoustic noise in certain applications (Henning). In applications such as downwind turbines, the wake from the cylindrical tower could negatively affect the turbine rotor blades. ${ }^{4.3}$ Contingent on design constraints, it could be necessary to minimize the unsteady aerodynamic wake behind a cylinder.

Many forms of cylinder flow control operate on the principle to delay the point of boundary layer separation as long as possible. This leads to a thinner wake, less pressure drag, and mitigating other potentially negative flow characteristics. The most conventional method, useful in sub critical Reynolds numbers, $\operatorname{Re}<10^{5}$, is the use of a perturbation, often a spanwise wire, to trip the boundary layer from the laminar to the turbulent mode. ${ }^{4.5}$ Turbulent boundary layers stay attached to surfaces better than laminar boundary layers.

If the boundary layer is in the turbulent regime another method for delaying separation is to add energy to the boundary layer. ${ }^{4.6}$ For certain conditions a more energetic boundary layer will stay attached longer than in similar, but less energetic, cases. Passively, energy can be added by introducing streamwise vorticity, by means of vortex generators, grooves, helical strakes, tabs, or other methods. ${ }^{4.7,7.8,4.9}$ Active methods include, plasma actuators, synthetic jets, ion wind, and many more. The strengths and limitations of these methods have been studied in depth in the literature. ${ }^{4.10,4.11,4.12,4.13}$

A different approach to flow control is to aerodynamically tailor the surface geometry to delay boundary layer separation and minimize the unsteady wake. This can be done by shrouding 
the cylinder in an aerodynamic fairing. Certain well designed fairings have been shown to decrease the drag from a cylinder by up to $97.5 \% .{ }^{4.14}$ Fairings have been used to reduce cylinder's damaging vibrations. ${ }^{4.15,4.16}$ Fairings have been used to diminish noise from airplane's landing gear axils. ${ }^{4.17}$ Aerodynamic fairings have been used to lower drag and minimize the unwanted and potentially damaging wake behind the cylinders. ${ }^{4.18}$

One disadvantage of aerodynamic fairings is that they are designed to be aligned in the streamwise direction. A misaligned fairing may exaggerate the criteria that they were designed to mitigate. ${ }^{4.19}$ For applications where flow direction is unknown, or might change, a more extensive understanding of the fairing performance is required at various misalignment angles. One particular example could be wind turbines with rotors downwind of the tower. Relocating the rotor downwind of the tower leads to structural advantages, ${ }^{4.20}$ however the blades must pass through the wake from the cylindrical tower, causing adverse aerodynamic effects. ${ }^{4.21} \mathrm{~A}$ fairing could be used to reduce the wake of the tower, ${ }^{4.19}$ however due to wind gusts in the atmospheric environment, aligning the fairing to the wind direction at all times becomes impossible. In order to provide fundamental fairing physics for a robust system design, this study experimentally analyzes the wakes behind three aerodynamic fairings, two with rounded trailing edges, at misalignment angles of $0^{\circ}, 10^{\circ}$ and $20^{\circ}$. The angles were chosen to mimic similar work done by O’Connor et al., 2012, for more conventional fairing geometries.

\subsection{Methods}

To explore faring performance specifically as they perform for a variety of wind directions, three fairings were modeled in Solidworks CAD software. An E863 profile ${ }^{4.22}$ was used as the base fairing. The E863r40 and E863r45 fairings were designed by circularly rounding the trailing edge and forcing the thickness to chord ratio to be $40 \%$ and $45 \%$ respectively, Fig. 4.1a. The three 
fairings were manufactured using a Fortus 3D printer by Stratasys. The dimensions chosen were, cylinder diameter, $\mathrm{D}$, of $67 \mathrm{~mm}$ and a fairing span of $381 \mathrm{~mm}$. The three chord lengths in increasing order were $149 \mathrm{~mm}, 167 \mathrm{~mm}$ and $188 \mathrm{~mm}$. A PVC tube was purchased with and outer diameter of D and cut to a length of $381 \mathrm{~mm}$ to be used as a baseline cylinder model. All four models were tested at misalignment angle, $\chi_{\mathrm{F}}$, of $0^{\circ}, 10^{\circ}$ and $20^{\circ}$ and a flow speed, $V_{\text {inlet, }}$ of $1 \mathrm{~m} / \mathrm{s}$, Fig. $4.1 \mathrm{~b}$.

A skim plate was used to force a uniform top boundary condition of the water channel. The water channel combined with the skim plate had an effective cross sectional area of $0.38 \mathrm{~m} \times 0.38 \mathrm{~m}$. The PIV system used a New Wave Yag Solo laser to illuminate the PIV window twice, separated by a delay of $1 \mathrm{~ms}$. A TSI Power View Plus camera was used to capture the images which would later be processed into $63 \times 63$ element vector arrays by Insight 4G. The process was repeated 500 time at a frequency of $7.25 \mathrm{hz}$. The PIV window had dimensions of 3D x 3D, and was taken at two locations downstream of the model. The concatenation of both PIV windows lead to a larger window spanning from 2-8 cylinder diameters from the cylinder center, Fig. 4.2.

$\mathrm{V}_{\text {inlet }}=1 \mathrm{~m} / \mathrm{s}$ led to a Reynolds number, Re, of $6.82 \times 10^{4}$. Note, due to the variety of chord lengths, Re was calculated using D as the characteristic length. Re based on fairing chord length would be between 2 and 3 times larger, depending on the fairing. This Re is less than the critical Reynolds number for cylinders, $\operatorname{Re}_{\text {crit }} \approx 10^{5}$. Motivated by large scale applications with Re much larger than $\mathrm{Re}_{\text {crit, }}$, The boundary layers was artificially tripped into its turbulent mode.

It has been found that tripping the boundary layer of a cylinder by use of a trip wire was sensitive to both wire diameter and wire location. ${ }^{4.23}$ Based on that study two $1.6 \mathrm{~mm}$ diameter wires were placed on the top and bottom surfaces of the cylinder, $50^{\circ}$ from the leading edge. Fig. 4.3 illustrates flow over a cylinder with different boundary layer separation. Fig. 4.3a illustrates 
flow with laminar boundary layer separation, whereas Fig. 4.3b shows flow with turbulent boundary layer separation. The average experimental boundary layer separation from the dye visualization, Fig. $4.3 \mathrm{c}$ was measured to be $114^{\circ}$. This shows that the trip wire was very nearly successful in bringing the separation point to the theoretical value of $120^{\circ} .^{4.24}$

When the trip wires were placed on the fairing models using the same wire diameter and maintaining the same arc length from the leading edge, the result varied from the cylindrical case. In many cases the trip wire caused premature boundary layer separation from the fairings. In the literature $^{4.25}$ the boundary layer is often artificially tripped into its turbulent mode using trip tape between $2-5 \%$ the chord length from the leading edge. This is much closer to the leading edge and a much smaller dimension trip tape than the study by Igarashi would have predicted. However if the cylinder chosen to base the trip wire dimensions was not the inscribed cylinder but instead the leading edge curvature, trip tape at $3 \%$ the chord length from the leading edge greatly agrees with the study. This is shown in Fig. 4.4. Trip tape placed at 3\% the chord length was used instead of a trip wire for all the fairing models.

\subsection{Results}

Fig. 4.5-4.7 shows the instantaneous velocity magnitude downstream of all four models. The discontinuity at $\mathrm{x} / \mathrm{D}=5$ is a result from taking data from two continuous windows but at different times. From Fig. 4.5, where $\chi_{\mathrm{F}}=0^{\circ}$, it can be seen that the flow past the cylinder is unsteady, with eddies at least as large as the cylinder diameter. Conversely the flow behind all three fairings is much more uniform and steady. The wakes are drastically thinner with significantly less variation in velocity magnitude and direction. As the trailing edge rounding becomes more extreme i.e. the progression from E863 to E863r40 toE863r45, it can be seen that the wake grows slightly in width, and develops a slight shedding pattern. 
As the misalignment angle is increased to $10^{\circ}$, shown in Fig. 4.6, the wakes behind the fairing models become much more extreme compared with those at $\chi_{F}=0^{\circ}$. The wakes have a larger region where the velocity magnitude is much less than the free stream value of $1 \mathrm{~m} / \mathrm{s}$, velocity deficit wake. In general the wakes behind the fairing models approximately resemble that of the wake behind the cylinder. The E863 model appears to have the largest velocity deficit wake compared with the other fairing models.

In Fig. 4.7 the misalignment angle is set to $20^{\circ}$. The velocity deficit wake behind the E863 model fairing is much larger and of greater magnitude than either the region behind the cylinder or from either of the other two fairing models. The velocity deficit wake behind the E863r45 appears to be the smallest measured from all four models, in length, width and magnitude.

The instantaneous velocity magnitude plots, Fig. 4.5-4.7, only show data from one instant in time. Due to the unsteady nature of the flow the results may vary significantly from one sampled time to another. Therefore the sample average velocity magnitude of the wakes is shown in Fig. 4.8-4.10. The average velocity magnitude is calculated by averaging each of the (x,y) grid elements across all 500 instantaneous data points. Fig. 4.8 shows the average velocity for the flows with $\chi_{F}$ $=0^{\circ}$. The average velocity deficit for the cylinder is severe. After about four diameters downstream of the cylinder center does the average flow recover to about $50 \%$ of $\mathrm{V}_{\text {inlet }}$ and it does not fully recover to $\mathrm{V}_{\text {inlet }}$ in the entire domain. The average velocity wake behind the E863r45 is wider compared with the E863 wake, however it recovers to $\mathrm{V}_{\text {inlet }}$ faster. Possibly because of turbulent mixing of momentum inferred from Fig. 4.5.

The average velocity deficit wakes behind the models at $\chi_{\mathrm{F}}=10^{\circ}$, Fig. 4.9 , is much more extreme then at $\chi_{F}=0^{\circ}$. The wake from the E863 airfoil is comparable with the wake from the 
cylinder, the length in the $\mathrm{x}$ direction is of similar magnitudes, the width in the $\mathrm{y}$ direction is slightly smaller, but the magnitude is slightly larger. The wake from E863 fairing is larger by all metrics than the other two airfoils.

Fig. 4.10 shows the average velocity wake at $\chi_{F}=20^{\circ}$. The wake from the E863 model is the largest by all metrics, length, width, and magnitude. There is a region, ranging to $\mathrm{x} / \mathrm{D} \approx 4$, where the average flow is in the anti-streamwise direction. The other models have only slight average recirculation regions. At this misalignment angle the E863r40 has a comparable wake to the cylinder. It is smaller in the spatial dimensions but larger in magnitude. The wake from the E863r45 is the smallest in the spatial dimensions and comparable to the cylinder in magnitude. None of the models significantly turn the average centerline flow in any direction away from streamwise.

All of the flows measured had significant unsteady components that are not captured with the sample average portrayal of the data. A measure of the unsteady component can be gathered by analyzing the turbulence intensity, TI. The PIV data is two dimensional, therefore it is not possible to directly calculate the full three dimensional turbulence intensity. A two dimensional approximation for the turbulence intensity was therefore calculated.

$T I \equiv \frac{\sqrt{\frac{1}{2}\left(u_{r m s, x}^{\prime}{ }^{2}+u_{r m s, y}^{\prime}\right)}}{V_{\text {inlet }}}$

Fig. 4.11 shows the turbulence intensity at $\chi_{\mathrm{F}}=0^{\circ}$. The TI wake is much more significant in the case of the cylinder compared with any of the fairing models. The larger the rounded edge of a fairing the greater the resulting turbulence intensity at this misalignment angle. This results from the shedding wake structure seen in the instantaneous representations of the data, Fig. 4.5. In 
all cases the TI wake decreases in magnitude and increases in width as $\mathrm{x}$ increases, however it never reaches the free stream magnitude.

At $\chi_{\mathrm{F}}=10^{\circ}$, Fig. 4.12, The turbulence intensity wakes from the fairing models are significantly less than that of the cylinder, in length, width, and in magnitude. Which is a contrary result than seen in Fig. 4.9, where the average velocity deficit wake for the E863 fairing was larger than that of the cylinder.

Fig. 4.13 shows the TI wake behind all the models at misalignment angle of $20^{\circ}$. The TI wake from the E863 is in general of lower magnitude than any of the other models. Which contrast the result from Fig. 4.10, where the E863 had the largest average velocity deficit wake of all the tested models. Regions of greater TI may correlate with shorter velocity deficit wakes. Turbulent mixing of momentum could breakdown the turbulent eddies and recover the bulk flow to free stream faster than with less mixing. This could explain why the E863r45 has both regions with the highest measured TI as well as the shortest average velocity deficit wake.

Fig. 4.14-4.16 show the average streamwise velocity component normalized by the free stream velocity at $\mathrm{x} / \mathrm{D}$ values from $3-8$. Turbulence intensity is added to the profile in red. All of the velocities converge to free stream at y values far from 0 . For the cylinder case the velocity comes to a full halt at $\mathrm{x} / \mathrm{D}=3$. The magnitude of the velocity drop decreases in the $\mathrm{x}$ direction. In Fig. 4.14, the three faired cases predictably have very small streamwise velocity deviations from free stream. The E863r45 has wider profile with more turbulence intensity compared with the other two fairings. Similarly the E863 has the thinnest, and sharpest profiles of the three fairings.

At misalignment angle of $10^{\circ}$, Fig. 4.15 , the peak deficits from the E863 model are of similar magnitude of that behind the cylinder. Both the E863r40 and E863r45 fairings lower peak 
deficits compared with either the E863 fairing or the cylinder model. The velocity profiles behind the three fairings appear to be turned downward toward the pressure side of the airfoil.

In Fig. 4.16, the misalignment angle equals $20^{\circ}$. From this figure it is shown that the E836 fairing at $\chi_{\mathrm{F}}=20^{\circ}$ has a much larger recirculation region than any of the other tested models. At $\mathrm{x} / \mathrm{D}=3$ the flow behind the E863 fairing is roughly 0.5 the free stream in the anti-streamwise direction. The E863r45 faring results in flow profiles of similar intensity as the cylinder with slightly thinner profiles in the y direction.

\subsection{Conclusions}

Three aerodynamic fairings with varying degrees of trailing edge rounding were tested and compared against an unfaired cylinder. These fairings were tested at several misalignment angles to give insight into the performance at a variety of inflow conditions, where the maximum misalignment angle is $20^{\circ}$. Fairings with greater rounding at aligned flow had slightly wider wakes with slightly more turbulent intensity, however they additionally had lower peak velocity deficits and recovered to undisturbed velocities faster than fairings with less rounding. All fairings at aligned flow had much less significant wakes compared with the unfaired cylinder. At higher misalignment angles, the wake behind the unrounded fairing was larger and had a much larger peak velocity deficit compared with the rounded fairings and the unfaired cylinder. The fairing with the greatest degree of trailing edge rounding had slightly higher turbulence intensity compared with the unrounded fairing but had significantly less peak velocity deficit compared with the other fairings and the unfaired cylinder. In summary, rounding the trailing edge of the fairing can reduce the wake and the drag at high misalignment angles without losing performance at aligned flows when the system is operating with varying flow conditions. 
Future work could include investigating other fairing profile adaptations, such as a flat back profile. This profile might be useful at fixing the separation point further along the chord than a similar profile with a rounded trailing edge, leading to a thinner wake. Although it is possible that it would lead to higher lift than its rounded trailing edge counterpart, which depending on the application one might want to avoid. Another option for improvement would be synthesizing other methods of a passive flow control with a robust aerodynamic fairing. Such flow control methods could include using vortex generators to promote boundary adhesion over the chord of the fairing, spanwise bumps on the trailing edge of the fairing. A third possibility is to design the fairing to adapt its geometry with the wind direction. This could be done with a hinged trailing edge that has a positive corrective moment so that it would align itself to the direction of the wind. 


\section{References}

[4.1] Anderson, E. A., and A. A. Szewczyk. "Effects of a splitter plate on the near wake of a circular cylinder in 2 and 3-dimensional flow configurations." Experiments in Fluids 23.2 (1997): 161-174.

[4.2] Chen, Wen-Li, Hui Li, and Hui Hu. "An experimental study on a suction flow control method to reduce the unsteadiness of the wind loads acting on a circular cylinder." Experiments in Fluids 55.4 (2014): 1-20.

[4.3] Henning, Arne, et al. "Investigation of aeroacoustic noise generation by simultaneous particle image velocimetry and microphone measurements." Experiments in fluids 45.6 (2008): 1073-1085. [4.1] Quarton, D. C. " The Evolution of Wind Turbine Design Analysis: A Twenty Year Progress Review". Wind Energy 1 (1998): 5-24.

[4.4] Ichter, Brian, et al. "Structural design and analysis of a segmented ultralight morphing rotor (SUMR) for extreme-scale wind turbines." Proceedings of the 42nd AIAA Fluid Dynamics Conference, New Orleans, LA. 2012.

[4.5] Ekmekci, Alis, and Donald Rockwell. "Control of flow past a circular cylinder via a spanwise surface wire: effect of the wire scale." Experiments in fluids 51.3 (2011): 753 769.

[4.6] Choi, Haecheon. "Control of flow over a bluff body." TSFP DIGITAL LIBRARY ONLINE. Begel House Inc., 2007. 
[4.7] Korkischko, Ivan, and Julio Romano Meneghini. "Volumetric reconstruction of the mean flow around circular cylinders fitted with strakes." Experiments in fluids 51.4 (2011): $1109-1122$.

[4.8] El-Makdah, Adnan M., and Ghanem F. Oweis. "The flow past a cactus-inspired grooved cylinder." Experiments in fluids 54.2 (2013): 1-16.

[4.9] Ünal, Uğur Oral, and Mehmet Atlar. "An experimental investigation into the effect of vortex generators on the near-wake flow of a circular cylinder." Experiments in Fluids 48.6 (2010): 1059-1079.

[4.10] Feng, Li-Hao, and Jin-Jun Wang. "Synthetic jet control of separation in the flow over a circular cylinder." Experiments in fluids 53.2 (2012): 467-480.

[4.11] Chen, Wen-Li, Hui Li, and Hui Hu. "An experimental study on a suction flow control method to reduce the unsteadiness of the wind loads acting on a circular cylinder." Experiments in Fluids 55.4 (2014): 1-20.

[4.12] Benard, N., and E. Moreau. "Response of a circular cylinder wake to a symmetric actuation by non-thermal plasma discharges." Experiments in fluids 54.2 (2013): 1-19.

[4.13] Hyun, K. T., and C. H. Chun. "The wake flow control behind a circular cylinder using ion wind." Experiments in Fluids 35.6 (2003): 541-552.

[4.14] O’Connor, Kyle, Eric Loth, and Michael S. Selig. "Design of a 2-D fairing for a wind turbine tower." 31st AIAA Applied Aerodynamics Conference. 2013.

[4.15] Ehrmann, R. S., et al. "Lock-in of elastically mounted airfoils at a 90 angle of attack." Journal of Fluids and Structures 44 (2014): 205-215. 
[4.16] Hale, Neville E. "Fairing for tow-cables." U.S. Patent No. 4,700,651. 20 Oct. 1987.

[4.17] Murayama, Mitsuhiro, et al. "Computational study of low-noise fairings around tire-axle region of a two-wheel main landing gear." Computers \& Fluids 85 (2013): 114-124.

[4.18] Reiso, Marit. The Tower Shadow Effect in Downwind Wind Turbines. Diss. Norwegian University of Science and Technology, 2013.

[4.19] O’Connor, Kyle, Eric Loth, and Michael S. Selig. "Experiments on Fairing Designs for a Wind Turbine Tower." AIAA Journal (2016): 1-7.

[4.20] Ichter, Brian, et al. "A morphing downwind-aligned rotor concept based on a 13-MW wind turbine." Wind Energy (2015).

[4.21] Reiso, Marit, and Michael Muskulus. "The simultaneous effect of a fairing tower and increased blade flexibility on a downwind mounted rotor." Journal of Renewable and Sustainable Energy 5.3 (2013): 033106.

[4.22] Eppler, Richard. Airfoil design and data. Springer Science \& Business Media, 1990.

[4.23] Igarashi, Tamotsu. "Effect of tripping wires on the flow around a circular cylinder normal to an airstream." Bulletin of JSME 29.255 (1986): 2917-2924.

[4.24] Brown, S. N. "Boundary Layer Theory, 8th Edn. By H. SCHLICHTING \& K. GERSTEN. Springer 2000. 799 pp. ISBN 3-540-66270-7. DM 179." (2000): 346-347.

[4.25] Baker, J. P., E. A. Mayda, and C. P. Van Dam. "Experimental analysis of thick blunt trailing-edge wind turbine airfoils." Journal of Solar Energy Engineering 128.4 (2006): $422-431$. 

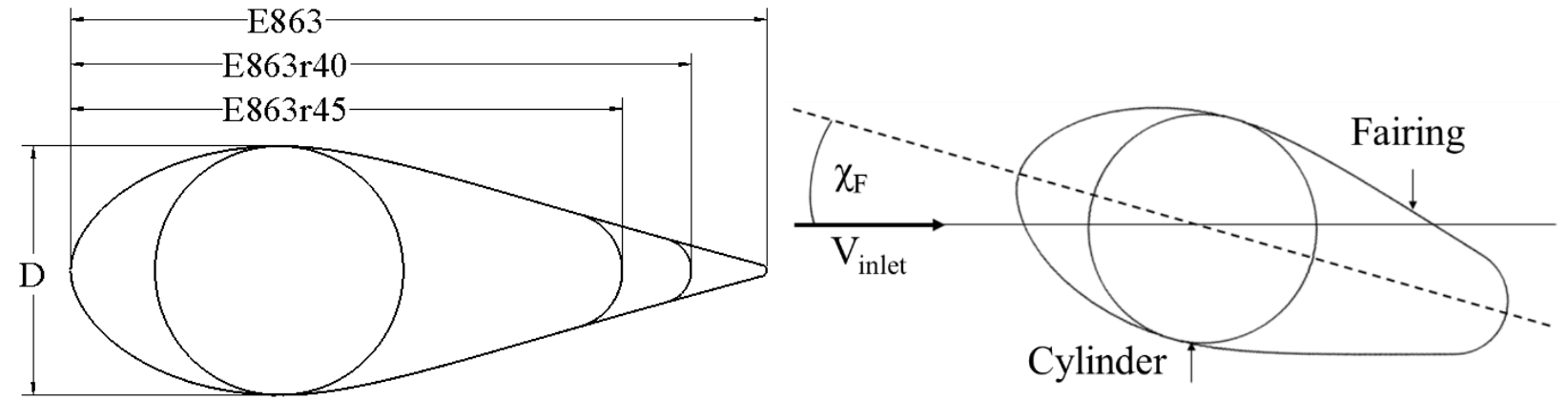

Figure 4.1: Chord view schematics of fairings: a) the profiles of all four models, \& b) inlet velocity and fairing misalignment angle displayed. 


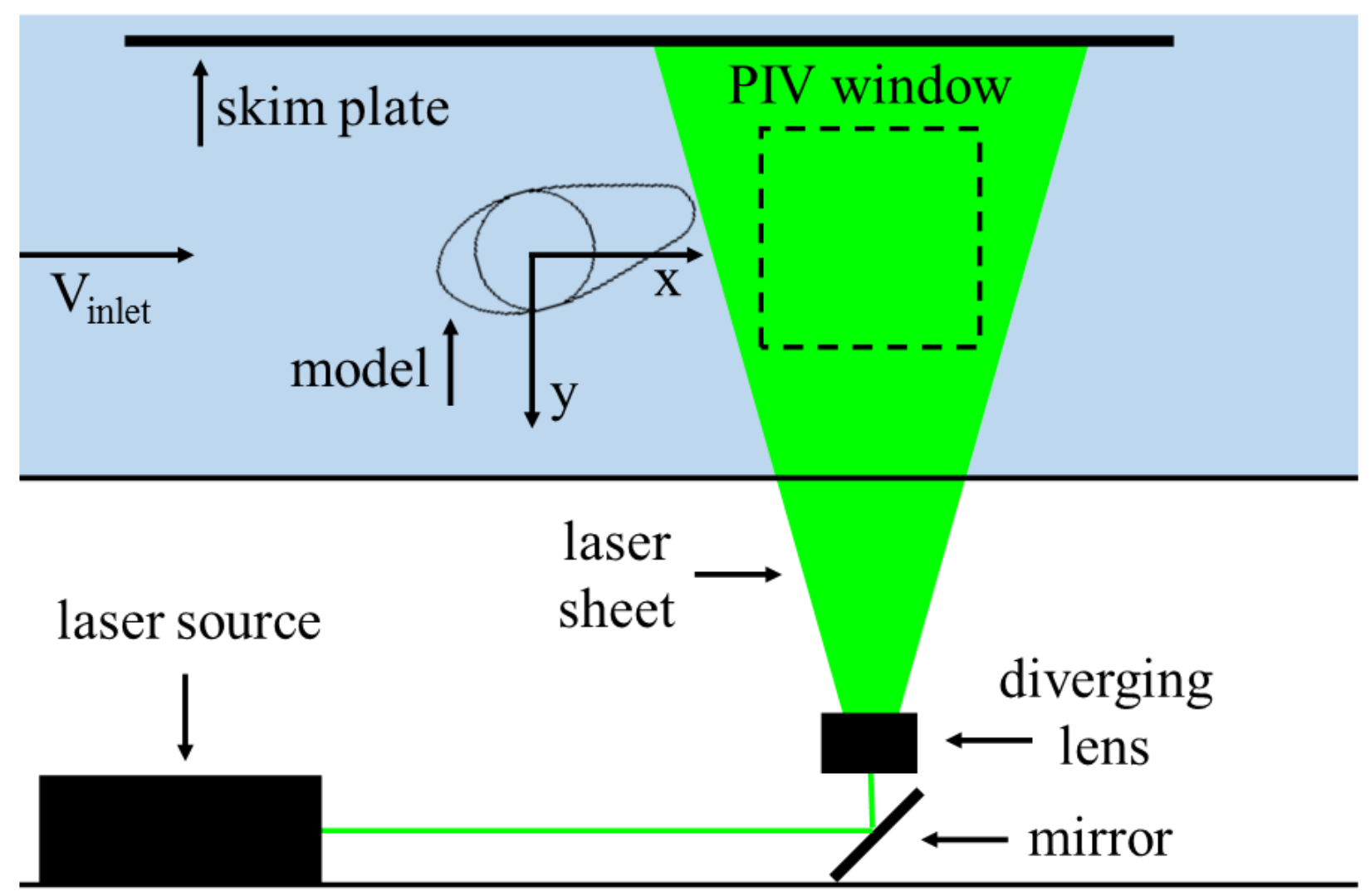

Figure 4.2: Schematic of water channel, skim plate and PIV setup. 


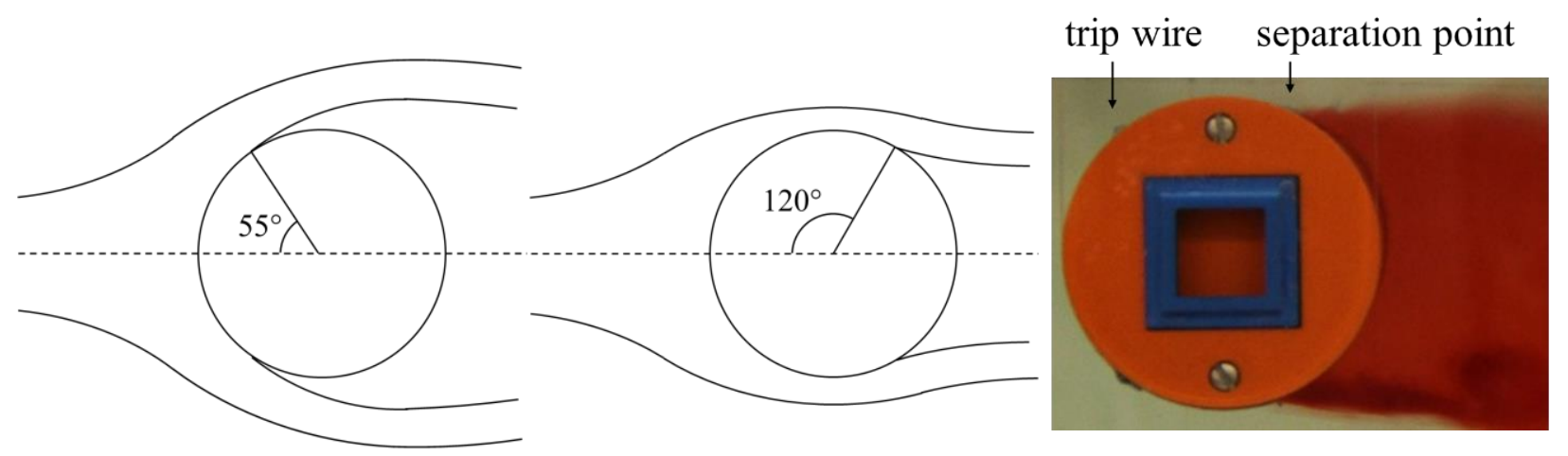

Figure 4.3: Boundary layer separation at different Reynolds number: a) laminar boundary layer separation at $\operatorname{Re}<<10^{5}$, b) turbulent boundary layer separation at $\operatorname{Re}>>10^{5}, \&$ c) separation at $R e=6.8 \times 10^{4}$ with the use of trip wires. 


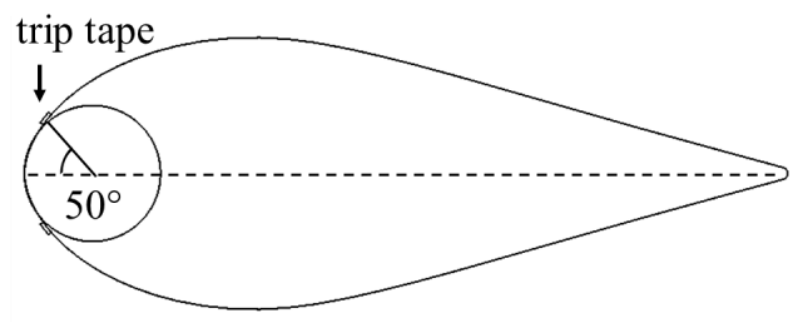

Figure 4.4: Trip tape located at 3\% chord length from the leading edge. Approximately located at $50^{\circ}$ based on leading edge curvature. 

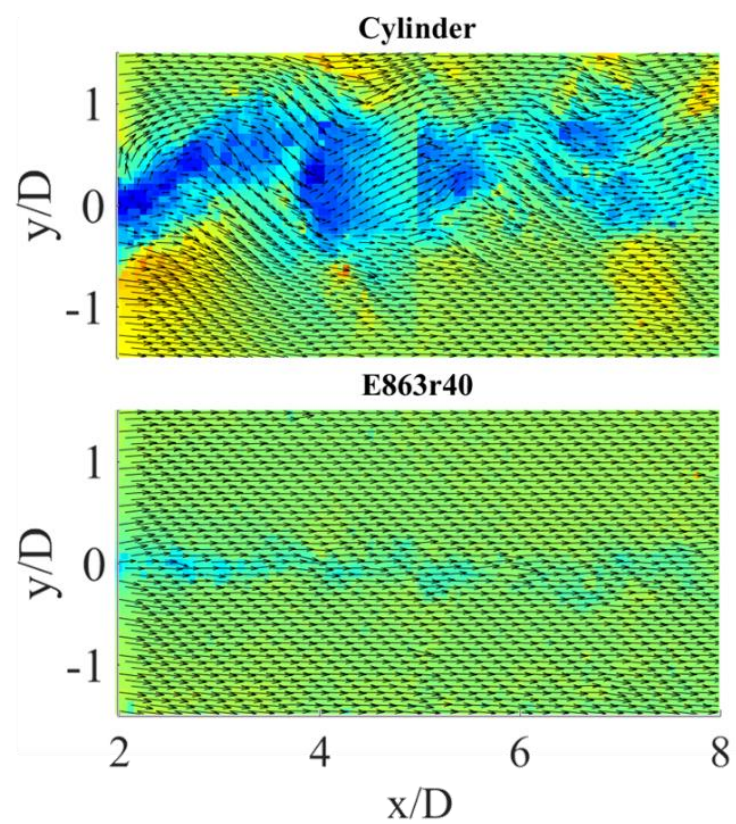

E863

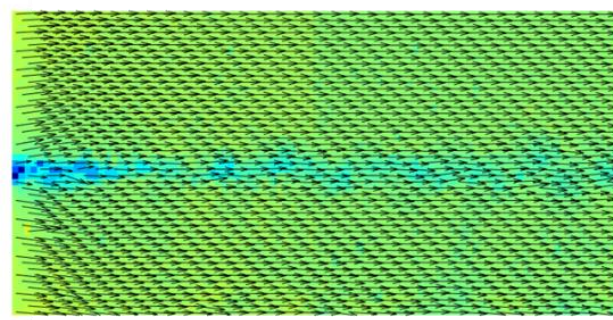

E863r45

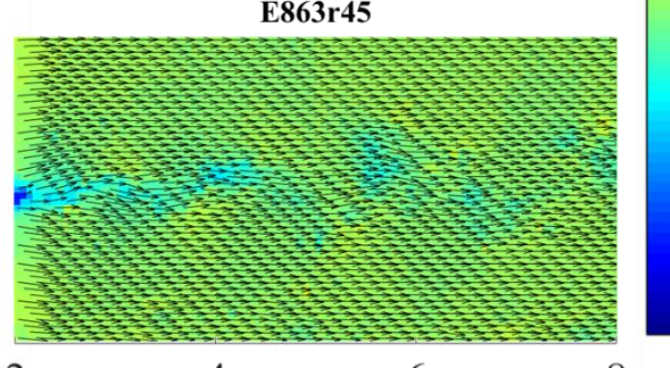

2

4

6

1.5

象

1 द्व

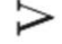

0.5

8

$\mathrm{x} / \mathrm{D}$

Figure 4.5: Instantaneous velocity field at fairing misalignment angle of $0^{\circ}$. 

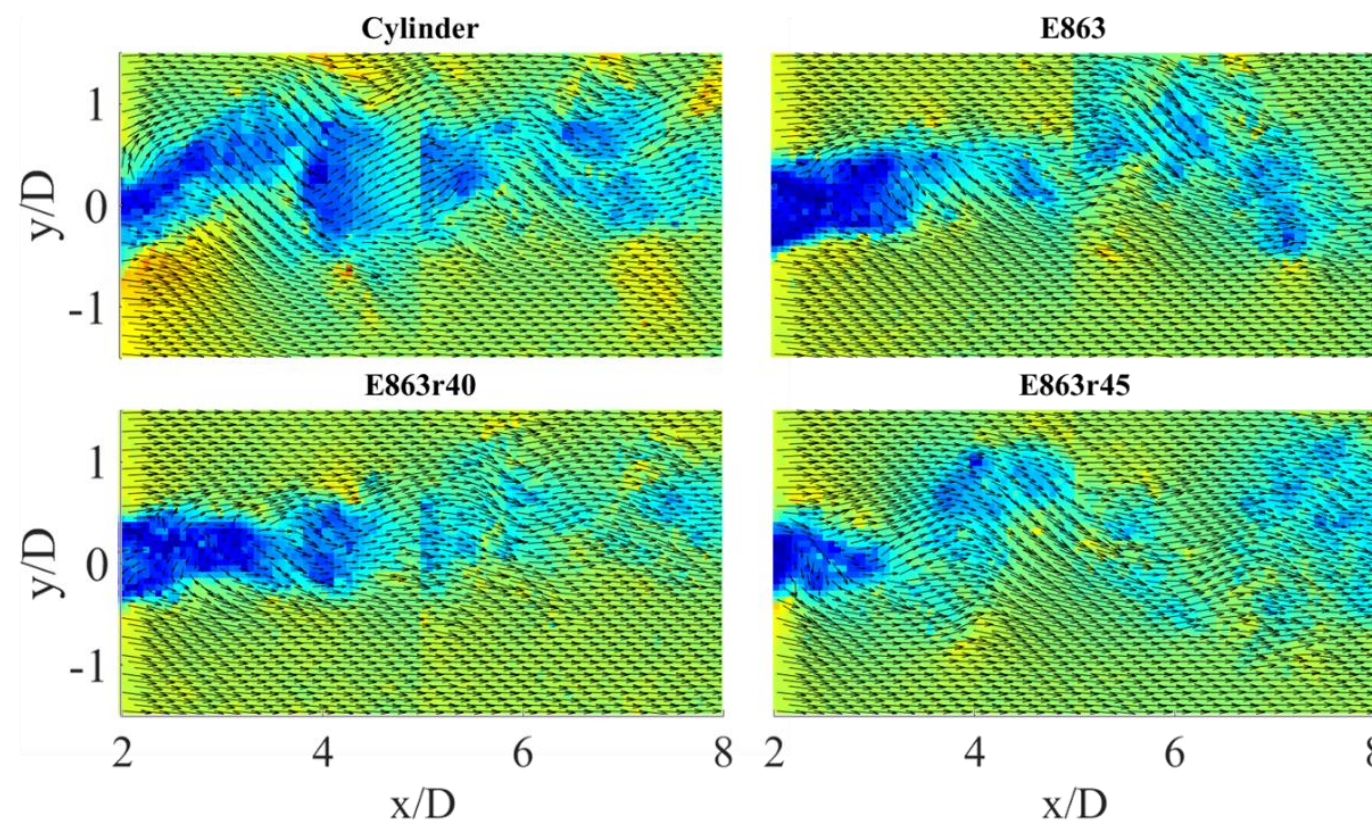

E863r45

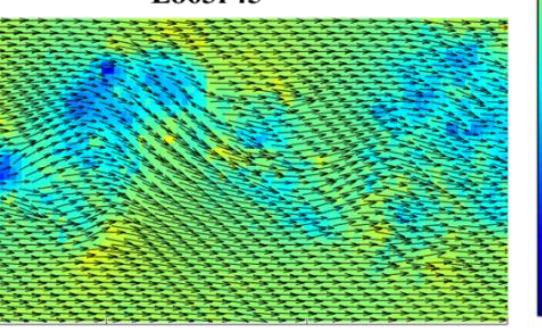

4 x/D 6

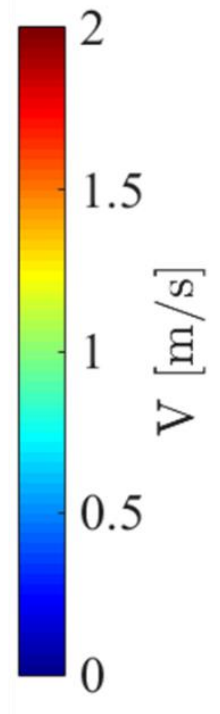

Figure 4.6: Instantaneous velocity field at fairing misalignment angle of $10^{\circ}$. 

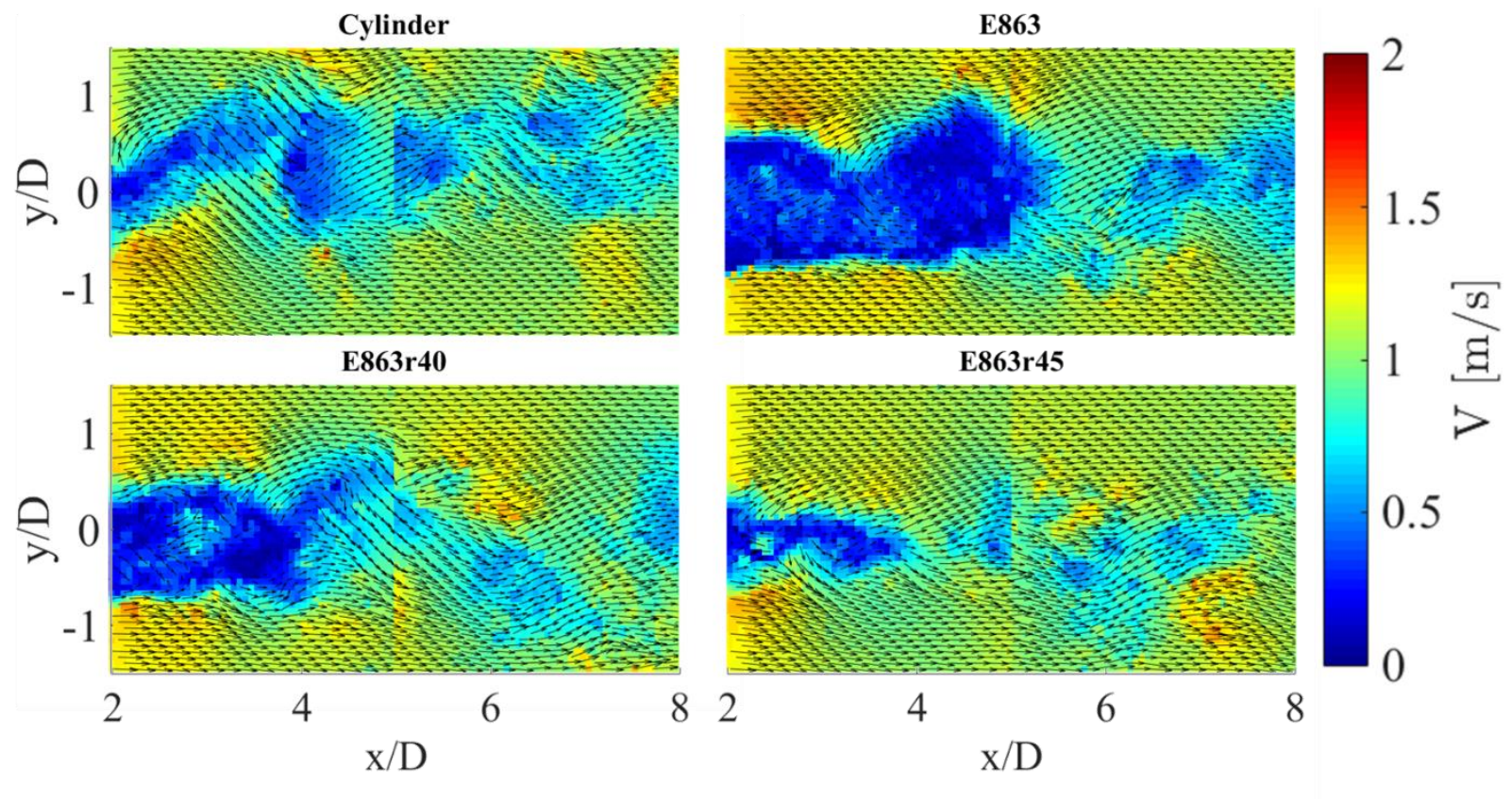

Figure 4.7: Instantaneous velocity field at fairing misalignment angle of $20^{\circ}$. 

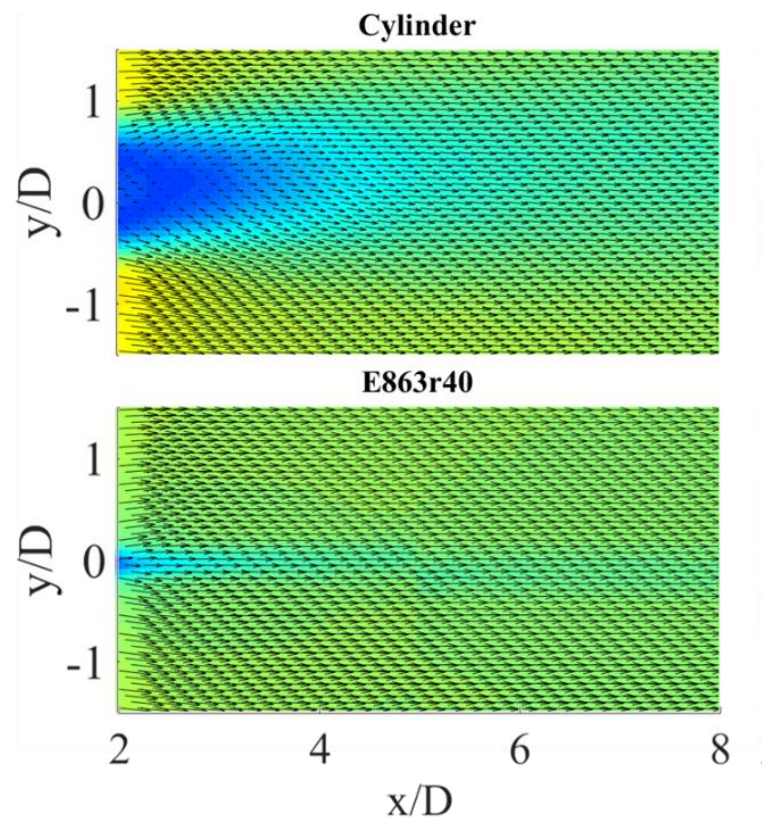

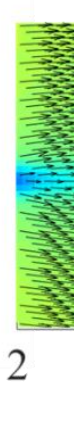

E863

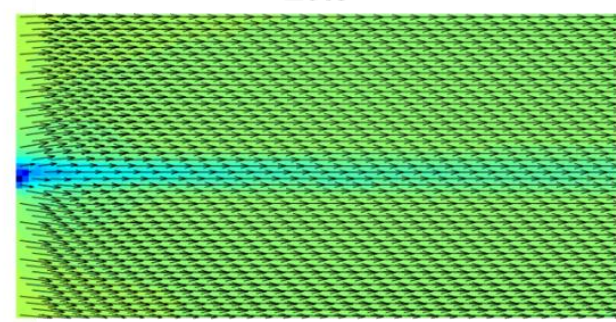

E863r45

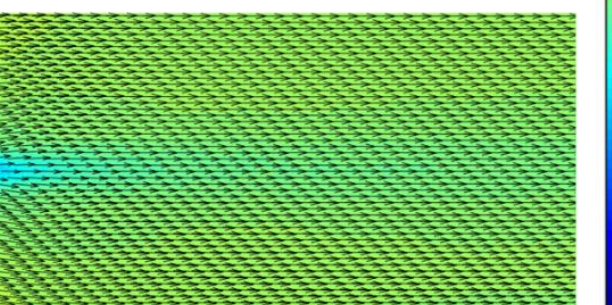

4

$\mathrm{x} / \mathrm{D}$
1.5

$1 \frac{\pi}{g}$

0.5

Figure 4.8: Average velocity field at fairing misalignment angle of $0^{\circ}$. 

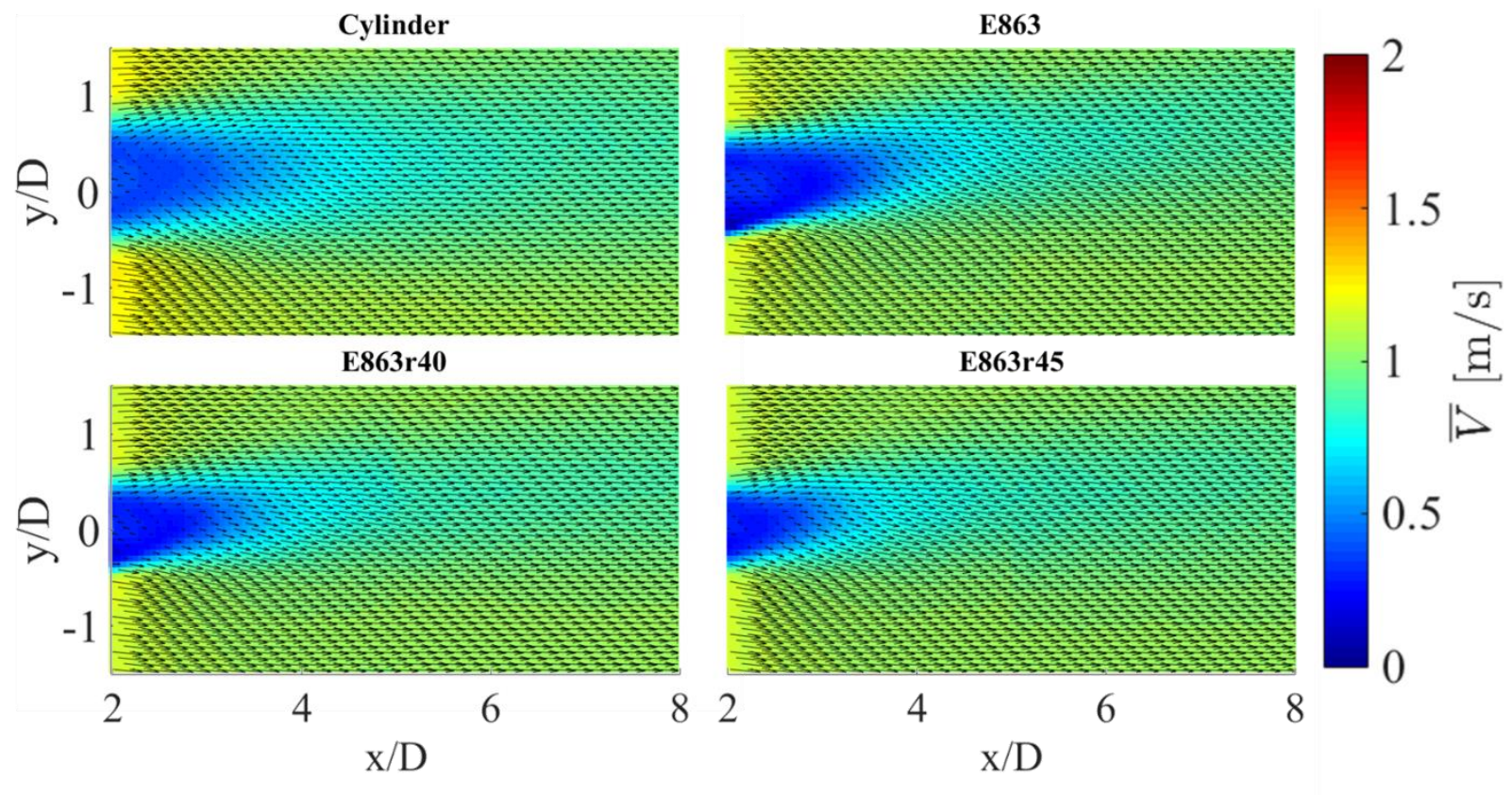

Figure 4.9: Average velocity field at fairing misalignment angle of $10^{\circ}$. 

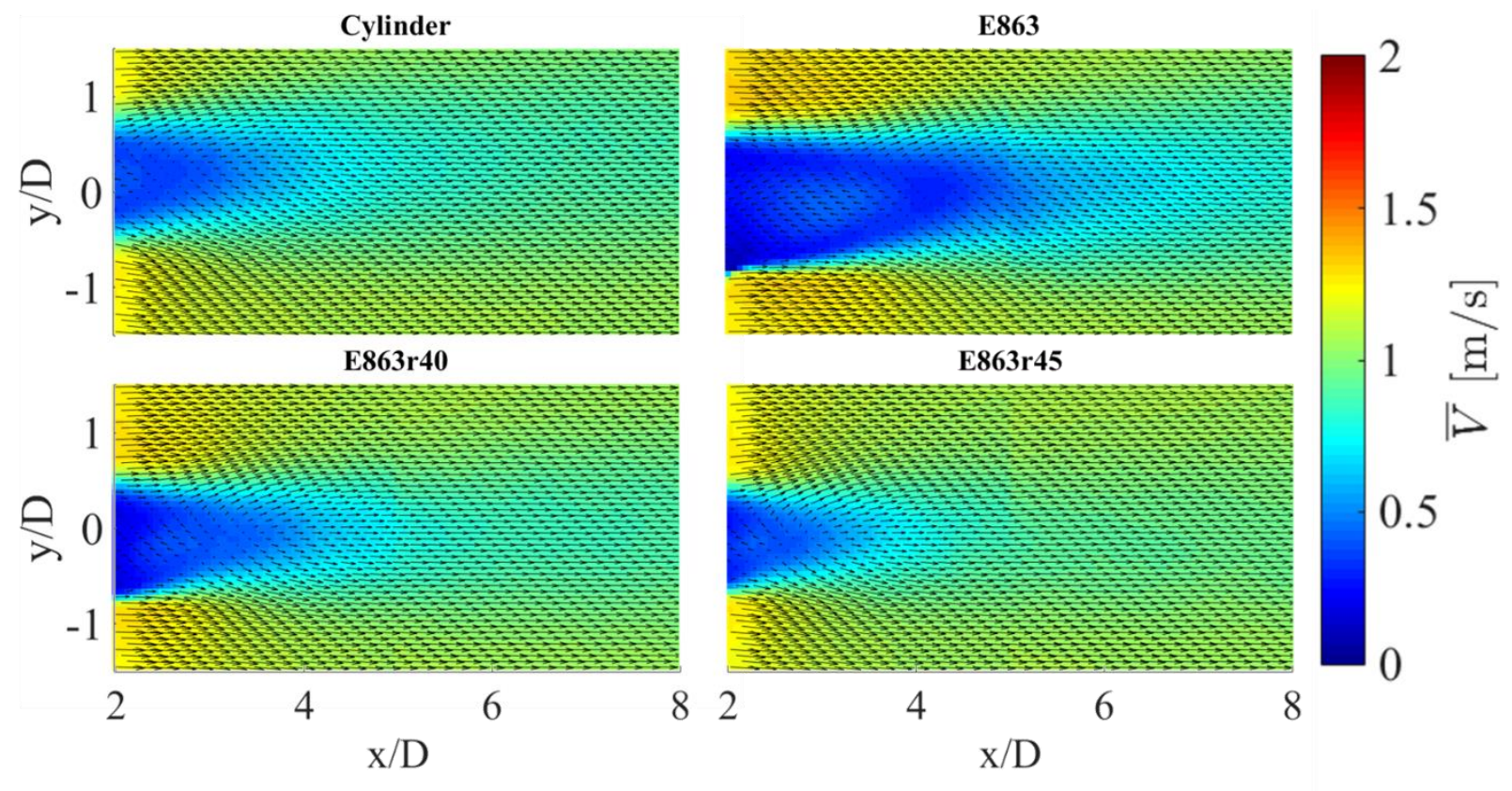

Figure 4.10: Average velocity field at fairing misalignment angle of $20^{\circ}$. 


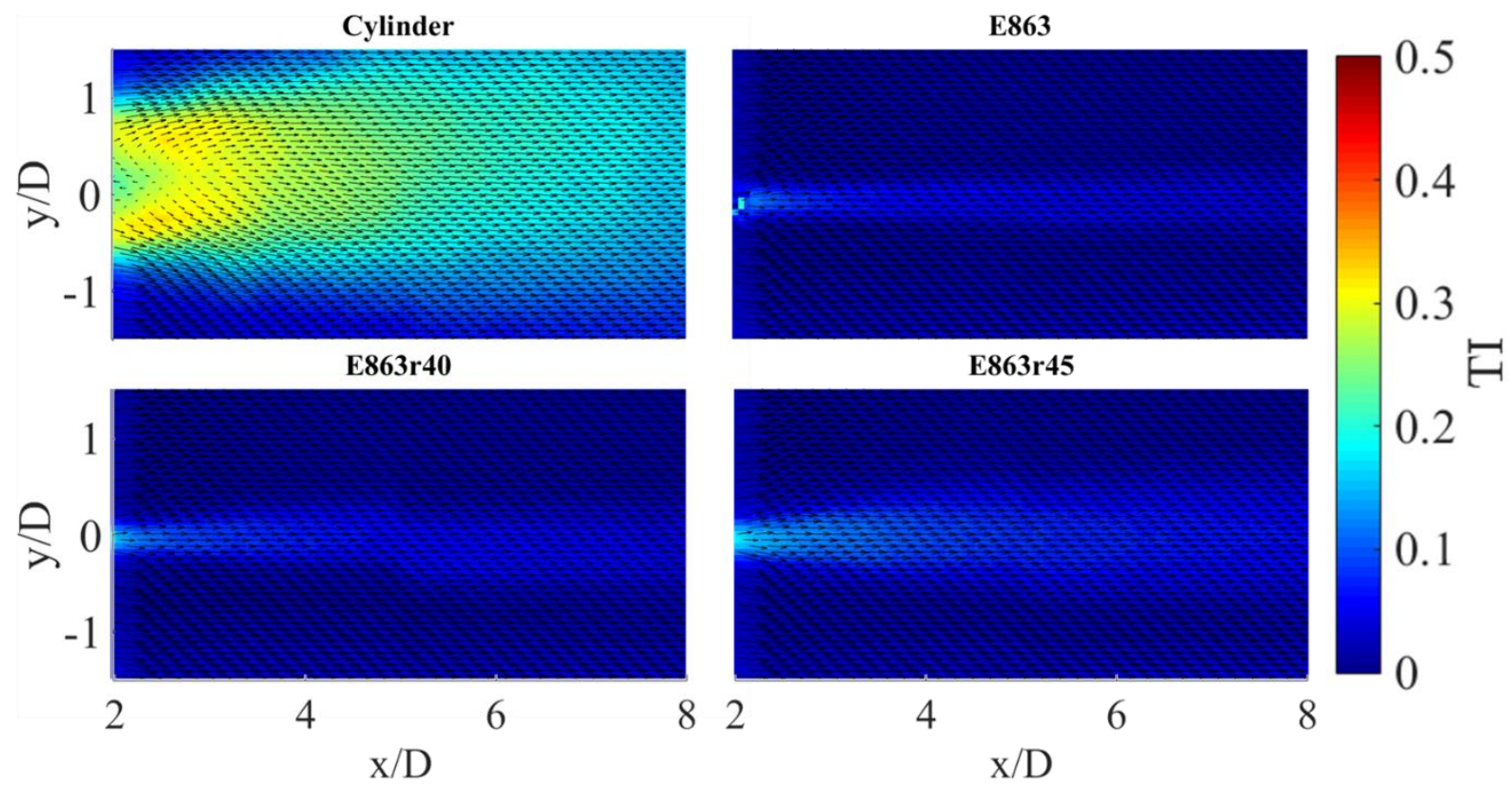

Figure 4.11: Turbulence intensity field at fairing misalignment angle of $0^{\circ}$. 

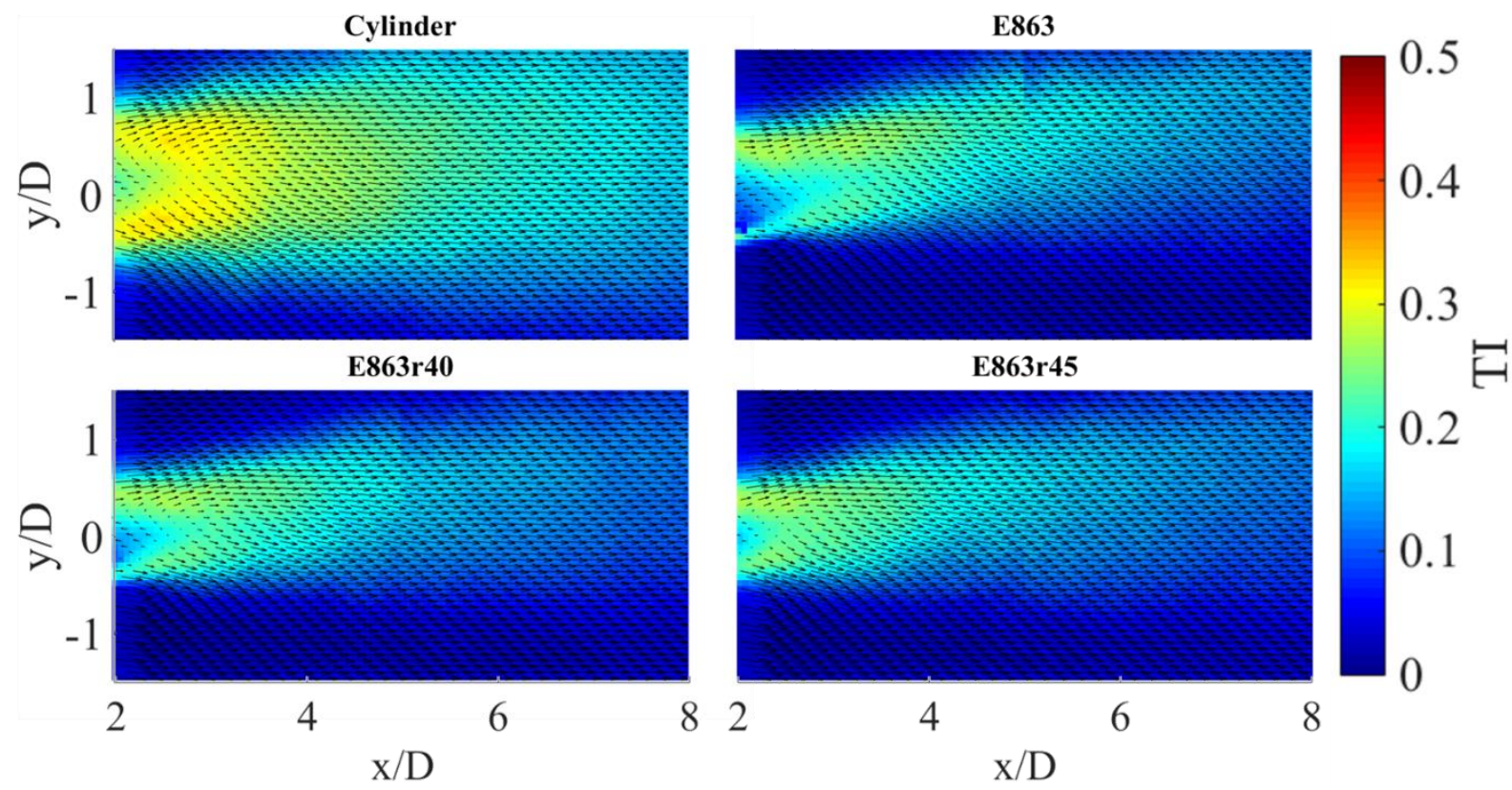

Figure 4.12: Turbulence intensity field at fairing misalignment angle of $10^{\circ}$. 


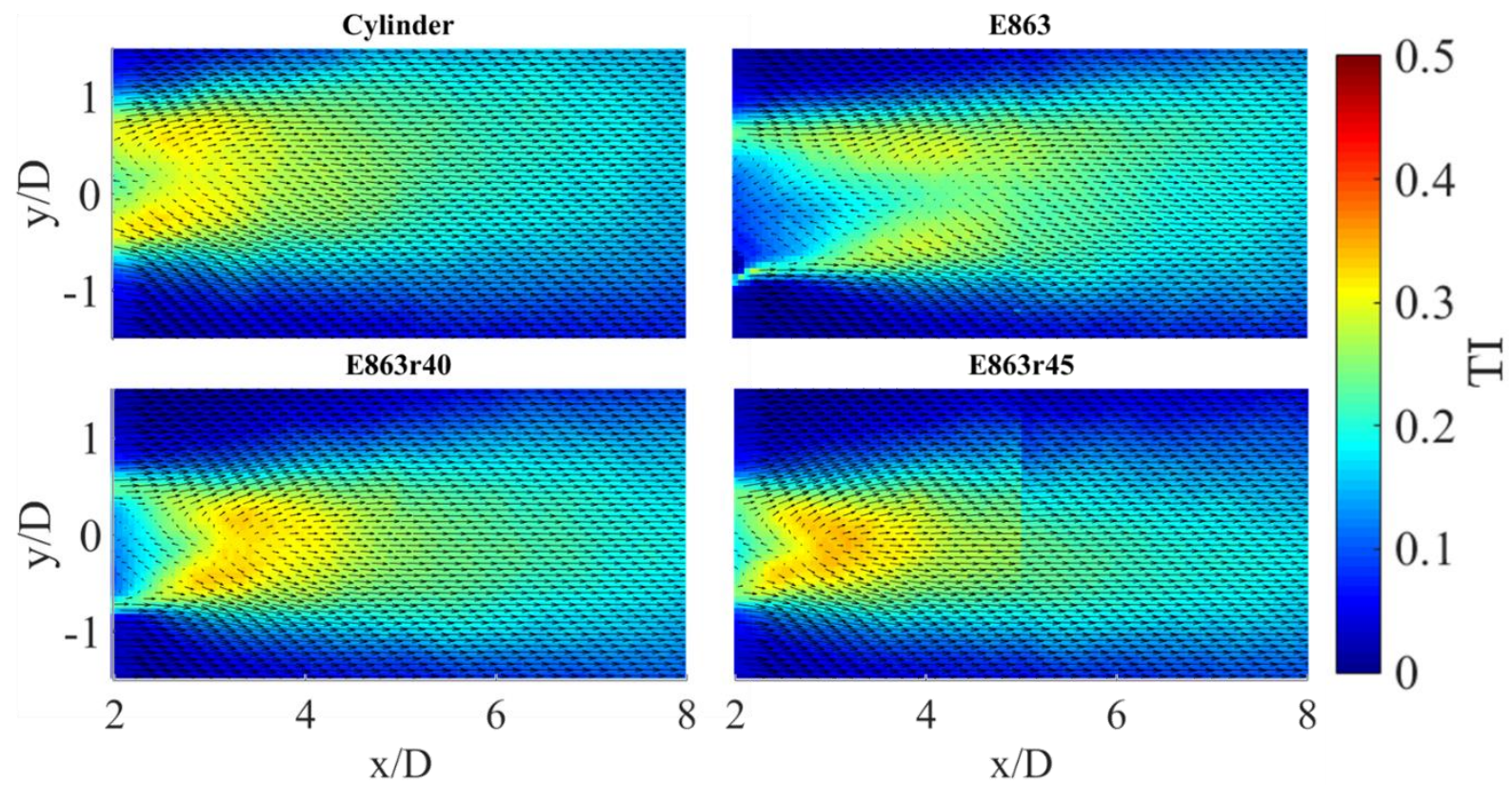

Figure 4.13: Turbulence intensity field at fairing misalignment angle of $20^{\circ}$. 

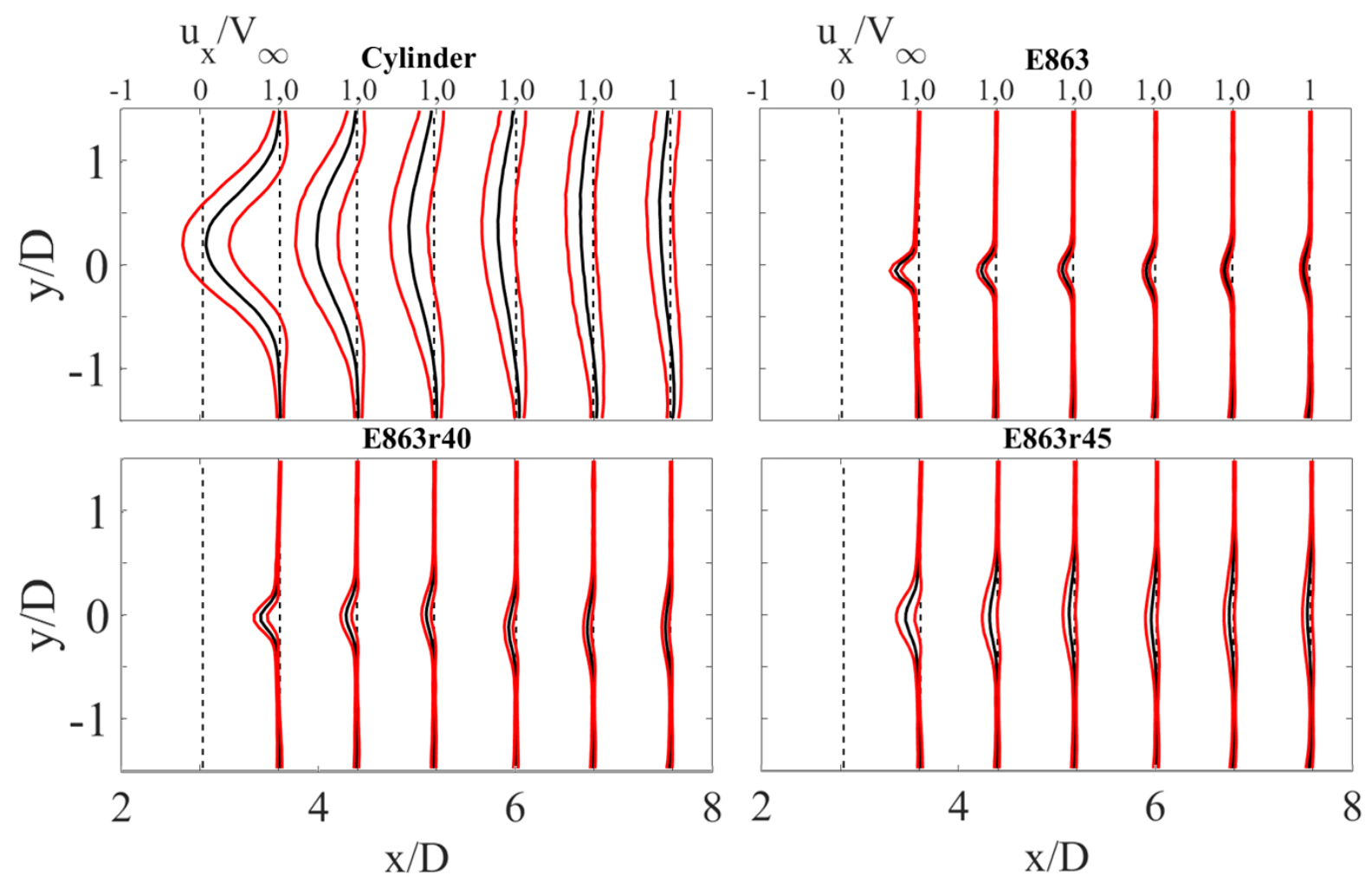

Figure 4.14: Normalized streamwise velocity component profiles at fairing misalignment angle of $0^{\circ}$. 

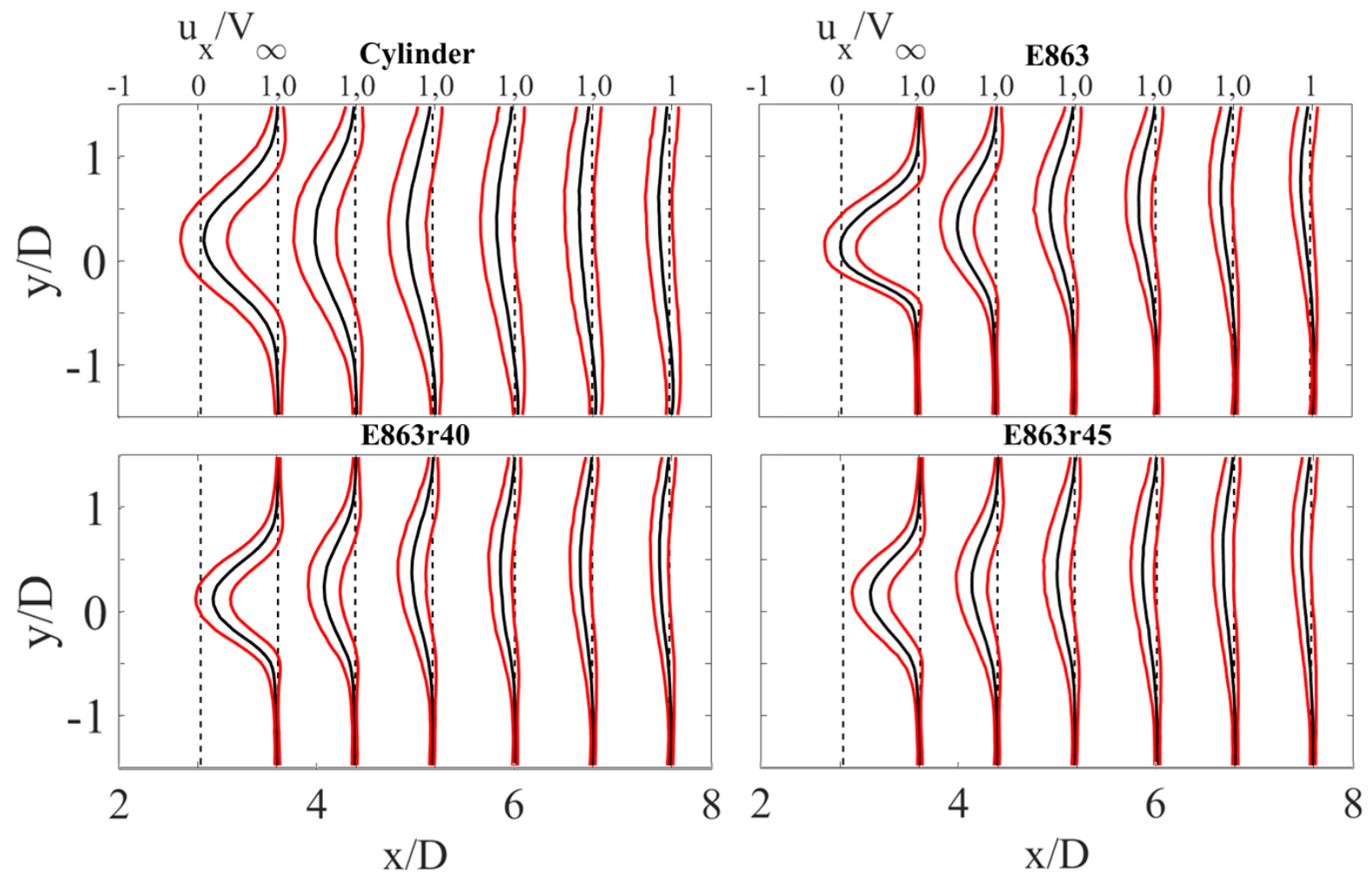

Figure 4.15: Normalized streamwise velocity component profiles at fairing misalignment angle of $10^{\circ}$. 

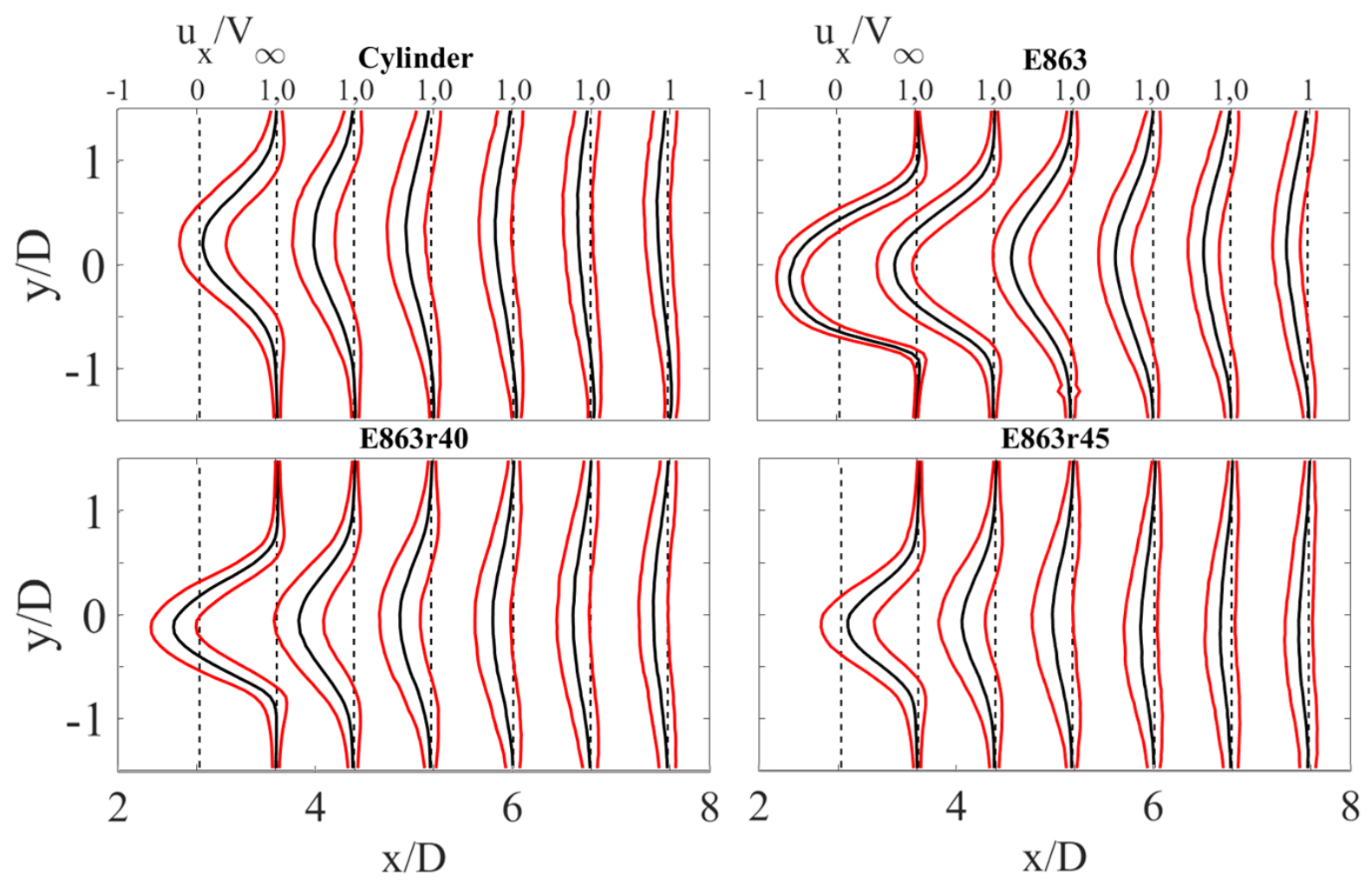

Figure 4.16: Normalized streamwise velocity component profiles at fairing misalignment angle of $20^{\circ}$. 


\title{
Chapter 5
}

\section{Robust Tower Fairing Design for Downwind Wind Turbines}

\begin{abstract}
Aerodynamic fairings are utilized for the optimization of many mechanical systems. They are a potential solution to the tower shadow effect, perhaps the single greatest obstruction for deployment of large-scale, downwind wind turbines. For optimal performance fairings should be aligned with the flow (zero degrees angle of attack), but this is not always feasible in turbine applications due to rapid changes in wind direction caused by gusts. To understand the potential impact of fairings for a variety of incident angles, this study investigated the E863 airfoil, which has been shown to have very low drag for a given airfoil thickness, and compared this to a cylinder, which represents a conventional wind turbine tower cross-section. In addition, two fairings were studied which were based on the E863 but with circularly rounded trailing edges. The modified fairings have a forced thickness ratio of $40 \%$ and $45 \%$ respectively and were termed E863r40 and E863r45. The fairings were tested in a water tunnel at Reynolds number based on diameter of $6.82 \times 10^{4}$ using dye for flow visualization and particle image velocimetry for wake quantification. Of the three fairings tested, only the E863r45 fairing reduced the wake compared to a cylinder at misalignment angles as great as $20^{\circ}$, and thus is recommended for testing at higher Reynolds numbers and in unsteady flow conditions typical of turbulent wind.
\end{abstract}




\section{Nomenclature}

D tower diameter

D2 downwind two blade rotor

DPPA downwind two pre-aligned rotor

L lift

PIV particle image velocimetry

$\mathrm{r} \quad$ radial location of the blade

$\mathrm{R} \quad$ total blade length

Re Reynolds number based on tower diameter

S shadow load

$\mathrm{S}_{\text {peak }} \quad$ largest azimuthal averaged $\mathrm{S}$ value

U3 upwind three blade rotor

V instantaneous flow velocity magnitude

$\mathrm{V}_{\text {inlet }} \quad$ tunnel inlet velocity

$\mathrm{V}_{\text {rel }} \quad$ instantaneous relative flow velocity magnitude

$\mathrm{V}_{0} \quad$ velocity after axial induction

$\mathrm{V}_{\infty} \quad$ free stream velocity magnitude

$\mathrm{x} \quad$ streamwise location from the tower center

y streamwise normal location from the tower center

$\alpha \quad$ instantaneous flow angle

$\alpha_{0} \quad$ angle resulting in zeros lift

$\alpha_{\text {rel }} \quad$ instantaneous relative flow angle

$\Delta \mathrm{x}_{\min } \quad$ distance between the tower edge and the loaded U3 blade 
$\psi \quad$ azimuth angle

$\chi_{\mathrm{F}} \quad$ fairing misalignment angle

[]* normalized by zero wake value 


\subsection{Introduction}

Aerodynamic fairings are utilized for the optimization of many mechanical systems. They are used to decrease aeroacoustic noise, as in the case of aircraft landing gear. ${ }^{5.1,5.2}$ They are also used to reduce vortex-induced vibrations, often for the application of box girders bridges or cablestayed bridges. ${ }^{5.35 .4}$ However, aerodynamic fairings are primarily used to reduce aerodynamic drag, making them highly useful in the transportation industry. Different fairings have been developed to increase tractor trailer fuel efficiency ${ }^{5.5,5.6}$ and fairings have been used as the base design of extremely low drag solar vehicle concepts. ${ }^{5.7}$

Due to ever increasing wind turbine rotor size demand, optimization and innovation is constantly required to allow ever larger rotors to be physically realistic and cost effective. One such proposed innovation is the force-aligned blade with a downwind rotor. ${ }^{5.8}$ This concept may significantly reduce blade stress facilitating larger rotors. However, the tower upstream of the rotor adds an aerodynamic complication found in all downwind configurations. In particular, the turbulent wake from the tower, 'tower shadow', can negatively affect the rotor, to the point where downwind flexible rotors may have higher damage equivalent loadings compared with baseline upwind cases. ${ }^{5.9}$

For the above reasons, aerodynamic fairings have been proposed as a solution to the tower shadow problem. Numerical predictions indicate that a well-designed fairing at zero incidence angle can reduce the drag of tower by as much as $97.5 \%$ and effectively eliminate the tower shadow. However, realistic wind conditions can be associated with rapid changes in wind direction due to gusts. As such, a significant fairing misalignment angle ( $\chi_{F}$, as shown in Fig. 1) can occur.

To minimize misalignment caused by such a gust, fairings may be connected to nacelle yaw control, or actuated independently. For even faster response, the fairing can be design as a 
lightweight aerodynamic covering that rotates independently of the tower and which is shaped so that its aerodynamic moment tends the fairing to alignment. ${ }^{5.11}$ Even with such advantages, the fairing may not be able to accommodate quickly if one considers extreme-scale wind turbines (rated power of $10 \mathrm{MW}$ or more) for which inertial effects are large. In addition, misalignment can also be caused by wind veer, a vertical gradient of wind direction, ${ }^{5.12}$ so that alignment at one height does not correspond to alignment at another height. This is a concern since at $\chi_{\mathrm{F}}$ of $20^{\circ}$ to the free stream, can increase the wake thickness and turbulence relative to that of a cylinder. ${ }^{5.11}$ These issues motivates the development of a more robust tower fairing, which is effective for a variety of wind directions.

\subsection{Methods}

For comparison, all the fairings were compared to a cylinder, made of PVC tube, located near the center of the water tunnel. Based on the water tunnel configuration, the cylinder was set with a diameter of $67 \mathrm{~mm}$ with a span of $381 \mathrm{~mm}$. The E863 profile ${ }^{5.13}$ was used as the baseline fairing to compare with an airfoil thickness, equal to the cylinder diameter, D. The E863r40 and E863r45 fairings were designed by circularly rounding the trailing edge and forcing the thickness to chord ratio to be $40 \%$ and $45 \%$ respectively, as shown in Fig 2 . The three fairings were manufactured using a Fortus 3D printer by Stratasys. The three fairing chord lengths, in increasing order, were 149mm (E863r45), 167mm (E863r40) and 188mm (E863). All four models were tested at a flow speed, $\mathrm{V}_{\text {inlet }}$, of $1 \mathrm{~m} / \mathrm{s}$ resulting in a Reynolds number, Re, based on model diameter of $6.82 \times 10^{4}$. The boundary layer was artificially tripped into the turbulent mode using a trip wire

for the cylinder case and trip tape for the fairing cases, based on a study by Igarashi et al. ${ }^{5.14}$ The fairings were tested at misalignment angles, $\chi_{\mathrm{F}}$, of $0^{\circ}, 10^{\circ}$ and $20^{\circ}$. Dye visualization and particle image velocimetry, PIV, was performed to qualify and quantify the wakes. 
In order to select downstream distances in the water tunnel of the highest relevance to extreme-scale wind turbines, the relative distance between the wind turbine tower and blade path were carefully considered. In particular, the relative distance (normalized by tower diameter) were obtained for two downwind turbine configurations, D2 and D2PA. ${ }^{5.15}$ Both turbines are 2-bladed downwind versions of Sandia's 13.2 MW upwind turbine, ${ }^{5.16}$ which had a forward coning angle of $2.5^{\circ}$. For the downwind geometries, the $\mathrm{D} 2$ rotor has a coning angle of $2.5^{\circ}$, while the D2PA has a Pre-Aligned rotor with a coning angle equal to $17.5^{\circ}$, Fig. $1 b$.

To determine the distance between blade path and tower center with aeroelastic deflections, three simulations were conducted in FAST: ${ }^{5.17} \mathrm{U} 3$ (upwind, 3 bladed, baseline), D2 (downwind, 2 bladed, baseline) and D2PA (downwind, 2 bladed, pre-aligned). The FAST simulations were conducted for the full-scale 13.2 MW turbine at steady operating conditions, free stream velocity, $\mathrm{V}_{\infty}$, of $11.3 \mathrm{~m} / \mathrm{s}$. Fig. $3 \& 4$ show the rotor clearance $(\Delta \mathrm{x})$ normalized by tower diameter (D) as a function of rotor span (r) normalized by rotor radius (R). The unloaded line shows the spanwise blade location from the tower center for unloaded conditions (ignoring blade deflection due to gravitational, centrifugal and aerodynamic forces). The loaded line shows the blade location assuming parabolic variation based on the blade tip deflection. The distance between the loaded U3 blade and the tower edge, in Fig. 3 , is defined as $\Delta \mathrm{x}_{\min } . \Delta \mathrm{x}_{\min }$ varies along the span of the blade. The results for the upwind configuration were used to limit the maximum chord length of the fairings for the downwind configuration. In particular, it was decided that the distance between the loaded blade of a downwind rotor and the trailing edge of the tower fairing should be at least as great as $\Delta \mathrm{x}_{\mathrm{min}}$, obtained from the upwind case. Based on this criterion, Fig.4 shows the unloaded and loaded blades for the D2 and D2PA rotors, as well as the position of the trailing edge of the fairings, limited by $\Delta \mathrm{x}_{\min }$. The D2PA rotor of Fig. $7 \mathrm{~b}$ has sufficient clearance such that no 
limitation was deemed necessary for a fairing that extends downward for $r / R>0.25$. In contrast, the D2 rotor of Fig.7a has a restricted clearance compared with the D2PA rotor therefore to keep the clearance at least as great as $\Delta \mathrm{x}_{\min }$, the fairings may not reach full length until $\mathrm{r} / \mathrm{R}=0.8$.

Based on the results of Fig. 7, the distance downstream of the wake for the rotor plane can be obtained for a given radial location. Herein, the location of $\mathrm{r} / \mathrm{R}=0.75$ is chosen for analysis. The dashed black lines of Figs. 7 are used to determine regions of interrogation for a conventional downwind turbine $(2<x / D<5$ based on Fig. $7 a)$ and for a pre-aligned turbine $(5<x / D<8$ based on Fig. 7b).

The above conditions are translated to the water tunnel flow field as shown in Fig. 5. The dotted red arrows indicate the location that the specific rotor passes through the flow field at $\mathrm{r} / \mathrm{R}=0.75$ for $\mathrm{D} 2$ and $\mathrm{D} 2 \mathrm{PA}$. The instantaneous velocity flow vectors along these lines of rotation can then be used to calculate the relative flow velocity and angle, $\mathrm{V}_{\text {rel }} \& \alpha_{\text {rel }}$. To translate the water tunnel flow-field to that associated with the wind turbine flow field, the axial velocity at the tower plane $\left(\mathrm{V}_{0}\right)$ is assumed to be $2 / 3$ of the freestream $\mathrm{V}_{\infty}$ by assuming an axial induction value of $1 / 3.5 .18$

Relative flow parameters, $V_{\text {rel }}$ and $\alpha_{\text {rel, }}$, that the blade element experiences are calculated from the addition of axial flow, $\mathrm{V}$, and rotational flow, $\omega \cdot r$, Fig. $6 . \mathrm{V}_{\text {rel }}$ and $\alpha_{\text {rel }}$ are calculated using equations $1 \& 2$ with $\alpha_{0}$, the angle of attack resulting in no lift, equal to $-4.2^{\circ}$ and $\beta$, the pitch plus local twist of the blade, equal to $0.64^{\circ}$. Assuming that the lift versus angle of attack is inside the linear region, lift (L) could be calculated with equation 3. However, the constant $\mathrm{k}$ in equation is unknown therefore L cannot be directly calculated. Instead, lift non-dimensionalized by the lift that the blade would experience ignoring shadow effects was calculated, $\mathrm{L}^{*}$, equation 4 . The purpose of the fairing is to minimize the load fluctuation on the rotor due to shadow effects. To 
quantify this load fluctuation a metric of performance was defined, shadow load, $\mathrm{S}^{*}$, defined as the fractional lift lost due to shadow effects, equation 5. Peak shadow load, $\mathrm{S}^{*}$ peak, was determined and compared with all cases. Parameters are often reported against blade azimuth angle, $\psi$, which is calculated using equation 6 .

$$
\begin{aligned}
& V_{r e l}=\sqrt{(V \cos (\alpha))^{2}+(\omega r-\mathrm{V} \sin (\alpha))^{2}} \\
& \alpha_{r e l}=\tan ^{-1}\left(\frac{V \cos (\alpha)}{\omega r-\mathrm{V} \sin (\alpha)}\right)-\beta \\
& L=k\left(v_{r e l}\right)^{2}\left(\alpha_{r e l}-\alpha_{0}\right) \\
& L^{*} \equiv\left(\frac{V_{r e l}}{\sqrt{\left(V_{0}\right)^{2}+(\omega r)^{2}}}\right)^{2}\left(\frac{\alpha_{r e l}-\alpha_{0}}{\tan ^{-1}\left(\frac{\left(V_{0}\right.}{\omega r}\right)-\beta-\alpha_{0}}\right) \\
& S^{*} \equiv 1-L^{*} \\
& \psi=\operatorname{atan}\left(\frac{y}{r}\right)
\end{aligned}
$$

\subsection{Results}

A subset of the experimental results is shown in Fig. 7: sub plots a \& b show instantaneous dye visualization for the cylinder and the E863r45 fairing at $\chi_{\mathrm{F}}=20^{\circ}$. The coordinate system is defined from the center of the cylinder or the inscribed circle of the fairings. Sub plots c and d show instantaneous wake measurements made using PIV of the same two models. Sub plots e and $\mathrm{f}$ show the time averaged velocity deficit profiles at different $\mathrm{x}$ locations. The black line shows the average streamwise velocity component, and the red line shows the turbulence intensity.

The general trends from the other test conditions were that the wakes behind the misaligned fairings were similar in intensity to those behind the cylinder model. In contrast, the wakes behind the aligned fairing were much less significant compared to the cylinder. While the raw data of the 
wake is of interest, the key issue is the effect that the wake has on wind turbine rotor blade. Therefore the PIV results will be used to estimate the resulting loads on a turbine blade from both a D2 and D2PA rotor.

Fig. 8 shows how flow velocity and flow angle (V and $\alpha$, based on measurements with the PIV in the water tunnel), are used to calculate relative velocity and relative angle $\left(\mathrm{V}_{\text {rel }}\right.$ and $\alpha_{\text {rel }}$, plotted against azimuth angle, $\psi$, calculated using equations $1,2 \& 6$ ) for a D2 rotor blade passing through the wake behind the cylinder. And how $\mathrm{V}_{\text {rel }}$ and $\alpha_{\text {rel }}$ are used to calculate normalized lift, $\mathrm{L}^{*}$, using equation 4 . The $\mathrm{V}$ profile, sub plot $\mathrm{a}$, is smooth, with a deficit minimum near $\mathrm{y} / \mathrm{D}=0$. The instantaneous values may differ by about $0.5 \mathrm{~m} / \mathrm{s}$ from the mean. The $\alpha$ profile, sub plot $\mathrm{b}$, is also smooth, however the average $\alpha$ is centered at $0^{\circ}$, with only unsteady variation from the mean. This variation is greatest near $y / D=0$, about equal to $75^{\circ}$. The average $V_{\text {rel }}$ profile, sub plot $c$, is very nearly flat with variations from the mean on the order of $5 \mathrm{~m} / \mathrm{s}$. The $\alpha_{\text {rel }}$ profile, sub plot $d$, resembles in structure the $\mathrm{V}$ profile. There is a mean deficit, with variations from that mean on the order of $3^{\circ}$. The profile of $\mathrm{L}^{*}$, sub plot e, resembles the profiles of $\mathrm{V}$ and $\alpha_{\text {rel }}$ with deficit of about 0.35 and variations from that of about 0.25 . From the similarity in profile structure between $V, \alpha_{\text {rel }}$ and $\mathrm{L}^{*}$, it can be concluded that $\mathrm{V}$ is the dominate parameter in calculating $\alpha_{\text {rel, }}$ and $\alpha_{\text {rel }}$ is the dominate parameter in calculating $\mathrm{L}^{*}$.

$\mathrm{L}^{*}$ is more important the other flow parameters, therefore Fig. 9 shows the $\mathrm{L}^{*}$ profiles on the $\mathrm{D} 2$ rotor for the cylindrical tower and the three tower fairings at $\chi_{\mathrm{F}}=0^{\circ}$. The profile show how the load on the rotor blade changes as it passes through the wake from the model. The $\mathrm{L}^{*}$ profile for the cylinder case is what could be expected from typical downwind turbine blade as it passes through the wake from the tower. On average, it decreases to about 0.7 of the non-wake value. With root mean square variations on the order of 0.15 . All three fairings, at $\chi_{\mathrm{F}}=0^{\circ}$, almost eliminate 
the variations in lift. In Fig. 10, the misalignment angle is increased to $\chi_{\mathrm{F}}=20^{\circ}$. With the higher misalignment angles the fairings do not reduce the wake effects compared with the cylinder. The $\mathrm{L}^{*}$ in the center of the wake behind the E863 fairing is about 0.25 that of the non-wake value. The modified fairings however, perform better than the E863 fairing at this misalignment angle. The lift profile from the E863r45 fairing is similar to that of the cylinder in magnitude.

From Fig. 9 and Fig. 10, it is shown that for the D2 rotor, all three fairings performed similarly well at $\chi_{\mathrm{F}}=0^{\circ}$, and the E863r45 fairing performed best at $\chi_{\mathrm{F}}=20^{\circ}$. For this reason when analyzing the $\mathrm{L}^{*}$ variations on the D2PA rotor, only the E863r45 fairing is shown. Fig. 11 shows the $\mathrm{L}^{*}$ profiles for the cylinder and the E863r45 at all three misalignment angles. It can be seen from cylinder plot that the D2PA rotor interacts with the wake differently than the D2 rotor interacts with the wake. This due to the larger $\mathrm{x} / \mathrm{D}$ distance for the $\mathrm{D} 2 \mathrm{PA}$ rotor. One difference is that there is a less pronounced dip in the average $\mathrm{L}^{*}$. There is still a large amount of unsteady deviation from this average value, a spread on the order of 0.5 . The aligned fairing significantly reduces the spread of $\mathrm{L}^{*}$ values by about 0.25 . The fairing at $\chi_{\mathrm{F}}=20^{\circ}$ does not greatly the effect $\mathrm{L}^{*}$ compared with the cylinder baseline.

The results for $\mathrm{L}^{*}$ were transformed in shadow load, $\mathrm{S}^{*}$, the fractional lift lost due to shadow effects. $S^{*}$ is related to the damage to the rotor. An $S^{*}$ of zero would refer to no shadow effect i.e. an ideal tower fairing. The results were further characterized by $\mathrm{S}^{*}$ peak, the largest average $S^{*}$ value measured, and $S^{*}{ }_{R M S}$, the root mean square variation of the measured data at $\mathrm{S}^{*}$ peak. $\mathrm{S}^{*}$ peak is the primary index or performance chosen because it is related to the magnitude of stress fluctuation experienced by the blade every cycle, which in turn is directly related the fatigue life of the blade. The $\mathrm{S}^{*}$ RMS is the secondary index of performance because fluctuating stress also indirectly effects the fatigue life of the blade. Fig. 12 shows these two parameters for both the D2 
and the D2PA rotors as they pass through all the different models wakes. The dot shows the location of $\mathrm{S}^{*}$ peak and the line shows the length of $\pm 1 \mathrm{~S}^{*} \mathrm{RMS}$. At $\chi_{\mathrm{F}}=0^{\circ}$ all three fairings have lower $\mathrm{S}^{*}$ peak and $\mathrm{S}_{\mathrm{RMS}}$ values compared with the cylinder baseline for both rotors. At $\chi_{\mathrm{F}}=20^{\circ}$ the $\mathrm{E} 863$ fairing has roughly twice as larger $\mathrm{S}^{*}$ peak values compared with the cylinder baseline for both rotors. But the E863r45 has slightly lower $\mathrm{S}^{*}$ peak values compared with the cylinder for both rotors. The E863r45 had lower $S *_{\text {peak }}$ values compared with every other model, at all at $\chi_{\mathrm{F}}$ angles, for both rotors.

\subsection{Conclusions}

Three tower fairing models were fabricated and tested with PIV against a baseline cylinder. The PIV data was scaled and used for analysis on the D2 and the D2PA rotors. Relative flow parameters were calculated from the PIV flow data. The relative flow field was then used to predict the fractional lift that the blades would experience as they passed through the experimental vector fields. Shadow load, the fraction of lift lost due to shadow effects, was calculated and averaged over the 500 repeated data points to achieve smooth average profiles.

Peak shadow load, the largest value of the average shadow load experienced was determined to be the index of performance of the fairing, because it is directly related to fatigue life of the blade. Shadow load variation at the location of the peak shadow load was determined to be the secondary index of performance, because it is indirectly related to the fatigue life of the blade. It was shown that for pre-aligned rotors, because of the larger distance between the blade and the tower, peak shadow load is substantially lower than traditional rotors. All three fairings at $\chi_{\mathrm{F}}=0^{\circ}$, for both rotors, performed better than the baseline cylinder. The E863 fairing had roughly twice as high peak shadow load than the cylinder at $\chi_{\mathrm{F}}=20^{\circ}$. The E863r45 fairing however had 
lower peak shadow load on both rotors, at all angles, compared with all other models, and comparable or better shadow load variation than the other models. For this reason the E863r45 fairing was the most robust fairing tested. 


\section{References}

[5.1] Murayama, Mitsuhiro, et al. "Computational study of low-noise fairings around tire-axle region of a two-wheel main landing gear." Computers \& Fluids 85 (2013): 114-124.

[5.2] Voutsinas, Spyros G. "Aeroacoustics research in Europe: The CEAS-ASC Report on 2005 highlights." Journal of sound and vibration 299.3 (2007): 419-459.

[5.3] Larsen, Allan. "Advances in aeroelastic analyses of suspension and cable-stayed bridges." Journal of Wind Engineering and Industrial Aerodynamics 74 (1998): 73-90.

[5.4] Yang, Yongxin, et al. "Aerodynamic instability performance of twin box girders for longspan bridges." Journal of Wind Engineering and Industrial Aerodynamics 145 (2015): 196208.

[5.5] Winston, Clifford, and Fred Mannering. "Implementing technology to improve public highway performance: A leapfrog technology from the private sector is going to be necessary." Economics of transportation 3.2 (2014): 158-165.

[5.6] Chowdhury, Harun, et al. "A study on aerodynamic drag of a semi-trailer truck." Procedia Engineering 56 (2013): 201-205.

[5.7] Wellington, R. P. "Model solar vehicles provide motivation for school students." Solar Energy 58.1 (1996): 137-146.

[5.8] Ichter, Brian, et al. "A morphing downwind-aligned rotor concept based on a 13-MW wind turbine." Wind Energy (2015). 
[5.9] Reiso, Marit, and Michael Muskulus. "The simultaneous effect of a fairing tower and increased blade flexibility on a downwind mounted rotor." Journal of Renewable and Sustainable Energy 5.3 (2013): 033106.

[5.10] O'Connor, Kyle, Eric Loth, and Michael S. Selig. "Design of a 2-D fairing for a wind turbine tower." 31st AIAA Applied Aerodynamics Conference. 2013.

[5.11] O'Connor, Kyle, Eric Loth, and Michael S. Selig. "Experiments on Fairing Designs for a Wind Turbine Tower." AIAA Journal (2016): 1-7.

[5.12] Brown, A. R., et al. "Wind turning across the marine atmospheric boundary layer." Quarterly Journal of the Royal Meteorological Society 131.607 (2005): 1233-1250.

[5.13] Eppler, Richard. Airfoil design and data. Springer Science \& Business Media, 1990.

[5.14] Igarashi, Tamotsu. "Effect of tripping wires on the flow around a circular cylinder normal to an airstream." Bulletin of JSME 29.255 (1986): 2917-2924.

[5.15] Qin, Chao, et al. "Investigation of Dynamic Loading for 13.2 MW Downwind Pre-Aligned Rotor." North American Wind Energy Academy 2015 Symposium. 2015.

[5.16] Griffith, D. T., and D. Ashwill. "The Sandia 100-meter All-glass baseline wind turbine blade: SNL 100-00, SAND2011-3779." Sandia National Laboratories, Albuquerque, NM, USA (2011).

[5.17] Jonkman, Jason M., and Marshall L. Buhl Jr. "FAST user's guide." National Renewable Energy Laboratory, Golden, CO, Technical Report No. NREL/EL-500-38230 (2005). 
[5.18] Spera, D. "Wind turbine technology-fundamental concepts of wind turbine technology." (1998). 

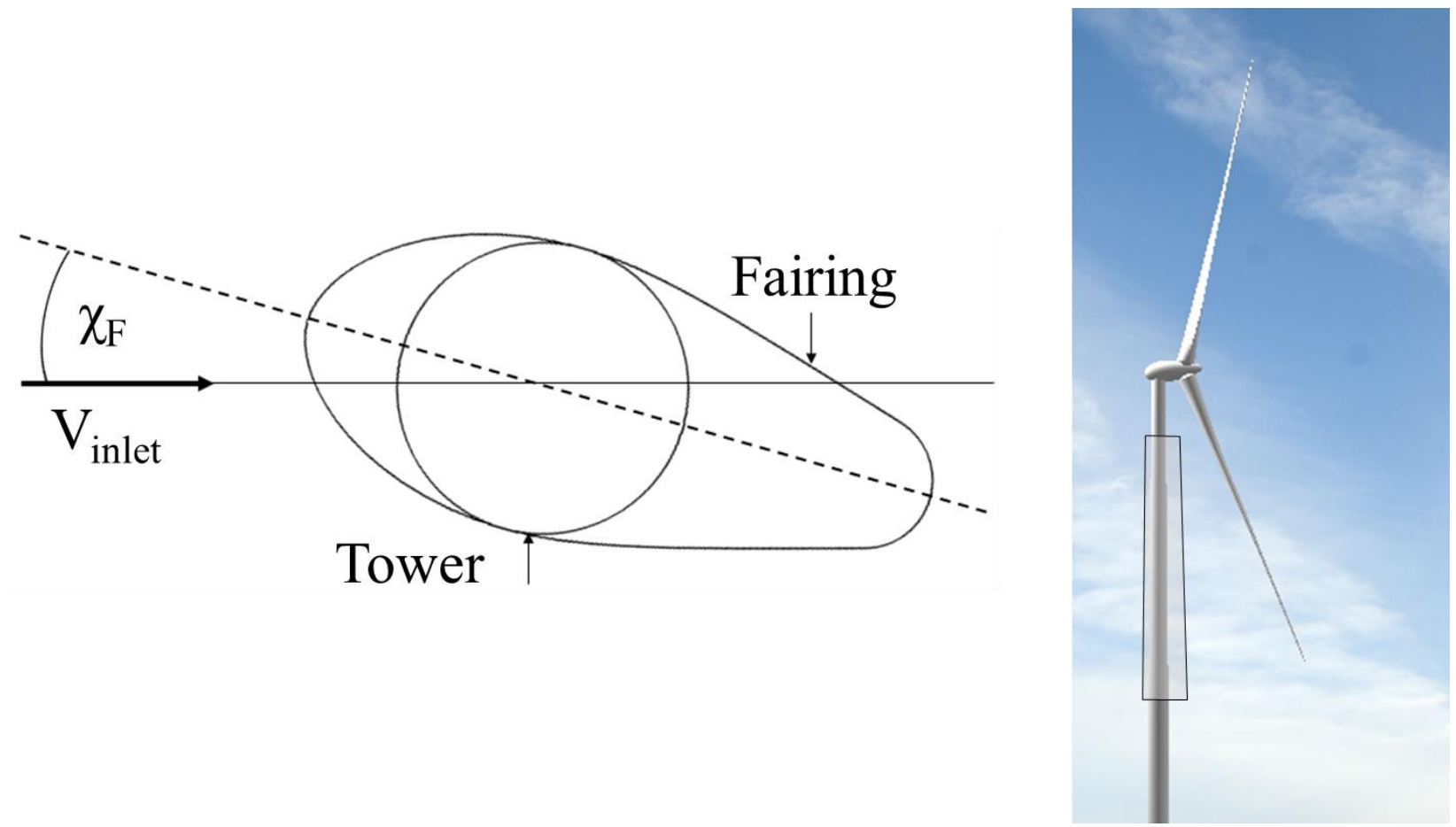

Figure 5.1: a) Schematic of tower fairing relative to the local incident flow and b) schematic of tower fairing used on a pre-aligned D2PA turbine. 


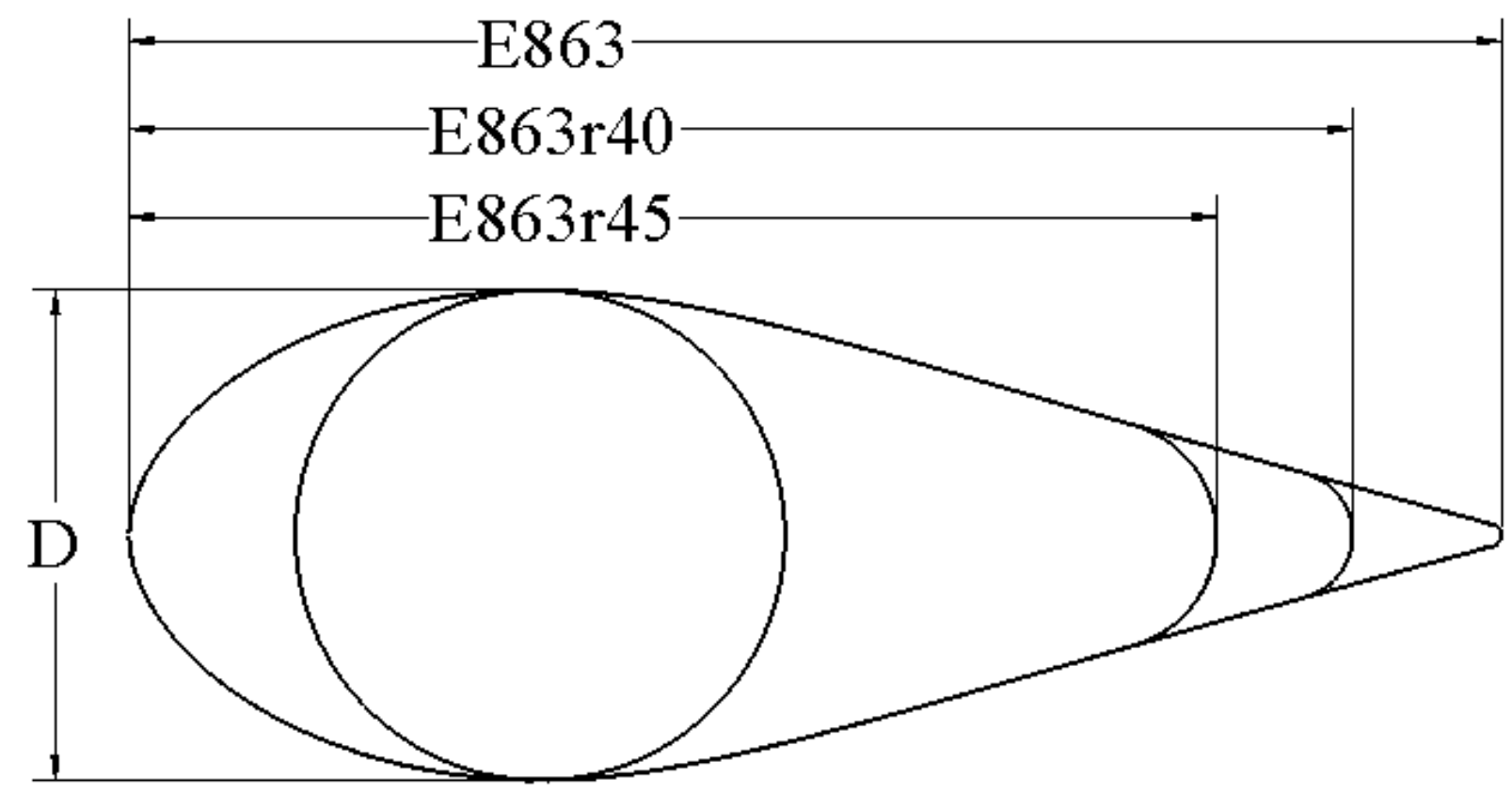

Figure 5.2: Fairings showing rounded trailing edge versions based on the Eppler 863 airfoil. 

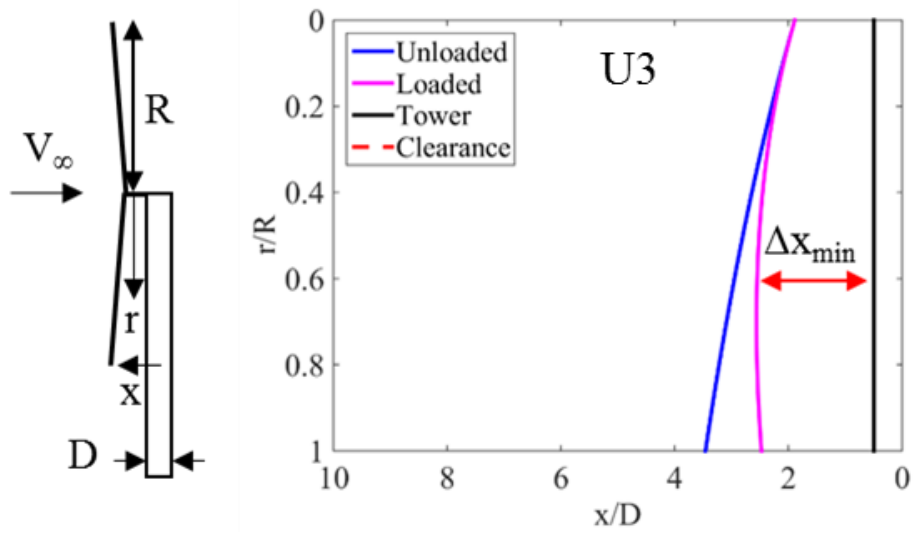

Figure 5.3: Steady-state blade clearance for U3 rotor relative to the tower exterior (shown by black line) for no loading (blue line) and for maximum loading (purple line), which occurs at rated conditions. 

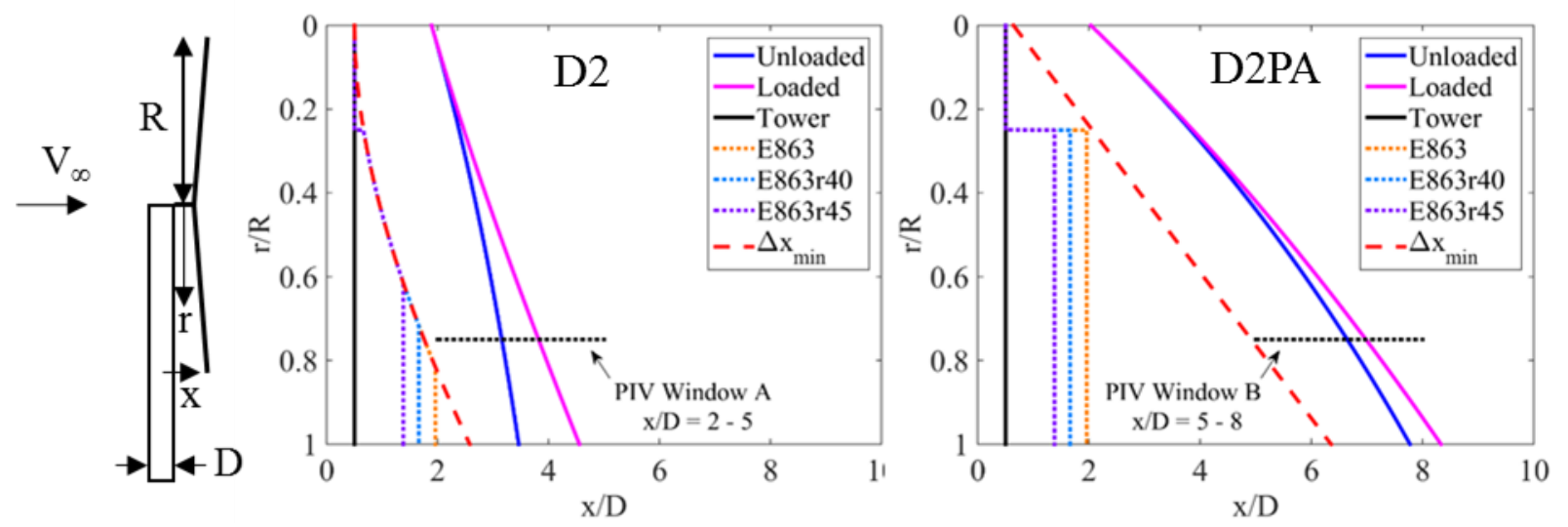

Figure 5.4: Blade clearance for a) the D2 rotor \& b) the D2PA rotor, based on a fairing length limited by a minimal clearance of $\Delta x_{\text {min. }}$. Showing region of interest for PIV results with dotted black line. 

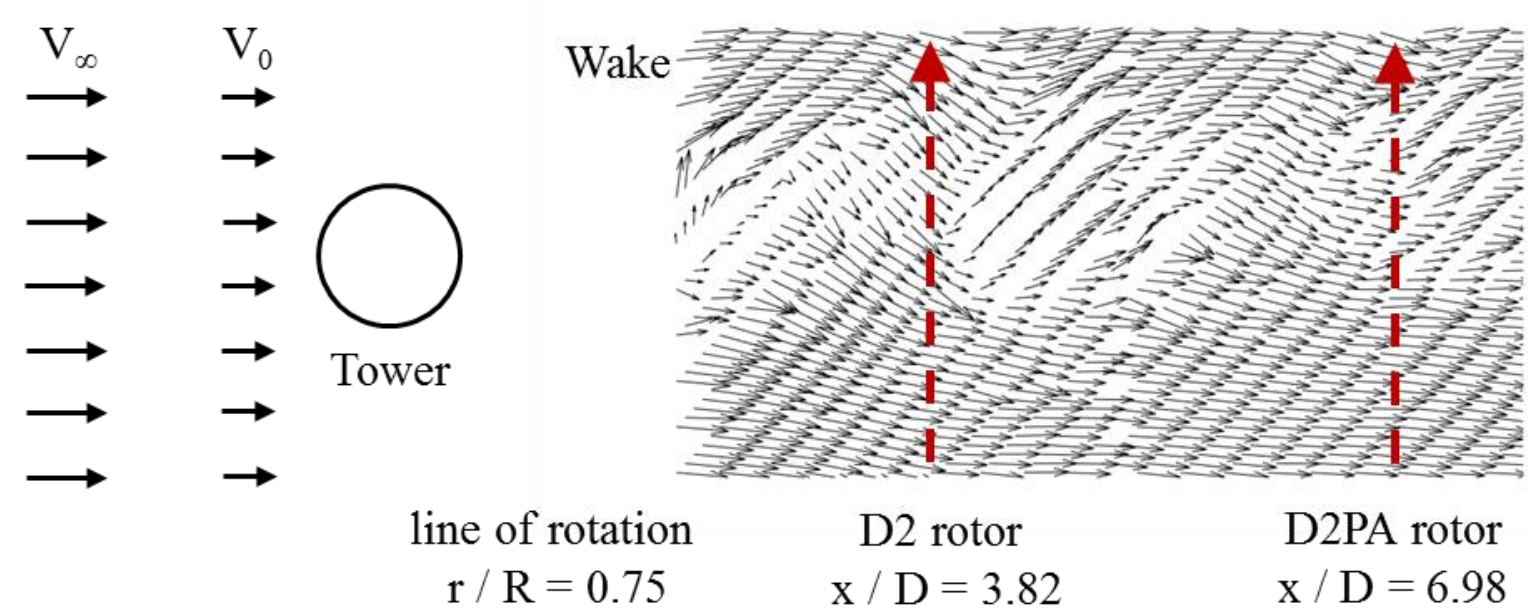

Figure 5.5: Example of PIV data scaled to be used in analysis for the D2 and D2PA turbines. 


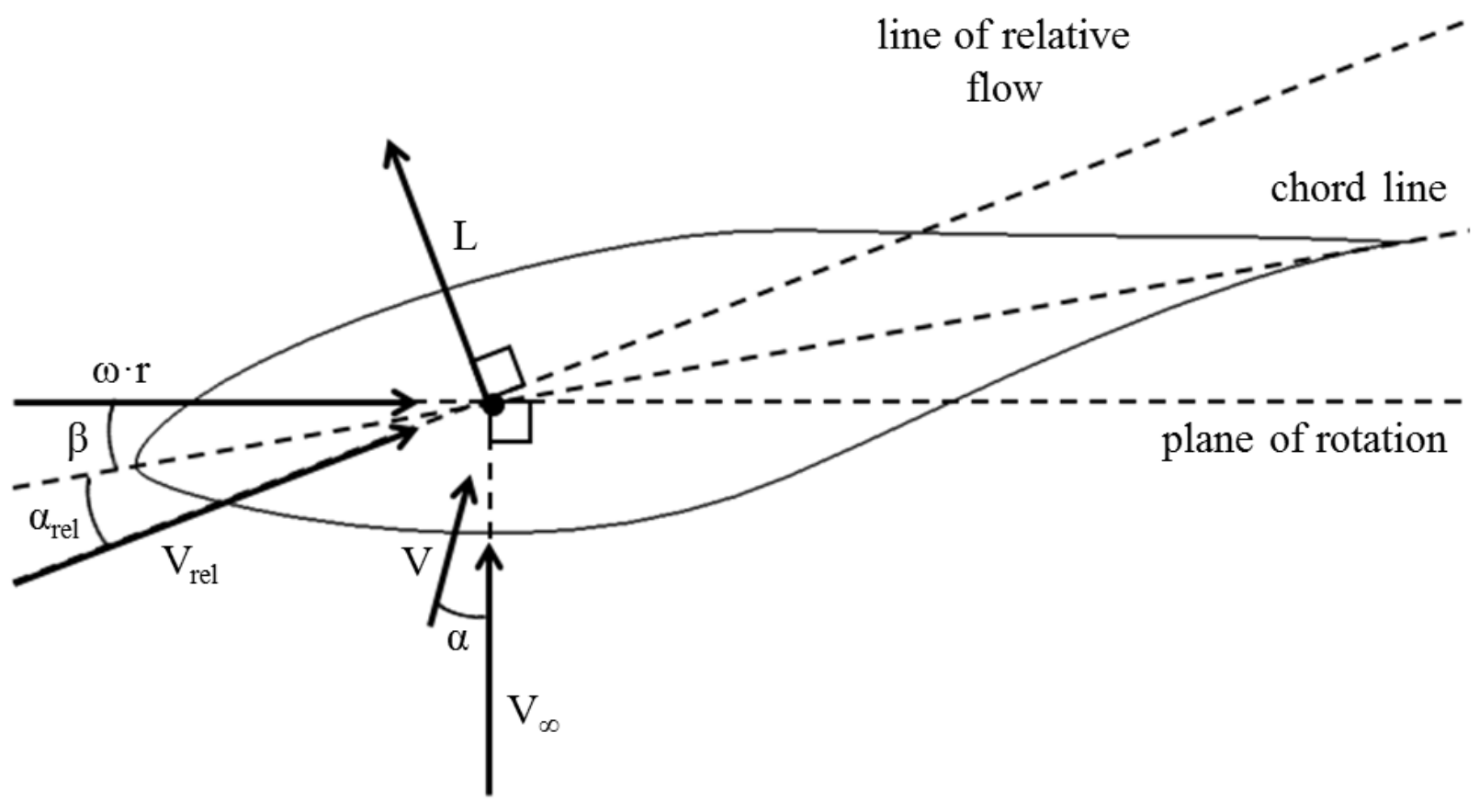

Figure 5.6: Schematic of flow vectors on rotating blade element. 

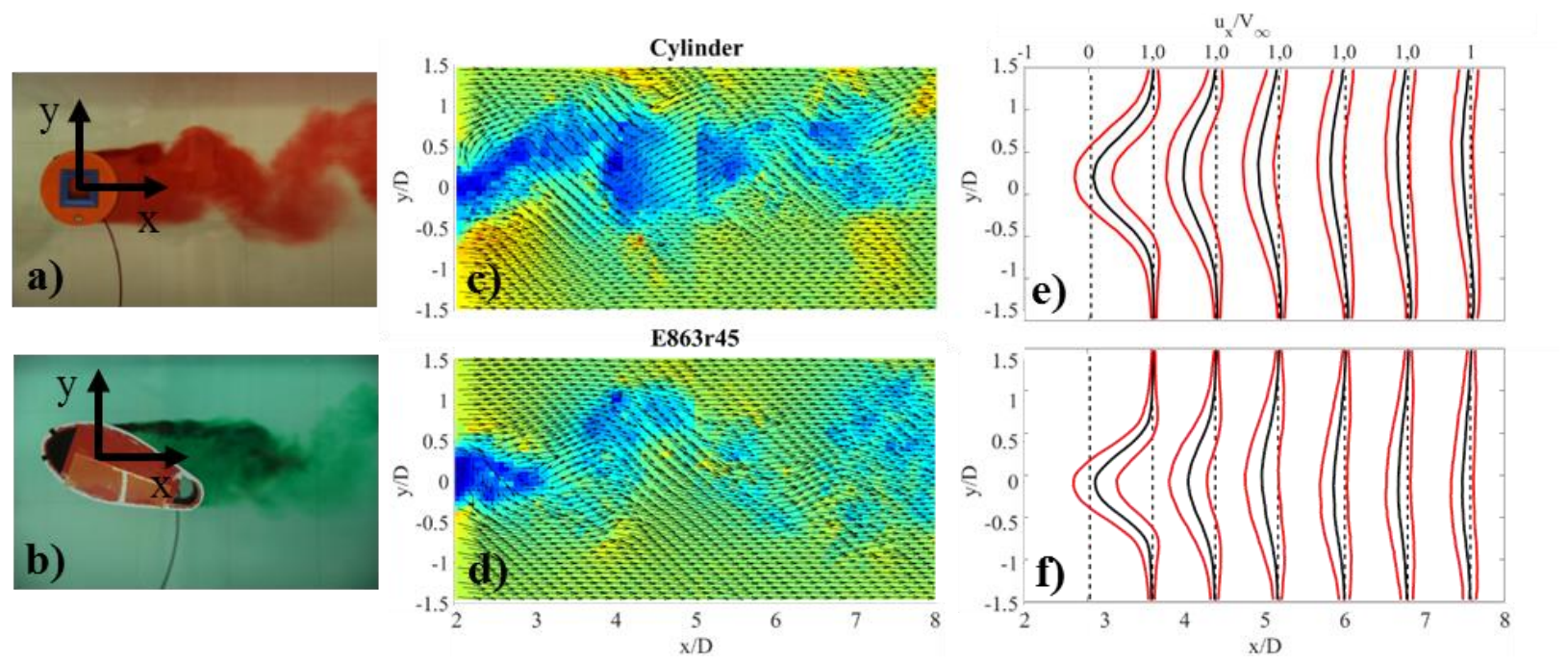

Figure 5.7: Dye visualization, PIV vector plots, and streamwise velocity profile plots, results for the cylinder \& the E863r45 fairing at a misalignment angle of $20^{\circ}$. 


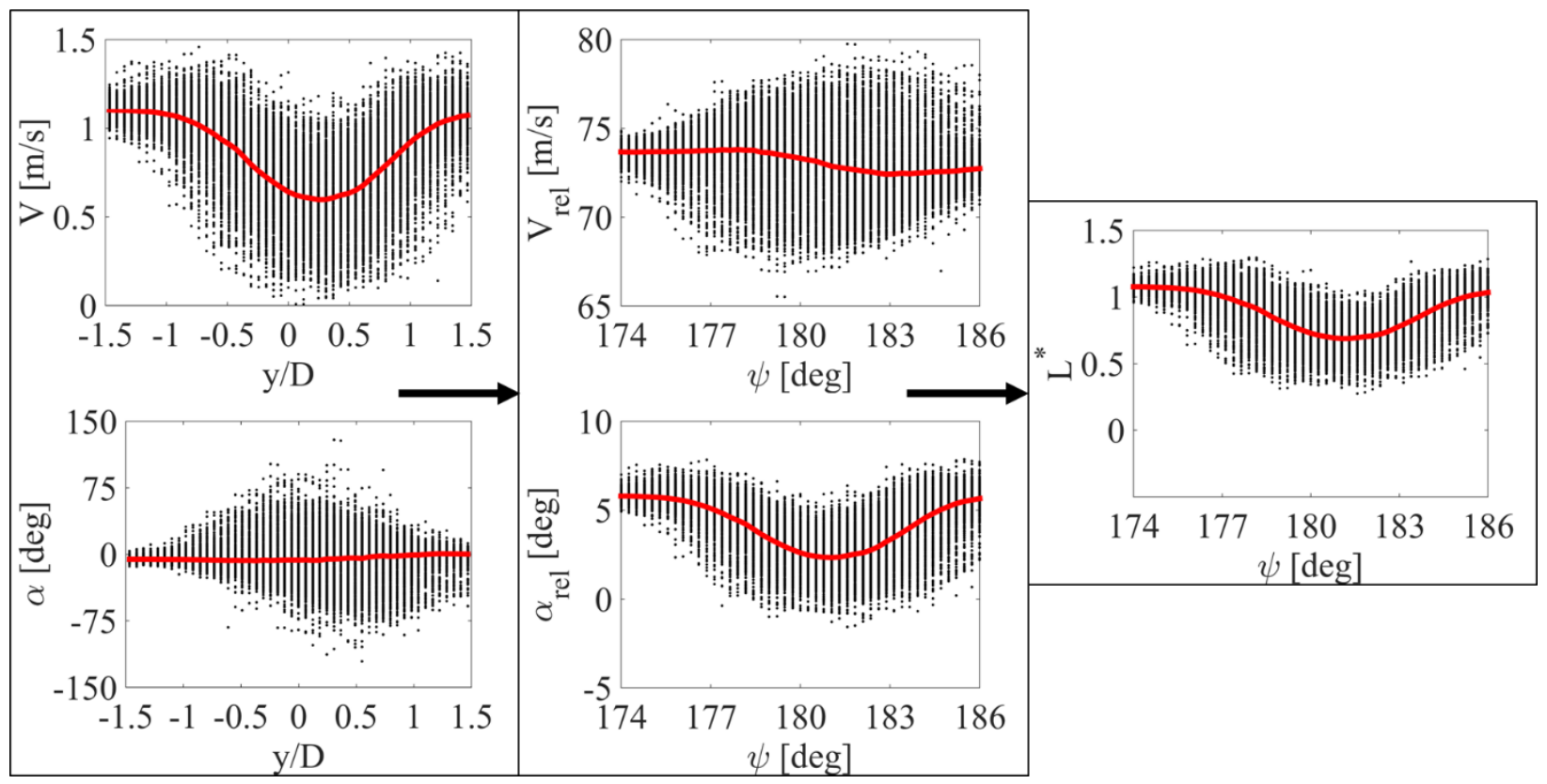

Figure 5.8: The progression from measured flow parameters to resulting blade lift for the cylinder model: $a \& b)$ show flow directly measured PIV, $c \& d$ ) show calculated relative flow for the D2 turbine, \& e) shows the fractional lift on $D 2$ rotor at $r / R=0.75$. 

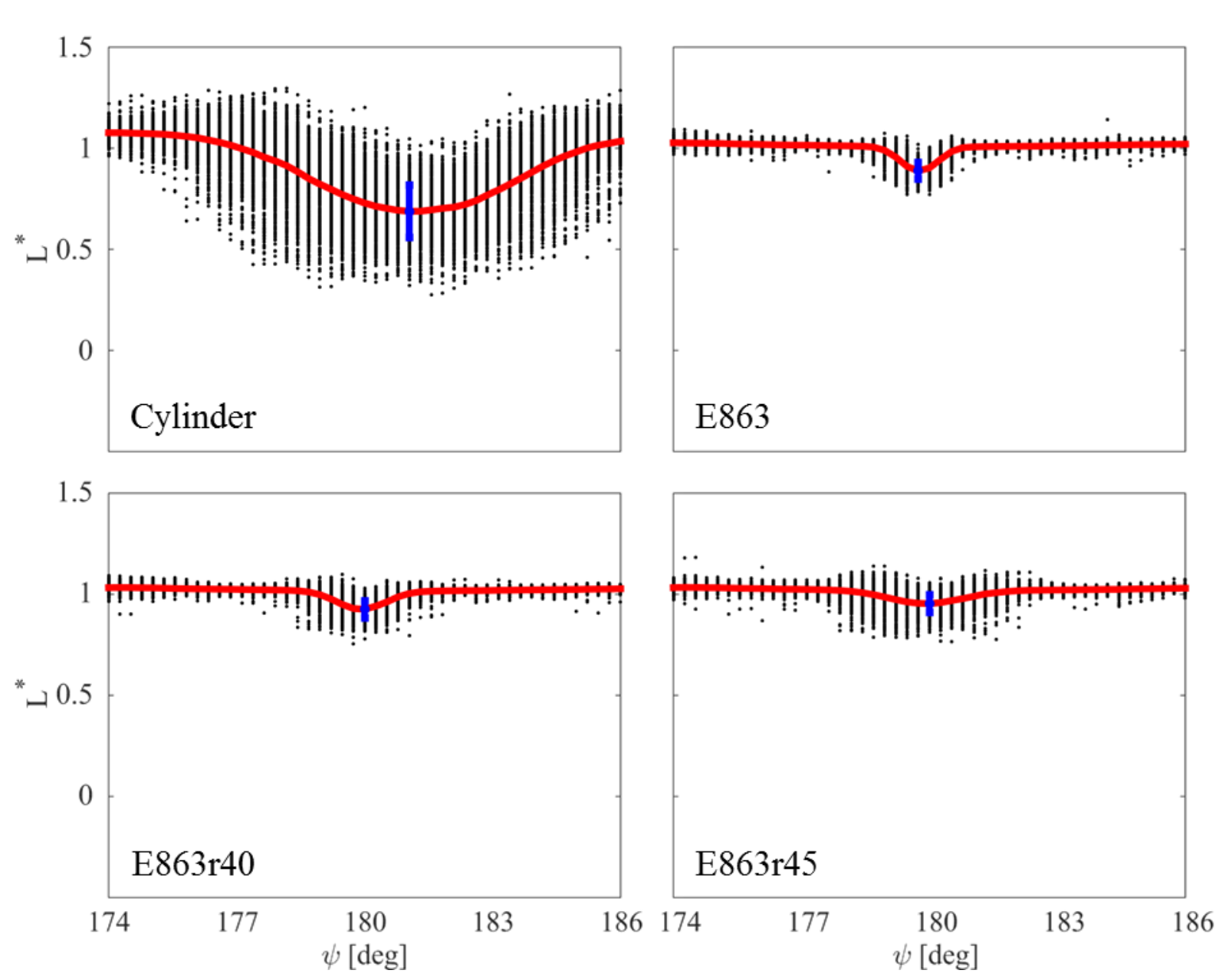

Figure 5.9: Fractional lift on the D2 rotor, for the cylinder and the fairings at a misalignment angle of $0^{\circ}$. 

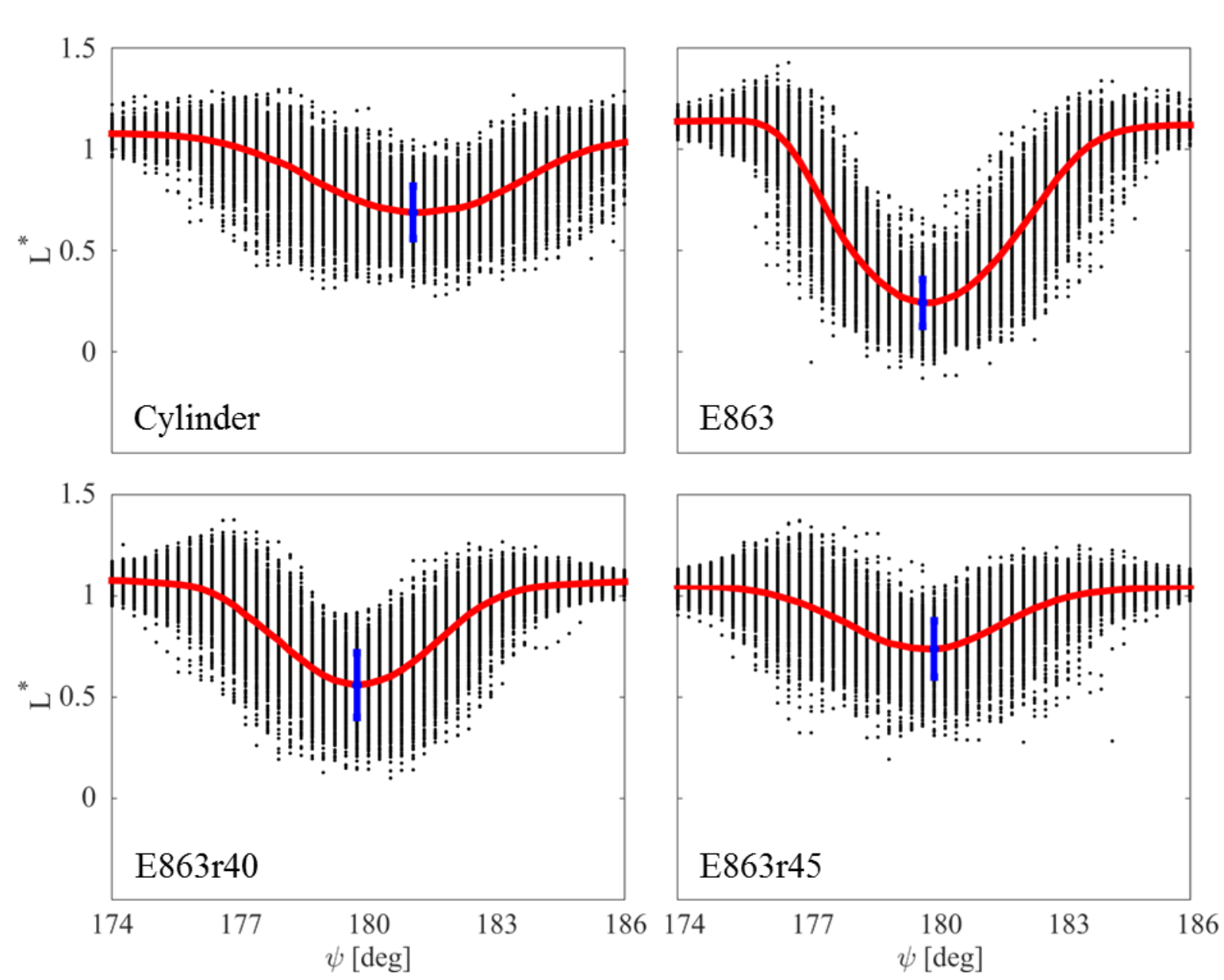

Figure 5.10: Fractional lift on the D2 rotor, for the cylinder and the fairings at a misalignment angle of $20^{\circ}$. 

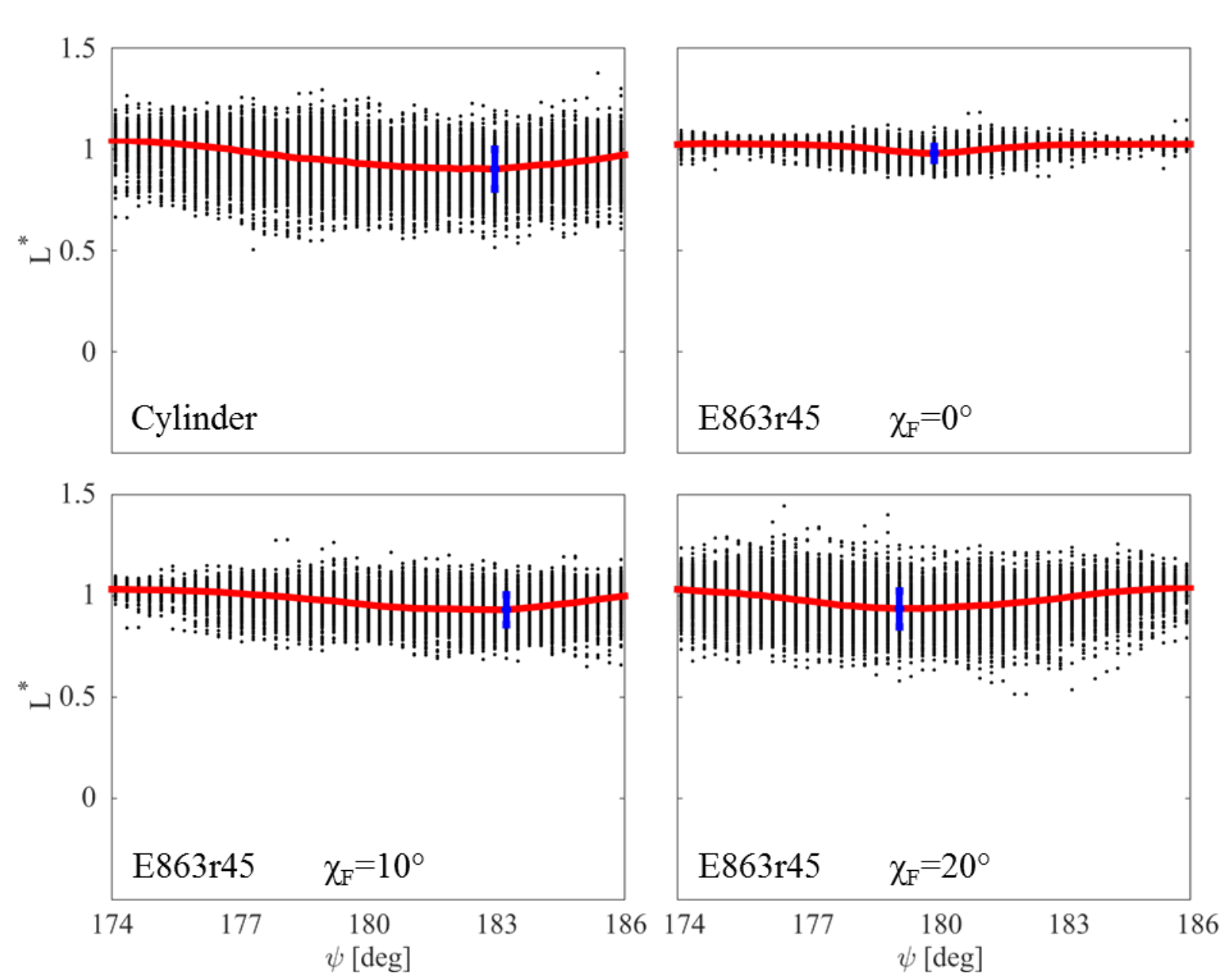

Figure 5.11: Fractional lift on the D2PA rotor, for the cylinder and the E863r45 fairings at all misalignment angles. 

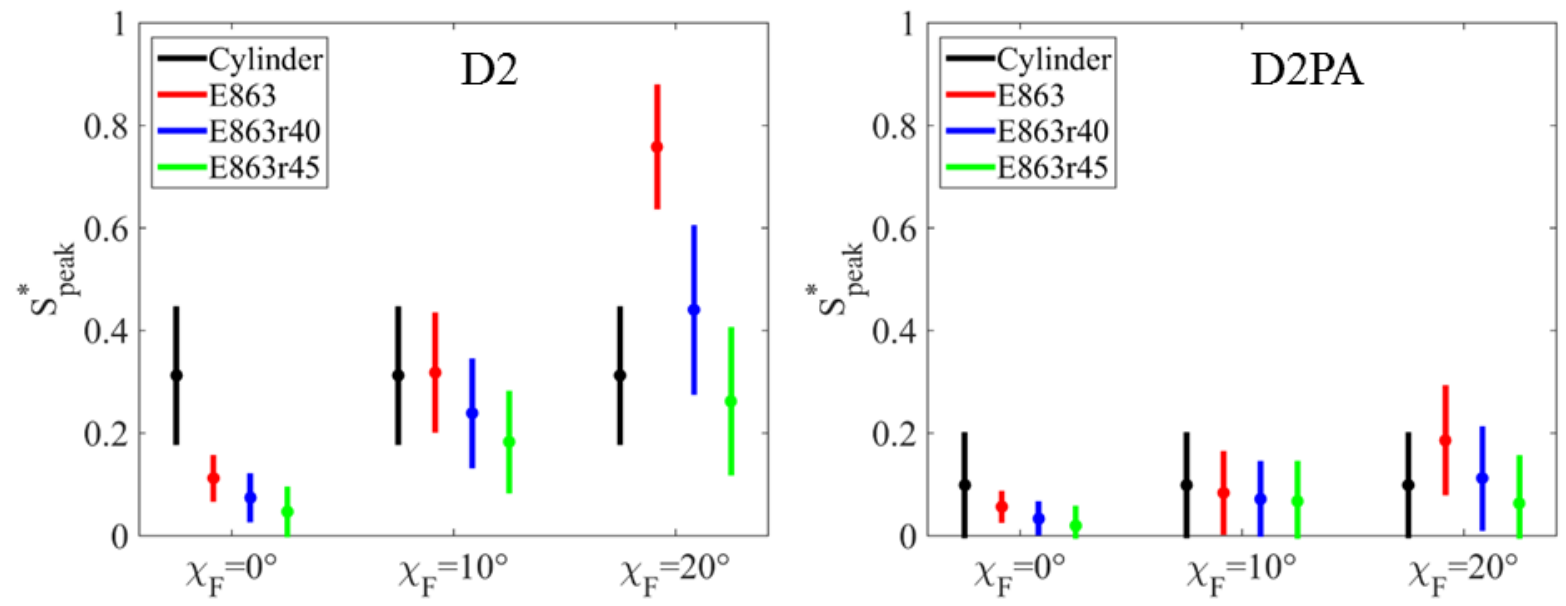

Figure 5.12: The peak shadow load for all test configurations measured for both rotors. 


\section{Chapter 6}

\section{Conclusions}

It was shown in Chapter 2 that by better aligning the average force vector with the direction of the blade, a two-bladed downwind rotor with high coning angle can reduce rotor mass compared with conventional upwind three-bladed baseline rotor, while simultaneously lowering blade DEL and increasing annual energy production. Lowering the damage can be done by increasing the coning angle greater than $9.5^{\circ}$, and a coning angle as large as $20^{\circ}$ will lead to $25.8 \%$ reduction in lifetime damage equivalent loading. Average power generation is increased by lengthening the remaining two rotor blades by $2.7 \%-12.3 \%$, depending on the coning angle. The mass saving comes from the reduction of rotor blade number from 3 to 2 . Some of the mass savings is lost due to the increased blade length which is dependent on coning angle. The net mass savings ranges from $31.5 \%$ to $25.8 \%$. The load-aligned concept is shown to be an effective and robust method for manufacturing less expensive and more effective rotors compared with conventional designs.

Future work could investigate the impact that blade curvature could play in further reduction of blade loading. Adjusting the coning angle can align the net blade load along the direction of the blade. However, a rotor blade that employs downwind curvature could be aligned with the non-torque loads along the entire span of the blade. Another option is to design a morphing rotor. This rotor could be dynamically actuated to adjust the coning angle to be optimized for 
changing wind conditions. A morphing rotor could also collapse in on itself during extreme wind conditions e.g. a hurricane, to protect from rare events which are a large design concern for extreme-scale wind turbines. Downwind, low mass, load-aligned, possibly dynamic, rotors are likely the most practical options for the extreme-scale wind turbines of the future.

Chapter 3 showed, at low free stream velocities (high tip speed ratios) there was a pronounced tower shadow effect on the relative flow angle and velocity, on the downwind UAE rotor blades. This translated to distinct effects on the normal force coefficient. Because the relationship between normal force coefficient and azimuth angle closely resembled that of the relative flow angle, it can be inferred that the relative flow angle is the dominant value driving the normal force coefficient. The fairing aligned with the flow was shown to reduce the tower shadow effects on the relative flow field, leading to a reduced effect on the normal force coefficient. Consequently, this led to a reduction on the root flap bending moment. However, the fairing with a misalignment angle of $20^{\circ}$, did not reduce the shadow effect on the relative flow field, and therefore did not significantly reduce the effect on the normal force coefficient or the root flap bending moment.

At high free stream velocities, it was similarly observed that the tower had a pronounced effect on the relative flow field, compared with the upwind case. However, it was seen that this did not directly correspond to a predictable effect on the normal force coefficient. The normal force coefficient was instead very unsteady and unpredictable. It is likely that normal force coefficient at these low tip speed ratios is not as sensitive to changes in the relative flow field as it is to unsteady aerodynamic effects such as unsteady aerodynamics and flow hysteresis. Therefore, at these high free stream velocities the root flap bending moment was unsteady in all cases. The fairing with a misalignment angle of $0^{\circ}$ had little positive effect reducing the root flap bending 
moment oscillations. However, the misaligned fairing was shown to have a significant and adverse effect on the root flap bending moment.

The FAST model of the UAE simulated some aspects of the experiment accurately. FAST models the azimuthal averages in the change of relative flow angle and velocity due to shadow effects well. FAST did not capture the spread of values measured experimentally, this is primarily true in the case of relative flow velocity. This unsteady deviation from the azimuthal average is not incorporated into the tower shadow model. When FAST predicted the aerodynamic and structural effect on the blades, as seen in the normal force coefficient and root flap bending moment the trends were captured, but there were non-negligible biases primarily at the higher tip speed ratios. At the lower tip speed ratios where the experimental data was shown to be much more unsteady with high deviations from the azimuthal average, the predictions by FAST were less physically realistic, not capturing the spread of values experimentally determined, however the predictions followed the azimuthal average closer than the simulations from higher tip speed ratios.

FAST is a useful tool, with some room for improvement. Some of the complexities of tower shadow have been revealed. At higher tip speed ratios tower shadow plays a larger role in blade aerodynamics and structural response. At these instances tower fairings can be very useful in mitigating negative effects on the rotor. At lower tip speed ratios it is likely that blade response is dominated by more factors than just tower shadow, and tower fairings may only aid in reducing a secondary factor. Additionally it was shown that tower fairings should be aligned with the wind direction or they could exaggerate the problem. In time, and after more experiments, tower shadow will be understood well enough that downwind rotors could be used as a viable and possibly superior alternative to upwind rotors. 
Three aerodynamic fairings with varying degrees of trailing edge rounding were tested and compared against an unfaired cylinder in Chapter 4. These fairings were tested at several misalignment angles to give insight into the performance at a variety of inflow conditions, where the maximum misalignment angle is $20^{\circ}$. Fairings with greater rounding at aligned flow had slightly wider wakes with slightly more turbulent intensity, however they additionally had lower peak velocity deficits and recovered to undisturbed velocities faster than fairings with less rounding. All fairings at aligned flow had much less significant wakes compared with the unfaired cylinder. At higher misalignment angles, the wake behind the unrounded fairing was larger and had a much larger peak velocity deficit compared with the rounded fairings and the unfaired cylinder. The fairing with the greatest degree of trailing edge rounding had slightly higher turbulence intensity compared with the unrounded fairing but had significantly less peak velocity deficit compared with the other fairings and the unfaired cylinder. In summary, rounding the trailing edge of the fairing can reduce the wake and the drag at high misalignment angles without losing performance at aligned flows when the system is operating with varying flow conditions.

Future work could include investigating other fairing profile adaptations, such as a flat back profile. This profile might be useful at fixing the separation point further along the chord than a similar profile with a rounded trailing edge, leading to a thinner wake. Although it is possible that it would lead to higher lift than its rounded trailing edge counterpart, which depending on the application one might want to avoid. Another option for improvement would be synthesizing other methods of a passive flow control with a robust aerodynamic fairing. Such flow control methods could include using vortex generators to promote boundary adhesion over the chord of the fairing, spanwise bumps on the trailing edge of the fairing. A third possibility is to design the fairing to 
adapt its geometry with the wind direction. This could be done with a hinged trailing edge that has a positive corrective moment so that it would align itself to the direction of the wind.

The PIV data for the three fairings was scaled and used for analysis on the D2 and the D2PA rotors, in Chapter 5. Relative flow parameters were calculated from the PIV flow data. The relative flow field was then used to predict the fractional lift that the blades would experience as they passed through the experimental vector fields. Shadow load, the fraction of lift lost due to shadow effects, was calculated and averaged over the 500 repeated data points to achieve smooth average profiles.

Peak shadow load, the largest value of the average shadow load experienced was determined to be the index of performance of the fairing, because it is directly related to fatigue life of the blade. Shadow load variation at the location of the peak shadow load was determined to be the secondary index of performance, because it is indirectly related to the fatigue life of the blade. It was shown that for pre-aligned rotors, because of the larger distance between the blade and the tower, peak shadow load is substantially lower than traditional rotors. All three fairings at a misalignment angle of $0^{\circ}$, for both rotors, performed better than the baseline cylinder. The E863 fairing had roughly twice as high peak shadow load than the cylinder at a misalignment angle of $20^{\circ}$. The E863r45 fairing however had lower peak shadow load on both rotors, at all angles, compared with all other models, and comparable or better shadow load variation than the other models. For this reason the E863r45 fairing was the most robust fairing tested. 